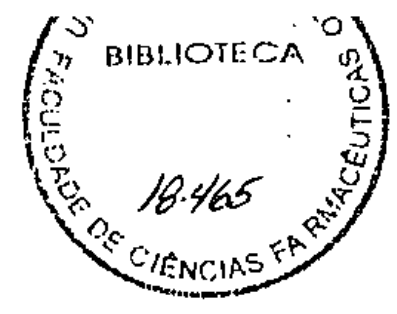

\author{
UNIVERSIDADE DE SÃO PAULO \\ FCF / FEA / FSP \\ Programa de Pós-Graduação Interunidades \\ Em Nutrição Humana Aplicada - PRONUT
}

\title{
AVALIAÇÃO DAS NORMAS DE UM SISTEMA DE PONTOS PARA CONTROLE DE COLESTEROL E GORDURA NO SANGUE
}

\section{PRISCILLA PRIMI HARDT}

\section{Dissertação para obtenção} do grau de Mestre

Orientadora:

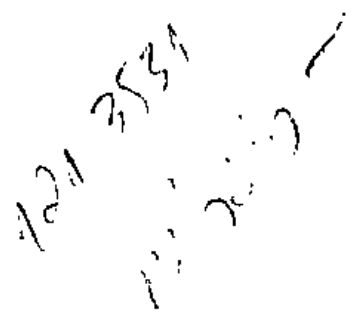

Prof. Assoc. Elizabeth A. F. S. Torres

SĀO PAULO

2004 


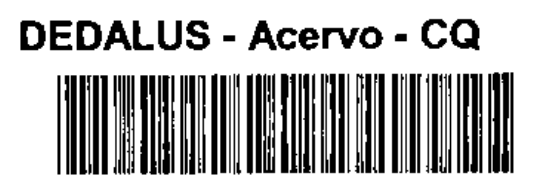

30100011687

Autorizo, exclusivamente para fins acadêmicos e científicos, a reprodução total ou parcial desta dissertação, por processos fotocopiadores.

Assinatura:

Data: __ I 12004

Hardt, Priscilla Primi

Avaliação das normas de um sistema de Pontos para Controle de Colesterol e Gordura no sangue - São Paulo/ Priscilla Primi Hardt - São Paulo, 2004

Dissertação (Mestrado) - Faculdade de Ciências farmacêuticas da USP.

Faculdade de Economia, Administração e Contabilidade da USP. Faculdade de saúde Pública da USP. Programa de Pós -Graduação Interunidades em Nutrição Humana e Aplicada

$$
\text { JoY P }+ \text { nuero }
$$

1. guias alimentares 2. Avaliação 3. colesterol

$\operatorname{DBd}$ 


\title{
AVALIAÇÃO DAS NORMAS DE UM SISTEMA DE PONTOS PARA CONTROLE DE COLESTEROL E GORDURA NO SANGUE
}

\author{
Comissāo Julgadora \\ Tese para obtenção do grau de Mestre
}

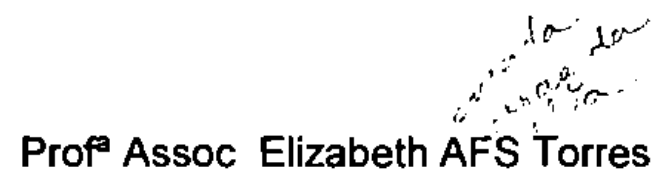

(Orientador/Presidente)

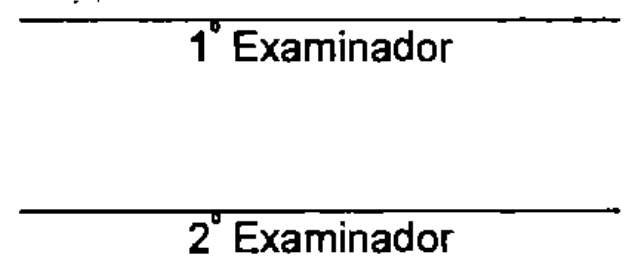

$2^{\circ}$ Examinador

- São Paulo, fl de fl. de 2005 
B।B1, OT:CA

Faculdate de Cięricios Farniacevuticas

Universidade de Sào Pauto

Por ordem de entrada em minha vida

\section{DEDICO ESTE TRABALHO AOS MEUS PAIS} NELSON E ANA MARIA...

....pelo exemplo de vida, amor incondicional, apoio, incentivo

e dedicação imensurável à suas filhas proporcionando sempre o melhor para o nosso crescimento pessoal.

\section{E AO MEU MARIDO FERNANDO...}

pelo amor, carinho, compreensão, companheirismo, estimulo, paciência e força em todos os momentos e por me dar minhas maiores riquezas: ISABELLA o MARIANA. 


\section{AGRADECIMENTOS}

A Profa Assoc. Elizabeth AFS Torres, que como minha orientadora me trouxe de volta a Nutrição me propiciando a realizaçăo do curso de mestrado, pela sua amizade, paciência e, sobretudo, pela postura nunca autoritária.

A Profa. Assoc. Sônia Tucunduva Philippi, pelas críticas construtivas e observações imprescindiveis para realização deste trabalho

A Profa Dra Edeli Simoni de Abreu, pelas sugestōes valiosas e análises minuciosas, ajudando a melhorar e enriquecer este trabalho.

Ao Profo Fábio Tadeu Montesano, por esclarecer minhas dúvidas estatisticas.

Ao Dr. Raul dos Santos Filho, pela sua gentileza, disponibilidade e entusiasmo e por abrir as portas do incor.

Às amigas Márcia Nacif, por sua disponibilidade, ajuda e esclarecimentos das minhas dúvidas e Paula Gasperazzo, pela colaboração na coleta de dados.

Às minhas queridas irmãs Juliana, por todo exemplo de dedicação ao estudo, apoio, estímulo, impecável correção e por ajudar a cuidar dos meus tesouros durante a redação deste trabalho e Ana Luiza, pela força e seu otimismo contagiante.

A todos os voluntários pela paciência em responder a tantos "porquês", que me auxiliaram a concluir esta pesquisa.

Ao CNPq que financiou esta pesquisa e concessão de bolsa de estudos.

A Deus, a quem agradeço tudo o que tenho e sou. 


\section{ÍNDICE}

1 INTRODUÇÃo

Página

1.1 Associação entre dislipidemias e aterosclerose 1

1.2 Epidemiologia das doenças cardiovasculares no Brasil 2

1.3 Fatores de risco para doenças cardiovasculares $\quad 4$

1.4 Binômio dieta - doença 6

1.5 Terapêuticas das dislipidemias 8

1.6 Indice de colesterol/Gordura saturada (CSI) $\theta$

1.7 Guias Alimentares $\quad 11$

1.8 Desenvolvimento de Guia Alimentar para controle de colesterol e gordura no sangue

1.9 Avaliaçăo e validação de Guias alimentares 19

2 JUSTIFICATIVA $\quad 21$

3 OBJETIVOS

3.1 Objetivo geral 22

3.2 Objetivos especificos 22

\section{METODOLOGIA}

4.1 Delineamento do estudo $\quad 23$

4.1.1 Populaçąa e local de estudo 23

4.2 Amostra 23

4.3 Critérios de seleçăo e exclusáo 24

4.4 Coleta de dados $\quad 24$

4.5 Variáveis de estudo $\quad 25$ 
4.5.1 Sexo e idade $\quad 25$

$\begin{array}{ll}\text { 4.5.2 Escolaridade } & 25\end{array}$

4.6 Procedimentos metodológicos 26

4.6.1 Avaliaçăo dos passos para uma alimentaçăo saudável propostas pelo siștema de pontos para o controle de colesterol e gordura no sangue

4.6.2 Sugestöes para o aperfeiçoamento dos passos para uma alimentação saudável propostas pelo sistema de pontos para o controle de colesterol a gardura no sangue

4.7 Análise estatística 28

$\begin{array}{ll}4.8 \text { Parte ética } & 30\end{array}$

5 RESULTADOS E DISCUSSÃO 31

5.1 Caracteristicas da populaçăo em estudo 31

5.2 Distribuição da amostra em quanto às respostas sobre as orientaçסes, segundo sexo, idade e escolaridade.

5.2.1 Orientaçäo 1: Consumir uma alimentaçáo variada

5.2.2 Orientação 2: Basear a alimentaçăo no consumo de alimentos derivados de grăos e raízes, hortaliças e frutas

5.2.3 Orientação 3: Evitar a obesidade, mantendo o peso corporal desejável.

5.2.4 Orientação 4: Praticar atividades físicas regularmente e com orientaçáo.

5.2.5 Orientação 5: Selecionar uma dieta com baixa quantidade de gordura, colesterol e gordura saturada. 
5.2.6 Orientação 6: Fracionar a dieta, fazendo três refeiçōes e dois lanches entre elas, escolhendo alimentos saudáveis.

5.2.7 Orientação 7: Evitar o consumo de frituras.

5.2.8 Orientação 8: Consumir produtos de origem animal moderadamente.

5.2.9 Orientação 9: Preferir carnes magras e retirar gorduras visíveis. $\quad 70$

5.2.10 Orientação 10: Consumir açúcar e doces com moderação.

5.2.11 Orientação 11: Reduzir o consumo de sal

5.2.12 Orientação 12: Limitar o consumo de álcool, se ingerir, faça-o com moderação.

5.2.13 Orientação 13: Não esquecer de consumir água, pois é essencial à saúde. 


\section{RESUMO}

Hardt PP. Avaliação das normas de um sistema de pontos para Controle de Colesterol e Gordura no Sangue; São Paulo 2004. [Dissertação de mestrado FCF-FEA-FSP/USP].

Objetivo: O objetivo principal deste estudo é avaliar a compreensão da população em relação aos passos para uma alimentação saudável propostas pelo Sistema de Pontos para controle do colesterol e gordura no sangue, clareza do conteúdo e a forma que foram expressos; identificar a linguagem apropriada para a compreensão das mensagens e correção de eventuais problemas lingüísticos. Metodologia: Foram estudados 30 voluntários de ambos os sexos, com 20 anos ou mais, usuários Do Instituto do Coração da Faculdade de Medicina da Universidade de São Paulo. Os participantes foram questionados quanto à compreensão, importância, credibilidade e cumprimento das mensagens contidas nos Passos para uma alimentação saudável propostos no Sistema de Pontos, através de um questionário de perguntas fechadas. Foram relatadas por meio de sugestōes dos entrevistados quanto à modificaçāo da linguagem utilizada, visando melhorar o entendimento das orientações. Analisou-se a associação das respostas em relação às variáveis sexo, idade e escolaridade dos entrevistados. Resultados e Discussão: Verificou-se que a maioria das orientaçōes é de fácil compreensão, grande credibilidade e importância, mas quanto ao cumprimento, duas dessas orientações não são seguidas por metade dos entrevistados. Conclusão: Em algumas das mensagens contidas nos Passos para uma alimentação saudável propostas pelo Sistema de Pontos para controle do colesterol e gordura no sangue é necessária a substituição de conceitos científicos e/ou termos menos usuais pela linguagem coloquial, a fim de melhorar a clareza do conteúdo e sua a compreensão.

Descritores: avaliação, indice colesterol/ gordura saturada, guias alimentares, sistema de pontos. 


\section{ABSTRACT}

Hardt PP. Avaliação das normas de um sistema de pontos para Controle de Colesterol e Gordura no Sangue. [Evaluation of the norms of Points System for Control serum lipids and Cholesterol levels]. São Paulo 2004. [Dissertação de mestrado - FCF-FEA-FSPIUSP].

Objective: The main objective of this study to evaluate the population's understanding of the "Passos para uma alimentação saudável" proposed by the "Sistema de Pontos para controle do colesterol e gordura no sangue", clarity of the content and the form that it had been expressed; to identify it to the appropriate language for the understanding of the messages and the correction of eventual linguistic problems.

Methodology: It had been studied 30 volunteers of both genders, 20 years-old or older, users of Instituto do Coração da Faculdade de Medicina da Universidade de São Paulo. The participants had been asked about the understanding, relevance, credibility and fulfilment of the messages contained in the "Passos para uma alimentação saudável" proposed in the "Sistema de Pontos", through a questionnaire of closed questions. Suggestions of the interviewed people had been told in relation to the modification of the used language to make it better. The answers were analyzed in relation to the variable gender, age and education of the interviewed people.

Results and Discussion: It was verified that the majority of the orientation is of easy understanding, great credibility and relevance, but in relation to the fulfilment, two of these orientations are not followed by half of the interviewed people.

Conclusion: In some of the messages contained in the "Sistema de Pontos para controle do colesterol e gordura no sangue" the less usual substitution of scientific concepts and/or terms for the coloquial language is necessary, in order to improve the clarity of the content and its understanding.

Key words: evaluation, cholesterol/saturated fat index, food guidelines, points system. 


\section{LISTA DE QUADROS E TABELAS}

Página

Quadro 1 - Recomendação Dietética para o tratamento das Hiperlipidemias.

Quadro 2 - Distribuição das dúvidas apresentadas quanto

à orientação 1. São Paulo, 2004.

Quadro 3 - Distribuição das sugestões quanto à troca

de palavras da orientação 1. Sāo Paulo, 2004.

Quadro 4 - Distribuição das dúvidas apresentadas quanto à orientação 2. São Paulo, 2004.

Quadro 5 - Distribuição das sugestōes quanto à troca

de palavras da orientação 2. São Paulo, 2004.

Quadro 6 - Distribuição das sugestōes quanto à troca

de palavras da orientação 3. São Paulo, 2004.

Quadro 7 - Distribuição das sugestōes quanto à troca

de palavras da orientação 4. São Paulo, 2004.

Quadro 8 - Distribuição das dúvidas apresentadas quanto à orientaçăo 5. São Paulo, 2004.

Quadro 9 - Distribuição das sugestōes quanto à troca

de palavras da orientação 6. São Paulo, 2004.

Quadro 10 - Distribuiçăo das dúvidas apresentadas quanto à

orientação 8. São Paulo, 2004.

65

Quadro 11 - Distribuição das dúvidas apresentadas quanto à orientação 11. São Paulo, 2004. 
Quadro 12 - Distribuição das sugestões quanto à troca

de palavras da orientação 12. São Paulo, 2004.

Tabela 1. Distribuição da amostra segundo sexo dos entrevistados.

São Paulo, 2004.

Tabela 2. Distribuição da amostra segundo a escolaridade dos entrevistados.

São Paulo, 2004.

Tabela 3. Distribuição da amostra segundo a idade dos entrevistados.

São Paulo, 2004.

Tabela 4. Distribuição da amostra quanto a dúvida na Orientação 1.

São Paulo, 2004.

Tabela 5. Distribuição da amostra quanto a substituição de palavra na

Orientação 1. São Paulo, 2004.

Tabela 6. Distribuição da amostra quanto a concordância com a

Orientação 1.São Paulo, 2004.

Tabela 7. Distribuição da amostra quanto a importância da Orientação 1.

São Paulo, 2004.

Tabela 8. Distribuição da amostra quanto o cumprimento da Orientação 1.

São Paulo, 2004.

Tabela 9. Distribuição da amostra quanto a dúvida na Orientação 2.

São Paulo, 2004.

Tabela 10. Distribuição da amostra quanto à substituição de palavra

na Orientação 2. São Paulo, 2004.

Tabela 11. Distribuição da amostra quanto à concordância com a

Orientação 2. Sāo Paulo, 2004. 
Tabela 12. Distribuiçăo da amostra quanto a importância da Orientaçăo 2.

Sāo Paulo, 2004.

Tabela 13. Distribuição da amostra quanto ao cumprimento da Orientaçăo 2.

São Paulo, 2004.

Tabela 14. Distribuiçāo da amostra quanto a dúvida na Orientação 3.

Săo Paulo, 2004.

Tabela 15. Distribuiçáo da amastra quanto à substituiçăo de palavra

na Orientação 3. Săo Paulo, 2004.

Tabela 16. Distribuição da amostra quanto à concordância com a

Orientação 3. São Paulo, 2004.

Tabela 17. Distribuiçăo da amostra quanto ao cumprimento da orientação

3, segundo sexo, escolaridade e idade dos entrevistados. São Paulo, 2004.

Tabela 18. Distribuição da amostra quanto a importârıcia da Orientação 3.

São Paulo, 2004.

Tabela 19. Distribuiçăo da amostra quanto ao cumprimento da Orientaçăo 3.

São Paulo, 2004.

Tabela 20. Distribuição da amostra quanto a dúvida na Orientação 4.

São Paulo, 2004.

Tabela 21. Distribuição da amostra quanto à substituição de palavra

na Orientação 4. São Paulo, 2004.

Tabela 22. Distribuição da amostra quanto a concordåncia com a Orientaçăo 4.

Săo Paulo, 2004

Tabela 23. Distribuiçăo da amostra quento a importáncia da Orientação 4.

Săo Paulo, 2004. 
Tabela 24. Distribuição da amostra quanto o cumprimento da Orientação 4.

São Paulo, 2004.

Tabela 25. Distribuição da amostra quanto a dúvida na Orientação 5.

São Paulo, 2004.

Tabela 26. Distribuição da amostra quanto à dúvida sobre a orientaçåo 5 , segundo sexo, escolaridade e idade dos entrevistados. São Paulo, 2004.

Tabela 27. Distribuição da amostra quanto à substituição de palavra na Orientação 5. São Paulo, 2004

Tabela 28. Distribuição da amostra quanto à substituição de palavra na orientação 5 segundo, sexo, escolaridade e idade dos entrevistados.

São Paulo, 2004.

Tabela 29. Distribuição da amostra quanto a concordância com a

Orientação 5. São Paulo, 2004

Tabela 30. Distribuição da amostra quanto ao cumprimento da

Orientação 5. São Paulo, 2004.

Tabela 31. Distribuição da amostra quanto ao cumprimento da orientação 5 , segundo sexo, escolaridade e idade dos entrevistados.

São Paulo, 2004.

Tabela 32. Distribuição da amostra quanto a dúvida na Orientação 6.

São Paulo, 2004.

Tabela 33. Distribuição da amostra quanto à dúvida sobre a orientação 6, segundo, sexo, escolaridade e idade dos entrevistados.

São Paulo, 2004 
Tabela 34. Distribuiçăo da amostra quanto à substituição de palavra na Orientação 6. São Paulo, 2004

Tabela 35. Distribuiçāo da amostra quanto à concordância com a Orientaçāo 6. São Paulo, 2004.

Tabela 36. Distribuição da amostra quanto a concordância com a orientação 6 , segundo sexo, escolaridade e idade dos entrevistados. São Paulo, 2004.

Tabela 37. Distribuição da amostra quanto à importância da

Orientação 6. São Paulo, 2004.

Tabela 38. Distribuição da amostra quanto a importância da orientação 6 , segundo sexo, escolaridade e idade dos entrevistados. São Paulo, 2004.

Tabela 39. Distribuição dos individuos quanto ao cumprimento da

Orientação 6. São Paulo, 2004.

Tabela 40. Distribuição da amostra quanto ao cumprimento da orientaçāo 6 , segundo sexo, escolaridade e idade dos entrevistados. São Paulo, 2004

Tabela 41. Distribuição da amostra quanto a dúvida na Orientação 7.

São Paulo, 2004.

Tabela 42. Distribuição da amostra quanto à substituição de palavra

na Orientaçăo 7. São Paulo, 2004.

Tabela 43. Distribuição da amostra quanto a substituição de palavras na orientação 7, segundo, sexo, escolaridade e idade dos entrevistados. São Paulo, 2004.

Tabela 44. Distribuição dos individuos quanto o cumprimento da

Orientação 7. São Paulo, 2004. 
Tabela 45. Distribuição da amostra quanto a dúvida na Orientação 8. São Paulo, 2004.

Tabela 46. Distribuição da amostra quanto a concordância com a

Orientação 8. São Paulo, 2004.

Tabela 47. Distribuição da amostra quanto a concordância com a orientação 8 , segundo sexo, escolaridade e idade dos entrevistados. São Paulo, 2004.

Tabela 48. Distribuição dos individuos segundo a importáncia da Orientação 8. São Paulo, 2004. 68

Tabela 49. Distribuição dos individuos segundo o cumprimento da Orientação 8. São Paulo, 2004. 68

Tabela 50. Distribuição da amostra quanto ao cumprimento da orientação 8, segundo sexo, escolaridade e idade dos entrevistados. São Paulo, 2004.

Tabela 51. Distribuição da amostra quanto à dúvida na Orientação 9. São Paulo, 2004.

Tabela 52. Distribuição da amostra quanto à substituição de palavra na Orientação 9. São Paulo, 2004.

Tabela 53. Distribuição da amostra quanto à concordância com a Orientação 9. São Paulo, 2004.

Tabela 54. Distribuição da amostra em relação à concordância com a orientação 9, segundo sexo, escolaridade e idade dos entrevistados. São Paulo, 2004. 
Tabela 55. Distribuição da amostra quanto à importância da Orientaçăo 9.

São Paulo, 2004.

Tabela 56. Distribuição da amostra quanto o cumprimento da

Orientação 9. São Paulo, 2004.

Tabela 57. Distribuição da amostra quanto à substituição de palavra na Orientação 10. São Paulo, 2004.

Tabela 58. Distribuição da amostra quanto à concordáncia com a

Orientação 10. São Paulo, 2004.

Tabela 59. Distribuição da amostra quanto à importância da Orientação 10.

São Paulo, 2004.

Tabela 60. Distribuição dos indivíduos quanto o cumprimento da

Orientação 10. São Paulo, 2004.

Tabela 61. Distribuição da amostra quanto a dúvida na Orientação 11.

São Paulo, 2004.

Tabela 62. Distribuição da amostra quanto à substituição de palavra

na Orientação 11. São Paulo, 2004.

Tabela 63. Distribuição da amostra quanto a substituição de palavras

na orientação 11 , segundo, sexo, escolaridade e idade dos entrevistados.

São Paulo, 2004.

Tabela 64. Distribuiçāo da amostra quanto à concordância com a

Orientação 11. São Paulo, 2004.

Tabela 65. Distribuição da amostra quanto à importáncia da Orientaçāo 11.

São Paulo, 2004. 
Tabela 66. Distribuição da amostra quanto o cumprimento da Orientaçăo 11. São Paulo, 2004.

Tabela 67. Distribuição da amostra quanto à dúvida na Orientação 12.

São Paulo, 2004.

Tabela 68. Distribuição da amostra quanto à substituição de palavra na Orientação 12. São Paulo, 2004.

Tabela 69. Distribuição da amostra quanto à importância da Orientação 12.

São Paulo, 2004.

Tabela 70. Distribuição da amostra quanto à importância da orientaçāo 12, segundo sexo, escolaridade e idade dos entrevistados. São Paulo, 2004.

Tabela 71. Distribuição da amostra quanto ao cumprimento da Orientação 12. São Paulo, 2004.

Tabela 72. Distribuição da amostra quanto à dúvida na Orientação 13.

São Paulo, 2004.

Tabela 73. Distribuição da amostra quanto a Substituição de palavra na

Orientação 13. São Paulo, 2004.

Tabela 74. Distribuição da amostra segundo o cumprimento da

Orientação 13. São Paulo, 2004. 


\section{LISTA DE ABREVIATURAS E SIGLAS}

SIGLA

AHA

CSI

DCV

ECNT

FCF

FEA

FSP

FR

HDL

ICS

IMC

INCAP

LDL

NCEP

OMS

OPS

SBC

SUS

USP

WHO
DESCRIÇÃo

American Heart Association

Cholesterol/satured -fat index

Doença cardiovascular

Enfermidade crônica não transmissivel

Faculdade de Ciências Farmacêuticas

Faculdade de Economia e Administração

Faculdade de Saúde Pública

Fator de risco

Lipoproteína de alta densidade

Índice de colesterol e gordura saturada

Índice de massa corpórea

Instituto de Nutrición de Centroamérica y Panamá

Lipoproteína de baixa densidade

National Cholesterol Education Program

Organização Mundial de Saúde

Organización Panamericana de la Salud

Sociedade Brasileira de Cardiologia

Sistema Único de Saúde

Universidade de São Paulo

World Health Organization 


\section{LISTA DE ANEXOS}

Página

ANEXO I - Guia Alimentar para Controle do Colesterol e Gordura no

Sangue

ANEXO II - Termo de Consentimento Livre e esclarecido

ANEXO III - Parecer do Comitê de Ética da Faculdade de Saúde

Pública da Universidade de São Paulo, sobre o presente estudo.

ANEXO IV - Questionário para coleta de dados

ANEXO IV - Resultados dos estudos de associação entre as respostas

e sexo, idade e escolaridade dos entrevistados 


\section{INTRODUÇÃO}

\subsection{Associação entre Dislipidemias e Aterosclerose}

As dislipidemias são definidas como distúrbios de transporte de lipídeos que resultam de anormalidades metabólicas na síntese ou degradação das lipoproteínas plasmáticas, que alteram as concentrações de seus diferentes componentes na circulação (NCEP 1994; LIMA 1999; NCEP 2001).

Diversos estudos epidemiológicos, desde Framingham, estabeleceram relação direta entre os valores de colesterol total e de LDL colesterol e a morbidade e mortalidade por doença vascular aterosclerótica (KEYS 1970; KEYS 1984; CONNOR e col. 1986; ANDERSON e col. 1987; BARNÁ e BIRÓ 1989).

No mesmo estudo de Framingham, após 30 anos de início, constatou-se que as mortes globais aumentaram $5 \%$ e as mortes por doenças cardiovasculares $9 \%$ para cada elevação de $10 \mathrm{mg} / \mathrm{dL}$ do colesterol total. O que sugere que niveis baixos de colesterol em indivíduos acima de 50 anos melhoram a longevidade (ANDERSON e col. 1987).

KATO e col. (1973) observaram em seus estudos com grupos populacionais migrantes que, ao adquirirem outros hábitos alimentares com correspondente elevação do nivel médio de colesterol total e do LDL colesterol, apresentaram, em 
relação a grupos controles, significativo aumento na incidência de doença coronariana.

\subsection{Epidemiologia das Doenças Cardiovasculares no Brasil}

As doenças cardiovasculares estão entre as principais causas de óbito nos países desenvolvidos e em muitos países em desenvolvimento, incluindo o Brasil, onde determinam um terço de todas as mortes (LOTUFO e LOLIO 1995; LOTUFO 1998; LAURENTI e BUCHALLA 2001; WILLET e HU 2002).

Atualmente, como nos Estados Unidos e Europa, as efermidades cardiovasculares são consideradas um problema de saúde pública, tendo em vista o seu papel no perfil de mortalidade e as alteraçōes patológicas que acarretam, muita das vezes irreversíveis, com conseqüente incapacidade residual (CERVATTO e col. 1997).

As doenças do aparelho circulatório, além de contribuírem de modo destacado para a mortalidade, são causas freqüentes de morbidade, implicando 10,74 milhões de dias de internação pelo Sistema Único de Saúde (SUS),

representando a principal causa dos gastos em assistência médica - 16,2 \% do total (LOTUFO e LOLIO 1995).

A participação das doenças cardiovasculares na mortalidade do país vem crescendo desde meados do século XX. Em 1950, 14,2 \% das mortes ocorridas 
nas capitais dos estados brasileiros eram atribuídas às moléstias circulatórias; passaram a $21 \%$ em 1960, 24,8 \% em 1970 e $30 \%$ em 1980 (MINISTÉRIO DA SAÚDE 1993; LOTUFO e LOLIO 1995). Em 2001, as cardiopatias contribuiram com $32 \%$ de todos os óbitos nas capitais dos estados brasileiros (MINISTÉRIO DA SAÚDE 2003; JUNIOR e col. 2003).

A comparação das taxas de mortalidade dos principais centros do Brasil com as de outros países já mostrou valores elevados de mortalidade geral e para todo o conjunto das doenças cardiovasculares (LOTUFO 1998).

No sexo masculino, as cidades brasileiras apresentaram valores elevados de óbitos para o conjunto de doenças do coração, destacando-se o Rio de Janeiro, Porto Alegre e Curitiba com taxas elevadas, superadas pela Hungria e próximas às da Finlândia e Polônia. São Paulo, Recife, Belém e Belo Horizonte situaram-se em uma posição intermediária e Salvador posicionou-se mais abaixo em valores próximos aos da Holanda e Canadá, porém distintos dos países imediatamente inferiores como Itália, Espanha e Portugal (LOTUFO 1998).

No sexo feminino, as taxas das cidades brasileiras foram as mais elevadas, posicionando o país juntamente com a Hungria como os de maior mortalidade entre as mulheres e as dos Estados Unidos em posição inferior (LOTUFO 1998).

Sendo assim, as doenças do coração devem constar nas prioridades de todas as esferas de governo e merecer a atenção de organismos não- 
governamentais preocupados em diminuir a desigualdade, dentro de países, entre nações.

\subsection{Fatores de Risco para Doenças Cardiovasculares}

Os estudos epidemiológicos sobre aterosclerose, principalmente o de Framingham (ANDERSON e col. 1987) observaram que certas condições biológicas e hábitos pessoais estavam fortemente relacionados à probabilidade de desenvolver doenças cardiovasculares. Essas características pessoais receberam a designação genérica de Fatores de Risco (FR), podendo ou não ser passiveis de intervenção (FISBERG e col. 2001).

A presença desses fatores em indivíduos não prediz o aparecimento de doenças cardiovasculares, porém indica uma predisposição ao seu desenvolvimento (ARAÚJO 2002). Os fatores de risco não ocorrem de maneira isolada, sendo comum a presença de duas ou mais condições. Segundo dados de Framingham, os riscos articulam-se de forma aditiva quando eles ocorrem concomitantemente (CASTELLI 1984).

São considerados passiveis de intervenção: hipertensão arterial, dislipidemias, obesidade, diabetes mellitus, dietas ricas em calorias, gorduras saturadas, colesterol e sal, tabagismo e sedentarismo (CERVATO e col. 1997; MONTEIRO 2000; FISBERG e col. 2001; SBC 2001). Os fatores que não são controláveis são idade, sexo, raça e hereditariedade (FISBERG e col. 2001). 
MARTINEZ e col. (2003) em seu estudo sobre a determinação dos niveis de colesterol de 81.262 indivíduos em 13 cidades brasileiras, observou os principais fatores de risco acima citados, sendo que $40 \%$ tinham antecedentes familiares de doença arterial coronariana, $19 \%$ possuiam hipertensão arterial sistêmica, $16 \%$ eram tabagistas e $5 \%$ portavam diabetes mellitus.

De acordo com as Diretrizes da Sociedade Brasileira de Cardiologia (2001) - LDL colesterol é considerado fator causal e independente da aterosclerose e sobre o qual devemos agir para diminuir a morbimortalidade.

Existem muitas demonstrações da relação dieta - aterosclerose, concluindo que esta é positiva com a ingestão de gordura e colesterol e pelo excesso de calorias, induzindo a obesidade (BATISTA e FRANCESCHINI 2003).

O excesso de peso, definido pelo Índice de Massa Corpórea $(\mathrm{IMC})>25$ $\mathrm{kg} / \mathrm{m}^{2}$, o acúmulo de gordura na região abdominal, do tipo central ou androgênico e o aumento do percentual de gordura corporal estăo associados a um maior risco de doença aterosclerótica (ARAÚJO 1997; MARTINS e col. 1989; DAVI e col. 2002; SBC 2002; ESPOSITO e col. 2003).

Estudos que objetivaram a comparação de diferentes populações, como o Seven Countries Study (KEYS 1970) relacionaram fatores de ingestão média dietética de 16 populações definidas em 7 paises e incidente de doença cardiaca 
nestes mesmos grupos. Houve uma forte correlação entre ingestão de gordura saturada com uma alto percentual de calorias e morte por doença coronariana.

\subsection{Binômio Dieta - Doença}

A estreita relação entre a dieta dos indivíduos e o desenvolvimento de enfermidades crônicas não transmissiveis (ECNT), principalmente doenças cardiovasculares (DCV) e câncer vem sendo demonstrada por diversos estudos epidemiológicos (FRAMINGHAN 1980; CONNOR 1989; CERVATO 1997; FORNÉS e col. 2000; WOO 2000; HU 2002).

A dieta ocidental, caracterizada pelos altos teores de gorduras, principalmente de origem animal, de açúcar e alimentos processados e baixos teores de carboidratos complexos e fibras, junto ao aumento da obesidade estão amplamente associados com a alta prevalência de ECNT e a diminuição de vida livre de doenças. As modificações na dieta descrita anteriormente ocorreram de forma lenta e gradual nos Estados Unidos e Europa, mas o ritmo de mudanças em países em desenvolvimento tem sido significativamente mais rápido, observando a progressão notável da obesidade (OLIVEIRA 1997, CERVATO 1997, MONTEIRO 2000).

No Brasil, observou-se uma mudança nos hábitos alimentares da população nas últimas décadas, ocorrendo a chamada transição nutricional, que pode ser definida como mudanças nos padrões nutricionais resultantes de modificações na 
estrutura da dieta dos indivíduos e que se correlacionam com variaçð̃es econômicas, sociais, demográficas e relacionadas à saúde (MONTEIRO 2000).

A relação entre dieta e doença coronariana foi estudada intensificamente durante o último século. Em 1908, IGNATOVSKY produziu aterosclerose em coelhos através de dietas ricas em colesterol e gordura saturada. Nos anos 50 , estudos de controle da dieta demonstraram que ácidos graxos saturados e colesterol, em menor grau, aumentaram a concentração de colesterol sérico em humanos (HU 2002).

Além disso, estudos epidemiológicos descobriram que o aumento de colesterol sérico prediz risco de doença coronariana em humanos. Estas descobertas levaram à clássica hipótese DIETA-CORAÇÃO, apresentada por GORDON (1988) e citada por WILLET (1998), que postula o papel principal da gordura saturada dietética e colesterol na causa da aterosclerose e doença coronariana (KATO 1973; KEYS 1980; MONTEIRO 2000).

A dieta habitual parece ser um elemento fundamental de análise de determinantes da susceptibilidade para aterosclerose e doenças isquêmicas do coração (CERVATO 1997; CONNOR e col. 1986; CONNOR e col. 1989; FORNÉS e col. 2000; BATISTA \& FRANCESCHINI 2003; PANAGIOTAKOS 2004). 


\subsection{Terapêutica das Dislipidemias}

A terapêutica deve ser iniciada com mudanças individualizadas no estilo de vida, que compreende hábitos alimentares saudáveis, busca e manutenção do peso ideal, exercício físico aeróbico regular, combate ao tabagismo e promoção do equilíbrio emocional. Não sendo atingidos os objetivos propostos, deve ser considerada a introdução de drogas isoladas ou associadas, dependendo das necessidades, com manutenção da dietoterapia (SANTOS 1999; SBC 2001; BATISTA E FRANCESCHINI 2003; SEISHIMA 2003).

Para o tratamento através da terapia nutricional, a Associação Americana do Coração (AHA) (2001) faz as seguintes orientações:

- Redução da ingestão de colesterol e de ácidos graxos: pois ambos elevam o LDL colesterol; portanto é importante diminuir a ingestão de alimentos de origem animal e de óleos de dendê e côco.

Porém, diversos estudos sobre a ingestão de ácidos graxos insaturados e polinsaturados (ômega 3, ómega 6 e ômega 9) reduzem o LDL colesterol sem a redução do HDL colesterol, além de, no caso do ômega 3, reduzir a trigliceridemia plasmática. Propठ̃e-se a substituição isocalórica dos ácidos graxos saturados por ácidos graxos insaturados. 
- Redução da ingestão dos ácidos graxos trans: produzidos durante a hidrogenação de óleos vegetais na produção de margarinas, e que elevam o LDL colesterol e reduzem o HDL colesterol;

- Aumento da ingestão de fibra dietética: as fibras solúveis ajudam na eliminação do colesterol;

- Ingestão de 3-4 g/dia de fitoesteróis promovendo a redução de $10-15 \%$ do LDL colesterol;

\section{6 Índice de Colesterol/ Gordura Saturada (CSI)}

O potencial de um alimento ou dieta em aumentar os níveis plasmáticos de colesterol total e LDL colesterol e promover aterosclerose é diretamente relacionado ao seu conteúdo de colesterol e gordura saturada (CONNOR e col. 1986; KRIS-ETHERTON e col. 1998).

A diminuição do colesterol e da gordura saturada da dieta contribui com uma redução média de $10 \%$ a $20 \%$ do colesterol plasmático (CONNOR e col. 1986; KRIS-ETHERTON e col. 1988).

Descrita a importância do colesterol e da gordura saturada dietética nos níveis plasmáticos de colesterol total e LDL colesterol, CONNOR e col. (1989) 
desenvolveram uma fórmula para indicar as concentrações de colesterol e gordura saturada nos alimentos, denominado Indice de Colesterol/ Gordura Saturada (CSI).

Tal índice é baseado em modificações de equações de regressão desenvolvidas desde KEYS (1965), para avaliar os efeitos de diferentes alimentos no colesterol sérico. Em 1979, ZILVERSMIT propôs a inclusão do indice de colesterol de alimentos na equação de regressão para demonstrar o efeito absoluto de porções individuais de alimentos nos niveis de colesterol plasmático dos individuos (CONNOR e col. 1986). Um baixo CSI indica um baixo conteúdo de gordura saturada e/ou colesterol e assim um potencial hipocolesterolêmico e de baixa aterogênicidade (CONNOR e col. 1989).

$$
C S I=(1.01 \times g . \text { gordura saturada })+(0.05 \mathrm{mg} . \text { colesterol })
$$

O CSI é uma ferramenta importante para a avaliação e o planejamento de dietas baixas em lipideos. Pode ser usado para comparar um alimento ou uma preparação com outras e ajudar a determinar facilmente qual escolha é a mais apropriada (menos aterogênica). CONNOR e col. (1989) desenvolveram uma tabela com cerca de 1.000 alimentos que indicam o CSI, o conteúdo de lipideos e de energia, por porção de alimento. O colesterol, gordura saturada, gordura total e conteúdo de energia foram determinados pelo uso de dados disponiveis comercialmente e provenientes de empresas alimenticias. A tabela foi subdividida em 38 categorias (por exemplo: doces, queijos, cereais matinais, etc.), ordenadas 
por ordem alfabética, agrupadas em duas sub - categorias (baixo e alto CSI) e listadas no estado mais comumente consumido.

\subsection{Guias Alimentares}

As normas/guias alimentares constituem um recurso para orientar a população a selecionar e consumir alimentos saudáveis, traduzindo os conhecimentos científicos sobre alimentação e nutrição adequada à vida cotidiana dos indivíduos em mensagens práticas e conceitos claros e de fácil compreensão, visando promover saúde e hábitos alimentares saudáveis, além de reduzir as chances de contrair determinadas doenças (MNHW 1988; SPILLER 1993; PHILIPPI e col. 1999; OLIVEIRA e col. 2002; PENA e MOLINA 1998).

No século XIX, ATWATER citado por PHILLIPI e col. (1999) foi o pioneiro na investigação nutricional e o primeiro a desenvolver vários dos componentes necessários para a elaboração de guias alimentares. Em 1894, ele publicou tabelas de composição de alimentos e padrōes dietéticos para a população norteamericana, dando inicio às bases cientificas para estabelecer relaçōes entre a composição dos alimentos, consumo e saúde dos indivíduos. A partir dai, foram propostos vários guias para diversos grupos populacionais com diferentes formas de apresentação. $O$ conteúdo deste também foi modificado devido às novas concep̧̧ões sobre alimentos, como por exemplo, o consumo de gorduras e açúcares, que é variável, conforme a população à qual se destina o guia (WELSH e col. 1992). 
WELSH e col. (1992) observaram que tem-se procurado uma forma gráfica de distribuição dos alimentos para uma melhor compreensão por parte da população, ou seja, fazer com que ocorra o consumo de vários alimentos e em quantidade suficiente para que juntos componham uma dieta adequada nutricionalmente.

PHILLIPI e col. (1999) afirmaram que para o desenvolvimento de guias alimentares deve haver um processo de pesquisa contendo: o diagnóstico da situação nutricional e dados epidemiológicos que fundamentem as dietas, os objetivos, as metas nutricionais e um banco de dados contendo a composição dos alimentos escolhidos e, segundo OLIVEIRA e col. (2002), na criação destas Normas/Guias devem ser considerados: o papel da alimentação/ nutrição sobre o desenvolvimento físico e mental, garantindo qualidade de vida ao homem, e a divulgação do conhecimento científico existente na área de alimentação/nutrição. A OPS/OMS e o INCAP recomendam ainda que seja considerada a informação sobre disponibilidade, custo, acesso ao consumo de alimentos e hábitos alimentares. $E$ a isto incorporar elementos da antropologia social, que se permitam adaptar os guias alimentares à realidade social, cultural e econômica da população-alvo (PENA e MOLINA 1998).

De acordo com WELSH e col. (1992) estes guias devem: 
- Promover e manter a saúde global do indivíduo com orientações para prevenção ou tratamento de qualquer doença;

- Ser baseados em pesquisas atualizadas;

- Ter uma visão global da dieta;

- Ser úteis ao público-alvo;

- Encontrar uma forma realista de suprir as necessidades nutricionais utilizandose da dieta habitual de cada população;

- Ser práticos e os nutrientes e energia adaptados segundo a idade, sexo e atividade física;

- Ser dinâmicos, permitindo o máximo de flexibilidade para a escolha dos alimentos, a fim de suprir as necessidades nutricionais do indivíduo.

Os guias devem ser representados por grupos de alimentos e baseados na variedade de informaçōes incluindo a relação existente entre os alimentos e a saúde dos indivíduos. Com um guia alimentar adequado à população, os objetivos propostos podem ser alcançados (SPILLER 1993). 
A OPS/OMS e o INCAP propõem um modelo de elaboração de Guias Alimentares no qual alguns passos devem ser seguidos:

- Planejamento: É necessária a incorporação de idéias e pontos de vista de diversas instituições dos setores públicos (saúde, educação, agricultura, economia, etc.), acadêmico e privado (universidades, associações profissionais, câmara de comércio e indústria, etc.), e dos seus usuários visando facilitar sua implementação em diferentes instâncias;

- Caracterização do público-alvo: a partir de um diagnóstico da situação da saúde e nutrição do grupo a quem serão dirigidos os guias, realizados através de revisão de publicações existentes. Como resultado, obtém-se um documento descritivo que incluem os fatores de risco e os problemas associados à dieta do grupo-alvo;

- Definição dos objetivos: devem estar direcionados a prevenir e reduzir os riscos e problemas prioritários detectados na etapa anterior, assim como promover dietas e estilo de vidas saudáveis;

- Elaboração de normas técnicas: consiste em converter as metas nutricionais no tipo e na quantidade de alimentos que a população deve ingerir para alcançar as recomendações nutricionais; 
- Provas de recomendações factiveis: prova de campo em pequena escala para conhecer a disposição (habilidades, motivação) da população-alvo para cumprir com as recomendações técnicas determinadas no passo anterior;

- Elaboração de Guias Alimentares: são as recomendações que a populaçãoalvo receberá através de mensagens que podem ser complementadas por um icone ou representação gráfica;

- Validação e prova dos Guias Alimentares: O guia deve ser validado com pessoas representativas da população-alvo, a fim de verificar se é compreendidos, relevantes, aceitáveis e persuasivos;

- Correção e ajuste dos Guias Alimentares: baseados nos resultados da validação, as mensagens e a representação gráfica são revistas e corrigidas a fim de se adaptarem à linguagem popular, sem distorção do conteúdo técnico;

- Implementação: após a sua elaboração, o próximo passo dos Guias Alimentares é a sua reprodução, disseminação e implementação em âmbito nacional, através dos setores público e privado e com uma estratégia de comunicação previamente definida;

- Avaliação: devem ser avaliadas periodicamente, tanto no processo de implementação como seu impacto no estilo de vida do público-alvo. 


\subsection{Desenvolvimento do Guia Alimentar para o Controle do Colesterol e Gordura no Sangue}

A influência do colesterol e gordura saturada da dieta é tão importante, que foi desenvolvido por CONNOR e col. (1986) o índice de colesterol/gordura saturada (CSI), que pode ser utilizado para comparar valores de alimentos e preparações, além de auxiliar na avaliação do consumo diário dos individuos.

Baseado neste índice, TORRES (2000) desenvolveu uma tabela contendo o valor energético e de CSI de 187 alimentos e preparaçōes normalmente consumidos pela população brasileira. A partir desses dados, ABREU (2003) elaborou o Sistema de Pontos para Controle de Colesterol e Gordura no Sangue (ANEXO I).

Para o desenvolvimento deste instrumento, elaborou-se uma lista de alimentos para constituir um sistema de pontos. Estes alimentos foram baseados em uma lista de alimentos desenvolvida por FORNÉS e col. (1998), que faziam parte da dieta habitual de indivíduos de um município da região metropolitana de São Paulo.

Para contemplar todos os alimentos que eventualmente possam integrar a dieta dos indivíduos adicionou-se à lista, outros alimentos que são consumidos pela população com menor freqüência. 
O CSI foi calculado pela metodologia citada por CONNOR e col. (1986). Os valores de gordura saturada e de colesterol foram obtidos utilizando-se dados de experimentos bromatológicos desenvolvidos no laboratório de Bromatologia da Faculdade de Saúde Pública da Universidade de São Paulo, apresentados por TORRES (2000). Os alimentos que não constaram dessa listagem foram calculados de forma indireta, por meio de tabelas de composição de alimentos: Tabela brasileira de composição de alimentos (LAJOLO e col. 2002), Tabela de composição de alimentos: suporte para decisão nutricional (PHILIPPI 2001) e The composition of foods (McCANCE e WINDDOWSON 1991).

O Sistema de Pontos possui material explicativo pelo qual o indivíduo recebe instruções detalhadas para determinar sua pontuação alvo de CSI. Optouse por denominar o CSI de ICS (Índice de colesterol e gordura saturada), para evitar siglas em outro idioma e assim facilitar o entendimento pela população.

Por se tratar de uma dieta de pontos, para controle do colesterol sérico, na qual não há proibições de alimentos e a escolha é feita diretamente pelo indivíduo, de acordo com suas preferências e hábitos alimentares, considerou-se importante o estabelecimento de uma relação da escolha de alimentos com uma alimentação balanceada (MITCHELL 1996).

Para tanto, utilizou-se como representaçāo gráfica o Guia Alimentar da Pirâmide, adaptado de WILLETT (2001). Foi apresentada em formato de coração, 
abordando variedade, proporção e moderação, sem indicar quantidades e porções, que devem ser decididas por meio da pontuação dos alimentos.

Foram criadas mensagens claras e objetivas em relação à necessidade de se manter o peso ideal, o qual pode ser obtido em tabela simplificada e de fácil utilização, tomando-se como base o IMC - Índice de Massa Corporal normal (WHO 1998), além dos passos a serem seguidos para uma alimentação saudável.

A necessidade individual de gorduras e colesterol, para o cálculo do CSI, foi calculada utilizando-se as recomendações sugeridas pela American Health Association (AHA) (2001), para a fase 2 apresentadas no Quadro 1.

Quadro 1. Recomendação Dietética para o tratamento das hiperlipidemias

\begin{tabular}{|l|r|}
\hline \multicolumn{1}{|c|}{ NUTRIENTE } & INGESTÃO RECOMENDADA \\
\hline Gordura total & $20-25 \%$ das calorias totais \\
\hline Ácidos Graxos Saturados & $<7 \%$ das calorias totais \\
\hline Ácidos Graxos Poliinsaturados & De 10 a 15\% das calorias totais \\
\hline Ácidos Graxos Monoinsaturados & $50-60 \%$ das calorias totais \\
\hline Carboidratos & Aproximadamente $15 \%$ das calorias totais \\
\hline Proteinas & $<200$ mg/dia \\
\hline Colesterol & $20-30$ g/dia \\
\hline Fibras & Para atingir ou manter o peso desejável \\
\hline Calorias &
\end{tabular}

Fonte: American Heart Association, 2001 
Desta maneira, foi elaborado o Sistema de Pontos para Controle de Colesterol e Gordura no Sangue, que pode ser usado pelos indivíduos para prevenir e controlar o colesterol.

\subsection{Avaliação e validação de Guias Alimentares}

Todo instrumento de promoção da saúde deve ser validado para que se possa medir sua eficácia.

Validar um instrumento significa conferir valor ao mesmo, ou seja, confirmar se ele realmente tem o potencial a que se propõe. Os resultados de um estudo de validação podem ser usados como base para ajustes no instrumento ou para sua adoção (WILLETT 1998).

Validação é um processo que se aplica a uma amostra da população com o objetivo de se conhecer o grau de entendimento que o grupo compreende sobre $\circ$ que the é apresentado e proposto (PENA E MOLINA 1998; OLIVEIRA e col. 2002; VILLAR 2001; ABREU 2003).

A eficácia dos Guias Alimentares para população como um instrumento de promoção de saúde necessita ser validada para que os conhecimentos científicos, atitudes e práticas possam ser transmitidos (OLIVEIRA e col. 2002). Os guias alimentares podem ser teoricamente corretos, mas se não sāo compreendidos, 
recordados e aplicados pelo grupo ao qual são destinados, não cumprirão seu propósito (PENA E MOLINA 1998). 


\section{JUSTIFICATIVA}

Estudos realizados por ABREU (2003) e NACIF (2003) demonstraram que o sistema de pontos proposto no Guia Alimentar para Controle de Colesterol e Gordura no Sangue mostrou-se eficaz como instrumento de orientação alimentar para indivíduos hiperlipidêmicos, sendo uma ferramenta de rápida e simples aplicação e de fácil entendimento, com resultado superior em relação à dieta tradicional para dislipidemias.

No entanto, para que o instrumento seja avaliado como um todo, pretendese verificar a compreensão da população em relação aos passos para uma alimentação saudável, propostos no Guia Alimentar para Controle de Colesterol e Gordura no Sangue. 


\section{OBJETIVOS}

\subsection{Objetivo Geral}

Avaliar a compreensão da população em relação aos passos para uma alimentação saudável propostos no "Guia Alimentar para Controle de Colesterol e Gordura no Sangue", considerando a clareza do conteúdo e a forma que foram expressos.

\subsection{Objetivos Especificos}

- Descrever as características da população em estudo;

- Identificar a linguagem mais apropriada para a compreensão das mensagens;

- Corrigir e ajustar eventuais problemas lingüísticos. 


\section{METOdOLOGIA}

\subsection{Delineamento do Estudo}

O delineamento da presente pesquisa corresponde a um estudo qualiquantitativo com coletas de dados primários.

\subsubsection{População e local de estudo}

A população do estudo constituiu-se de 30 indivíduos voluntários, de 20 anos ou mais, ambos os sexos e freqüentadores do Instituto do Coração da Faculdade de Medicina da Universidade de São Paulo (INCOR/FM/USP), no município de São Paulo, durante o ano de 2004.

\subsection{Amostra}

A amostra constituiu-se de todos os voluntários usuários do INCOR que aceitaram participar da pesquisa entre os meses de abril e maio de 2004, às sextas-feiras das 13 às 17 horas. Foram convidados para fazer parte do estudo 50 indivíduos, dos quais, 20 desistiram de responder a pelo menos metade do questionário e três responderam até $50 \%$ do total de perguntas, sendo considerado parte da amostragem. 


\subsection{Critérios de seleção e exclusão}

Foram convidados a participar do estudo todos os voluntários que não apresentaram algum quesito relativo aos critérios de exclusão.

Consideraram-se fatores de exclusão:

- Analfabetos - pela necessidade dos cartões com as Normas a serem lidas e entendidas.

- Pacientes portadores de problemas neurológicos, deficientes visuais e auditivos, pela impossibilidade de leitura dos cartōes - com os passos para uma alimentação saudável proposta pelo sistema de pontos para o controle de colesterol e gordura no sangue - e de responder à entrevista.

\subsection{Coleta de dados}

A coleta de dados foi realizada ente abril e maio de 2004 , às sextas-feiras, das 13 às 17 horas, no ambulatório da instituição escolhida para o estudo. 


\subsection{Variáveis de Estudo}

Para descrever as características da população e proceder ao levantamento de dados relativos à pesquisa, foram escolhidas as variáveis listadas abaixo, que poderão ser conferidas no instrumento utilizado para a coleta de dados:

Os aspectos demográficos e sociais serão analisados por meio das variáveis sexo, idade e escolaridade.

\subsubsection{Sexo e idade}

Os dados sobre sexo e idade dos participantes foram obtidos durante a entrevista. A idade foi calculada por meio da diferença entre a data de nascimento até a data da entrevista, em anos completos.

\subsubsection{Escolaridade}

O nível de escolaridade foi calculado em anos completos de estudo e posteriormente agrupados em:

- 1 - 4

- $5-8$

- $9-11$

- 12 ou + anos 


\subsection{Procedimentos Metodológicos}

Os individuos foram questionados pela nutricionista, autora deste estudo e por uma estudante do curso de Nutrição da Faculdade de Saúde Pública da Universidade de São Paulo previamente treinada, que registraram todas as respostas no questionário da pesquisa.

\subsubsection{Avaliação dos passos para uma alimentação saudável proposta pelo sistema de pontos para o controle de colesterol e gordura no sangue}

Para o desenvolvimento do presente estudo, seguiu-se a metodologia adaptada da pesquisa desenvolvida pelo Instituto Danone (OLIVEIRA e col. 2002). (Anexo IV)

Os participantes foram questionados quanto à compreensảo dos passos para uma alimentação saudável proposta pelo sistema de pontos para o controle de colesterol e gordura no sangue.

Os entrevistados foram abordados ao acaso, no ambulatório da instituição, e questionados sobre a possibilidade de responder à pesquisa; se houvesse concordância, seria apresentado o primeiro cartão contendo o Passo número 1. "Consumir uma alimentação variada" e seguiria-se o rol de perguntas. O mesmo processo foi seguido com os 13 cartōes. Para facilitar a leitura, foram confeccionados cartões em cartolina branca e com escritas em tinta preta 
contendo os passos escritos com letras grandes (fonte $n^{0} 18$ ), avaliados cada um por vez. A compreensão das mensagens foi realizada através de um questionário contendo perguntas fechadas e abertas.

As perguntas fechadas foram:

1. $O$ (a) senhor(a) tem dúvida a respeito da orientação alimentar apresentada? Sim ou Não;

2. Existe alguma palavra ou termo nesta orientação que a senhora acha que o(a) senhor(a) acha que deveria ser trocada, para que as pessoas entendam melhor o que diz essa orientação? Sim ou Não, se sim, qual?;

3. Quanto o(a) senhor(a) está de acordo com o que diz esta orientação? Concorda totalmente, concorda parcialmente ou discorda;

4. O que as pessoas de maneira geral acharão desta orientação? Acreditarão totalmente, acreditarão parcialmente ou não acreditarão;

5. Qual a importância da orientação sobre alimentação apresentada para as pessoas? Muito importante, pouco importante ou não é importante. 
6. Com relação à sua alimentação, qual a importância desta orientação sobre a alimentação apresentada? Sempre segue essa orientação, freqüentemente segue a orientação, quase nunca segue ou nunca segue a orientação.

\subsubsection{Sugestões para o aperfeiçoamento dos passos para uma alimentação saudável proposta pelo sistema de pontos para o controle de colesterol e gordura no sangue}

Os participantes da pesquisa foram questionados quanto a sugestão para o seu aperfeiçoamento através da pergunta aberta número 2 contida no questionário.

2. Existe alguma palavra ou termo nesta orientação que o(a) $\mathrm{Sr}$.(a) acha que deveria ser trocado para que as pessoas entendam melhor o que diz essa orientação? Se SIM, qual? 


\subsection{Análise de dados}

Os dados de interesse deste trabalho foram digitados em planilhas e armazenados no programa Microsoft EXCEL 1997 para Windows.

Os cálculos foram processados para se estabelecer os números e respectivas porcentagens dos dados que caracterizaram a população do estudo. Foram construídas tabelas de freqüência para todas as respostas observadas que permitiram obter indicaçōes dos resultados.

Cada uma das 13 orientações foi analisada para cada uma das seis perguntas do questionário de acordo com as três variáveis: sexo, idade e escolaridade dos entrevistados.

$\mathrm{Na}$ análise das perguntas foi realizado para cada variável o teste exato de Fisher ou sua extensão (AGRESTI 2002), adotando-se um nivel de significância de $10 \%(p<0,10)$. Através do valor de "p" (nivel descritivo do teste de associação de Fisher) pôde-se verificar se a associação observada foi devido ao acaso (quando $p>0,10$ ) ou uma grande probabilidade de não ser ao acaso (quando $p<0,10)$. Em outras palavras, aceita-se que existam diferenças entre as proporçōes apresentadas quando o valor de $p<0,10$.

Todos estes procedimentos foram realizados com o "software" $R$ (GNU). 


\subsection{Parte Ética}

De acordo com a resolução n. ${ }^{\circ} 196$ de 1996, do Conselho Nacional de Saúde, por se tratar de pesquisa envolvendo seres humanos, há a necessidade de aprovação do Comitê de Ética da Faculdade de Saúde Pública da USP ou da entidade onde é realizada a pesquisa (CONSELHO NACIONAL DE SAÚDE 1996).

A pesquisa foi autorizada pelo Comitê de Ética da Faculdade de Saúde Pública da USP, por meio do documento Of. COEP/191/03 (Anexo III). Desta forma, os individuos que participaram da pesquisa foram argüidos sobre a disponibilidade de participar da pesquisa, após terem sido informados do objetivo do estudo e de seus procedimentos, além do anonimato e da confidencialidade dos dados, bem como da possibilidade de desistir do estudo a qualquer momento, sem apresentar motivos ou sofrer qualquer tipo de constrangimento. Também foi esclarecido que eles teriam plena liberdade de aceitar ou não, ficando cientes de que a negativa de adesão não lhes traria qualquer prejuízo.

Os individuos que aceitaram participar da pesquisa assinaram um termo de consentimento livre e esclarecido conforme o ANEXO II. 


\section{RESULTADOS E DISCUSSÃO}

Os resultados da análise apresentados são os referentes às respostas obtidas de todas as treze orientações apresentadas aos entrevistados.

\subsection{Características da população em estudo}

Foram estudados 30 individuos. Destes, $8(26,7 \%)$ eram do sexo masculino e $22(73,3 \%)$, do feminino (Tabela 1$)$.

Tabela 1: Distribuição da amostra segundo sexo dos entrevistados. São Paulo, 2004.

\begin{tabular}{lll}
\hline Sexo & Frequència & Porcentagem \\
\hline Masculino & 8 & 26,7 \\
Feminino & 22 & 73,3 \\
\hline Total & 30 & 100 \\
\hline
\end{tabular}

Em relação à escolaridade, 7 indivíduos $(23,3 \%)$ tinham até 4 anos de estudo, os mesmos percentuais observados para até 8 anos e 12 ou mais anos de estudo, 9 indivíduos $(30,1 \%)$ tinham até 11 anos de estudo, podendo ser definidos como um grupo bastante heterogêneo em relação a escolaridade (Tabela 2).

Tabela 2: Distribuição da amostra segundo escolaridade dos entrevistados. São Paulo, 2004.

\begin{tabular}{lll}
\hline Escolaridade & Frequencia & Porcentagem \\
\hline $1-4$ & 7 & 23,3 \\
$5-8$ & 7 & 23,3 \\
$9-11$ & 9 & 30,1 \\
12 ou mais & 7 & 23,3 \\
\hline Total & 30 & 100 \\
\hline
\end{tabular}


A ldade média dos entrevistados foi 43,2 anos $(D P=12,66)$ e a idade mínima e máxima 20 e 78 anos, respectivamente (Tabela 3).

Tabela 3: Distribuição da amostra segundo a idade dos entrevistados. São Paulo, 2004.

\begin{tabular}{lll}
\hline Idade & Freqüencia & Porcentagem \\
\hline Até 45 anos & 7 & 23,3 \\
$46-59$ anos & 18 & 60 \\
60 anos ou + & 9 & 16,7 \\
\hline Total & 30 & 100 \\
\hline
\end{tabular}

5.2 Distribuição da amostra quanto às respostas sobre as orientaçōes, segundo sexo, idade e escolaridade.

\subsubsection{Orientação 1: Consumir uma alimentação variada}

Pôde ser constatado que $93,3 \%$ dos indivíduos referiram-se à terminologia utilizada de fácil compreensão (Tabela 4), pois apenas $6,7 \%$ da amostra não sabiam o que era uma alimentação variada, independente das variáveis estudadas (Anexo V).

Tabela 4: Distribuição da amostra quanto à dúvida na Orientação 1. São Paulo, 2004.

\begin{tabular}{lll}
\hline Dúvida sobre a orientaçåo & Freqüência & Porcentagem \\
\hline Sim & 2 & 6,7 \\
Não & 28 & 93,3 \\
\hline Total & 30 & 100,0 \\
\hline
\end{tabular}


As dúvidas relatadas por $6,7 \%$ dos indivíduos estão apresentadas a seguir (Quadro 2).

Quadro 2. Distribuição das dúvidas apresentadas quanto à orientaçāo 1. São Paulo, 2004.

\begin{tabular}{ll}
\hline Dúvida & Frequeéncia \\
\hline Nåo sabe o que é alimentaçåo saudável & 1 \\
Carne de porco é saudável? & 1 \\
\hline Total & 2 \\
\hline
\end{tabular}

Em relação à substituição de palavras na orientação, $86,7 \%$ dos indivíduos relataram que não havia necessidade de troca enquanto $13,3 \%$ disseram que alguma palavra deveria ser trocada (Tabela 5), independente das variáveis estudadas (Anexo V).

Tabela 5: Distribuição da amostra quanto à substituição de palavra na Orientação 1.

\begin{tabular}{lll}
\hline Alguma palavra deve ser trocada? & Freqüência & Porcentagem \\
\hline Sim & 4 & 13,3 \\
Não & 26 & 86,7 \\
\hline Total & 30 & 100,0 \\
\hline
\end{tabular}

As sugestões estão apresentadas a seguir (Quadro 3).

Quadro 3. Distribuição das sugestões quanto à troca de palavras da orientação 1. São Paulo, 2004.

\begin{tabular}{ll}
\hline Sugestōes & Freqüência \\
\hline Complementar "com mais freqüeência". & 2 \\
Trocar a palavra variada por "mais \\
colorida" & 1 \\
Trocar a palavra consumir & 1 \\
\hline Total & 4 \\
\hline
\end{tabular}


Quanto à concordância com a orientação, $83,3 \%$ da amostra concordaram totaimente com a orientação da forma como foi apresentada (Tabela 6), reforçando sua fácil compreensão. Este dado foi independente das variáveis estudadas (Anexo V).

Tabela 6: Distribuição da amostra quanto à concordância com a Orientação 1. São Paulo, 2004.

\begin{tabular}{lll}
\hline Concordância com a orientação & Freqúencia & Porcentagem \\
\hline Concorda totalmente com essa orientaçăo & 25 & 83,3 \\
Concorda parcialmente com essa orientaçăo & 4 & 13,3 \\
Discorda dessa orientação & 1 & 3,3 \\
\hline Total & 30 & 100,0 \\
\hline
\end{tabular}

Quando questionados sobre a importância da orientação, $96,7 \%$ dos individuos disseram ser muito importante (Tabela 7), reforçando a credibilidade da orientação 1, independente das variáveis estudadas (Anexo V).

Tabela 7: Distribuição da amostra quanto à importância da Orientação 1. São Paulo, 2004.

\begin{tabular}{lll}
\hline Importância da orientaçăo & Freqüencia & Porcentagem \\
\hline Muito importante & 27 & 90,0 \\
Um pouco importante & 3 & 10,0 \\
\hline Total & 30 & 100,0 \\
\hline
\end{tabular}

Em relação ao item "seguir a orientação" proposta, $40 \%$ dos indivíduos relataram que "sempre seguem" a orientaçāo, $43,3 \%$ disseram "freqüentemente seguir" a orientação e $16,7 \%$ disseram "nunca seguir" a orientação (Tabela 8 ), independente das variáveis estudadas (Anexo V). 
Tabela 8: Distribuição da amostra quanto ao cumprimento da Orientação 1. São Paulo, 2004.

\begin{tabular}{lll}
\hline Segue a orientaçăo? & Freqüència & Porcentagem \\
\hline Sempre segue essa orientaçăo & 12 & 40,0 \\
Frequientemente segue & 13 & 43,3 \\
Quase nunca segue & 5 & 16,7 \\
\hline Total & 30 & 100,0 \\
\hline
\end{tabular}

Os indivíduos que responderam que "freqüentemente ou quase nunca seguem a orientação" disseram não segui-la devido à falta de tempo ("trabalho fora de casa"), falta de recursos financeiros ("pobre não tem uma alimentação certinha", às vezes não tenho dinheiro pra comer direito"), hábitos alimentares ("não consigo viver sem came", "adoro doces") e fatores pessoais ("sou teimoso").

Tais resultados mostram que mesmo a mensagem sendo de fácil entendimento, de grande importância e credibilidade, a população nem sempre cumpre a orientação. Isso pode ser explicado por questões financeiras ou hábitos alimentares, sendo necessários mais estudos nessa área. 


\subsubsection{Orientação 2: Basear a alimentação no consumo de alimentos derivados de grãos e raizes, hortaliças e frutas.}

Sobre a existência de dúvidas em relação a esta orientação, $27,6 \%$ dos indivíduos relataram apresentarem dúvidas em relação a esta orientação e $72,4 \%$ dos indivíduos disseram não apresentarem dúvidas (Tabela 9), independente das variáveis estudadas (Anexo V).

Tabela 9: Distribuição da amostra quanto à dúvida na Orientação 2. São Paulo, 2004.

\begin{tabular}{lll}
\hline Dúvida sobre a orientação & Frequéncia & Porcentagem \\
\hline Sim & 8 & 27,6 \\
Não & 21 & 72,4 \\
\hline Total & 29 & 100,0 \\
\hline
\end{tabular}

Diante dos resultados acima, observou-se que mais de um quarto dos entrevistados não compreenderam totalmente a orientação 2 , sendo que 0 desconhecimento do significado da palavra "grãos" foi o mais freqüente (Quadro 4).

Quadro 4. Distribuição das dúvidas apresentadas quanto à orientação 2. São Paulo, 2004

\begin{tabular}{ll}
\hline Dúvida & Frequềncia \\
\hline O que são grãos? & 4 \\
Posso tomar suco ao invés de comer frutas? & 1 \\
Macarrão é grão também? & 1 \\
Batata e mandioca podem ser fritas? & 1 \\
Está confuso & 1 \\
\hline Total & 8 \\
\hline
\end{tabular}


Cerca de $30 \%$ deles sugeriram a substituição de palavras (Tabela 10), principalmente trocar a terminologia "grãos e raízes" por exemplos usuais: arroz, feijão, batata, mandioca, cenoura, lentitha, etc., apontando a necessidade de simplificar a linguagem da orientação, a fim de facilitar sua compreensão (Quadro $5)$.

Os resultados quanto à substituição de palavras foi independente das variáveis estudadas (Anexo V).

Tabela 10: Distribuição da amostra quanto à substituição de palavra na Orientação 2. São Paulo, 2004.

\begin{tabular}{lll}
\hline Alguma palavra deve ser trocada? & Freqúência & Porcentagem \\
\hline Sim & 9 & 31,0 \\
Năo & 20 & 69,0 \\
\hline Total & 29 & 100,0 \\
\hline
\end{tabular}

Quadro 5. Distribuição das sugestões quanto à troca de palavras na orientação 2. São Paulo, 2004.

\begin{tabular}{ll}
\hline Sugestőes & Freqüencia \\
\hline Falaria quais os grăo e raizes & 7 \\
Incluir a palavra "importante" & 1 \\
Trocar a palavra basear por consumir & 1 \\
\hline Total & 9 \\
\hline
\end{tabular}

Quanto à concordância com a orientação, $86,7 \%$ dos indivíduos concordaram totalmente com a orientação, enquanto $13,3 \%$ concordaram parcialmente com a orientação (Tabela 11), independente das variáveis estudadas (Anexo VI). 
Tabela 11: Distribuição da amostra quanto à concordância com a Orientação 2. São Paulo, 2004.

\begin{tabular}{lll}
\hline Concordância com a orientaçăo & Frequéncia & Porcentagem \\
\hline Concorda totalmente com essa orientaçăo & 26 & 86,7 \\
Concorda parcialmente com essa orientaçāo & 4 & 13,3 \\
\hline Total & 30 & 100,0 \\
\hline
\end{tabular}

Quando questionados quanto à importância da orientação, $90 \%$ relataram ser muito importante e $10 \%$ disseram ser pouco importante a orientação para o controle do colesterol e gordura no sangue (Tabela 12), independente das variáveis estudadas (Anexo $\mathrm{V}$ ).

Tabela 12: Distribuição da amostra quanto à importância da Orientação 2. São Paulo, 2004.

\begin{tabular}{lll}
\hline Importância da orientação & Freqüência & Porcentagem \\
\hline Muito importante & 27 & 90,0 \\
Um pouco importante & 3 & 10,0 \\
\hline Total & 30 & 100,0 \\
\hline
\end{tabular}

Sobre o cumprimento da orientação pelos entrevistados, $46,7 \%$ dos individuos relataram sempre seguirem a orientação, $40 \%$ disseram freqüentemente seguirem a orientação e $13,3 \%$ disseram nunca seguirem essa orientação (Tabela 13), independente das variáveis estudadas (Anexo V). Nota-se aqui o mesmo fato em relação à orientação 1 , onde existe dificuldade do cumprimento da orientação, mesmo quando ela é aceita e compreendida. 
Tabela 13: Distribuição da amostra quanto ao cumprimento da Orientação 2. São Paulo, 2004.

\begin{tabular}{lll}
\hline Segue a orientação? & Freqúéncia & Porcentagem \\
\hline Sempre segue essa orientaçăo & 14 & 46,7 \\
Freqüentemente segue & 12 & 40,0 \\
Quase nunca segue & 4 & 13,3 \\
\hline Total & 30 & 100,0 \\
\hline
\end{tabular}

Os individuos que responderam que "freqüentemente ou quase nunca seguem a orientação" disseram não segui-la devido a hábitos alimentares ("não como frutas e verduras todos os dias", "não gosto de verdura", "exagero no macarrão e doces"). 


\subsubsection{Orientação 3: Evitar a obesidade, mantendo o peso corporal desejável.}

Avaliando a orientação 3 , quando questionados sobre a existéncia de alguma dúvida na orientação, apenas $3,3 \%$ dos indivíduos relataram dúvidas, mas nota-se que não em relação à compreensão da orientação, mas em relação ao ideal de peso corpóreo ("Qual o peso ideal?") (Tabela 14), independente das variáveis estudadas (Anexo $\mathrm{V}$ )

Como o estudo não utilizou a cartilha completa do Sistema de pontos para o controle do colesterol e gordura no sangue, que possui uma tabela de peso ideal de acordo com a altura (WHO, 1998), mas somente a mensagem em forma de cartões, pode-se dizer que essa dúvida seria facilmente esclarecida.

Tabela 14: Distribuição da amostra quanto à dúvida na Orientação 3. São Paulo, 2004.

\begin{tabular}{lll}
\hline Dúvida sobre a orientaçåo & Frequencia & Porcentagem \\
\hline Sim & 1 & 3,3 \\
Nåo & 29 & 96,7 \\
\hline Total & 30 & 100,0 \\
\hline
\end{tabular}

Em relação à substituição de palavras na orientação, 10,3\% dos indivíduos disseram que alguma palavra deveria ser trocada enquanto $89,7 \%$ relataram que não havia necessidade de troca (Tabela 15).

As respostas não tiveram relação entre o sexo, idade e escolaridade dos entrevistados (Anexo V) 
Tabela 15: Distribuição da amostra quanto à substituição de palavra na Orientação 3. São Paulo, 2004.

\begin{tabular}{lll}
\hline Alguma palavra deve ser trocada? & Frequéncia & Porcentagem \\
\hline Sim & 3 & 10,3 \\
Não & 26 & 89,7 \\
\hline Total & 29 & 100,0 \\
\hline
\end{tabular}

Uma das sugestões apresentadas foi a de substituir obesidade por "ficar gordo", evidenciando a utilização da linguagem cotidiana como forma mais simples de expressão e conseqüente compreensão (Quadro 6).

Quadro 6. Distribuição das sugestões quanto à troca de palavras da orientação 6. São Paulo, 2004.

\begin{tabular}{ll}
\hline Sugestōes & Freqüência \\
\hline Tocar a palavra obesidade por "ficar gordo" & 2 \\
Colocar "não abusar dos doces" & 1 \\
\hline Total & 3 \\
\hline
\end{tabular}

Quanto à concordância com a orientação, 90\% da amostra estudada concordaram totalmente com a orientação e 10\% concordaram parcialmente, não havendo nenhum participante que discordou da orientação (Tabela 16).

Tabela 16: Distribuição da amostra quanto à concordância com a Orientação 3. São Paulo, 2004.

\begin{tabular}{lll}
\hline Concordância com a orientaçåo & Frequéncia & Porcentagem \\
\hline Concorda totalmente com essa orientaçåo & 27 & 90,0 \\
Concorda parcialmente com essa orientaçăo & 3 & 10,0 \\
\hline Total & 30 & 100,0 \\
\hline
\end{tabular}


Tabela 17: Distribuição da amostra quanto ao cumprimento da orientação 3, segundo sexo, escolaridade $e$ idade dos entrevistados. São Paulo, 2004.

\begin{tabular}{|c|c|c|c|c|c|c|c|}
\hline \multirow[t]{2}{*}{ Características } & \multicolumn{2}{|c|}{$\begin{array}{l}\text { Concorda } \\
\text { totalmente }\end{array}$} & \multicolumn{2}{|c|}{$\begin{array}{l}\text { Concorda } \\
\text { parcialmente }\end{array}$} & \multicolumn{2}{|c|}{ Discorda } & \multirow[t]{2}{*}{$\boldsymbol{P}$} \\
\hline & $\boldsymbol{N}$ & $\%$ & $\mathbf{N}$ & $\%$ & $\boldsymbol{N}$ & $\%$ & \\
\hline Sexo & & & & & & & 0,999 \\
\hline Masculino & 7 & 87,5 & 1 & 12,5 & 0 & 0,0 & \\
\hline $\begin{array}{l}\text { Feminino } \\
\text { Idade }\end{array}$ & 20 & 90,9 & 2 & 9,1 & 0 & 0,0 & $0 \cap 13$ \\
\hline Até 45 anos & 4 & 57,1 & 3 & 42,9 & 0 & 0,0 & 0,010 \\
\hline 46 a 59 anos & 18 & 100,0 & 0 & 0,0 & 0 & 0,0 & \\
\hline $\begin{array}{l}60 \text { anos ou }+ \\
\text { Escolaridade }\end{array}$ & 5 & 100,0 & 0 & 0,0 & 0 & 0,0 & 0,999 \\
\hline $1-4$ & 7 & 100,0 & 0 & 0,0 & 0 & 0,0 & \\
\hline $5-8$ & 6 & 85,7 & 1 & 14,3 & 0 & 0,0 & \\
\hline $9-11$ & 8 & 88,9 & 1 & 11,1 & 0 & 0,0 & \\
\hline 12 ou + & 6 & 85,7 & 1 & 14,3 & 0 & 0,0 & \\
\hline
\end{tabular}

Observou-se que individuos com $\mathbf{4 6}$ anos ou mais concordaram mais com a orientação em relação aos com idade até 45 anos, $p=0,013$ (Tabela 17, $p$ : nivel descritivo do teste de associação de Fisher). Tal relação pode ser devido ao fato de que pessoas com mais idade associarem a obesidade a dislipidemias, por já terem consultado um médico, enquanto indivíduos mais novos associem obesidade a estética e não a problemas de saúde.

Em relação à relevância (total ou parcial) da orientação, todos os individuos a acharam importante (Tabela 18), independente das variáveis estudadas (Anexo V). 
Tabela 18: Distribuição da amostra quanto à importância da Orientação 3. São Paulo, 2004.

\begin{tabular}{lll}
\hline Importância da orientaçåo & Freqüencia & Porcentagem \\
\hline Muito importante & 29 & 96,7 \\
Um pouco importante & 1 & 3,3 \\
\hline Total & 30 & 100,0 \\
\hline
\end{tabular}

Quando questionados sobre o cumprimento da orientação, um pouco mais de $50 \%$ dos indivíduos relataram que sempre seguem a orientação, percentual menor do que observado na mesma questão em relação às orientações 1 e 2 (Tabela 19), independente das variáveis estudadas (Anexo V).

Tabela 19: Distribuição da amostra quanto ao cumprimento da Orientação 3. São Paulo, 2004.

\begin{tabular}{lll}
\hline Segue a orientação? & Freqüencia & Porcentagem \\
\hline Sempre segue essa orientaçåo & 17 & 56,7 \\
Freqúentemente segue & 6 & 20,0 \\
Quase nunca segue & 3 & 10,0 \\
Nunca segue & 4 & 13,3 \\
\hline Total & 30 & 100,0 \\
\hline
\end{tabular}

Isso pode refletir a dificuldade dos indivíduos em manter o peso ideal, apontando a alta prevalência de obesidade como encontrada na população, na qual os dados divulgados pelo Ministério da Saúde revelaram que o Brasil apresenta $32 \%$ da população adulta com sobrepeso ou obesidade (IMC superior a $25 \mathrm{Kg} / \mathrm{m}^{2}$ ). 
Os indivíduos que responderam que "freqüentemente ou quase nunca seguem a orientação" disseram não segui-la devido a hábitos alimentares ("abuso dos doces") e fatores pessoais ("sou relaxado" e "sou descuidado"). 


\subsubsection{Orientação 4: Praticar atividades físicas regularmente e com orientação.}

A orientação 4 apresentou um alto grau de entendimento pela população, cerca de $93 \%$ não apresentaram dúvidas (Tabela 20), independente das variáveis estudadas (Anexo V).

Tabela 20: Distribuição da amostra quanto à dúvida na Orientação 4. São Paulo, 2004.

\begin{tabular}{lll}
\hline Dúvida sobre a orientação & Frequência & Porcentagem \\
\hline Sim & 2 & 6,7 \\
Não & 28 & 93,3 \\
\hline Total & 30 & 100,0 \\
\hline
\end{tabular}

A dúvida relatada pelos indivíduos sobre a orientação 4 foi "praticar atividade física com a orientação de quem?".

Considerando a necessidade de troca de palavras, 4 indivíduos sugeriram complementar a orientação (Tabela 21), o que esclareceria a única dúvida relatada pelos entrevistados que não sabiam qual profissional orienta a prática de atividade física (Quadro 7), independente das variáveis estudadas (Anexo V).

Tabela 21: Distribuição da amostra quanto à substituição de palavra na Orientação 4. São Paulo, 2004.

\begin{tabular}{lll}
\hline Alguma palavra deve ser trocada? & Frequéncia & Porcentagem \\
\hline Sim & 4 & 13,3 \\
Não & 26 & 86,7 \\
\hline Total & 30 & 100,0 \\
\hline
\end{tabular}


As sugestões para troca de palavras estão descritas a seguir (Quadro 7).

Quadro 7. Distribuição das sugestões quanto à troca de palavras da orientação 4. São Paulo, 2004.

\begin{tabular}{ll}
\hline Sugestőes & Freqüência \\
\hline Falaria "com orientação médica" & 2 \\
Falaria "com um especialista" & 1 \\
Falaria "com um Prof. De Ed. Fisica" & 1 \\
\hline Total & 4 \\
\hline
\end{tabular}

Em relação a quanto os indivíduos estavam de acordo com a orientação, a maioria dos entrevistados (93,3\%) concordou totaimente (Tabela 22), independente das variáveis estudadas (Anexo V).

Tabela 22: Distribuição da amostra quanto à concordância com a Orientação 4. São Paulo, 2004

\begin{tabular}{lll}
\hline Concordáncia com a orientaçăo & Frequéncia & Porcentagem \\
\hline Concorda totalmente com essa orientaçăo & 28 & 93,3 \\
Concorda parcialmente com essa orientação & 2 & 6,7 \\
\hline Total & 30 & 100,0 \\
\hline
\end{tabular}

O alto grau de entendimento da orientação 4 foi confirmado pela pergunta seguinte, em relação à importância da orientação, na qual apenas $6,7 \%$ dos individuos disseram ser "um pouco importante" (Tabela 23), independente das três variáveis estudadas (Anexo V). 
Tabela 23: Distribuição da amostra quanto à importância da Orientação 4. São Paulo, 2004.

\begin{tabular}{lll}
\hline Importância da orientaçăo & Frequencia & Porcentagem \\
\hline Muito importante & 28 & 93,3 \\
Um pouco importante & 2 & 6,7 \\
\hline Total & 30 & 100,0 \\
\hline
\end{tabular}

Embora a orientação tenha sido considerada muito importante por grande parte da população, metade dos indivíduos entrevistados disse quase nunca ou nunca seguir a orientação (Tabela 24), independente das variáveis estudadas (Anexo V) - fato que evidencia o grande número de pessoas sedentárias no país.

Os resultados confirmam o estudo realizado por MATSUDO e col. (2002), que encontraram uma porcentagem de $46 \%$ de individuos que não cumpriram as recomendações de atividade física, analisando 29 cidades no estado de São Paulo, apesar das distintas metodologias adotadas.

Tabela 24: Distribuição da amostra quanto ao cumprimento da Orientação 4. São Paulo, 2004.

\begin{tabular}{lll}
\hline Segue a orientação? & Freqüencia & Porcentagem \\
\hline Sempre segue essa orientação & 13 & 43,3 \\
Frequentemente segue & 2 & 6,7 \\
Quase nunca segue & 4 & 13,3 \\
Nunca segue & 11 & 36,7 \\
\hline Total & 30 & 100,0 \\
\hline
\end{tabular}

Os individuos que responderam que "freqüentemente ou quase nunca seguem a orientação", disseram não segui-la devido a falta de tempo ou hábito 
5.2.5 Orientação 5: Selecionar uma dieta com baixa quantidade de gordura, colesterol e gordura saturada.

Resultados relativos à orientação alimentar 5 , quanto à dúvida dos entrevistados, $34,4 \%$ dos entrevistados afirmaram terem dúvidas quanto à orientação 5 (Tabela 25).

Tabela 25: Distribuição da amostra quanto à dúvida na Orientação 5. São Paulo, 2004.

\begin{tabular}{lll}
\hline Dúvida sobre a orientação & Freqüéncia & Porcentagem \\
\hline Sim & 10 & 34,5 \\
Não & 19 & 65,5 \\
\hline Total & 29 & 100,0 \\
\hline
\end{tabular}

Este dado mais significativo para indivíduos com menor tempo de estudo $(85,7 \%)$ em relação àqueles com maior tempo de escolaridade; $14,3 \%$ para indivíduos que estudaram entre 5 e 8 anos, $22,2 \%$ para àqueles com tempo de estudo entre 9 a 11 anos e $16,7 \%$ para aqueles com 12 anos ou mais de escolaridade, $p=0,012$ (Tabela 26, $p$ : nivel descritivo do teste de associação de Fisher). 
Tabela 26: Distribuição da amostra quanto à dúvida sobre a orientação 5, segundo sexo, idade e escolaridade dos entrevistados. São Paulo, 2004.

\begin{tabular}{|c|c|c|c|c|c|}
\hline \multirow[t]{2}{*}{ Características } & \multicolumn{2}{|l|}{ Sim } & \multicolumn{2}{|c|}{ Não } & \multirow[t]{2}{*}{$\boldsymbol{P}$} \\
\hline & $\mathbf{N}$ & $\%$ & $\mathbf{N}$ & $\%$ & \\
\hline Sexo & & & & & 0,675 \\
\hline Masculino & 2 & 25,0 & 6 & 75,0 & \\
\hline Feminino & 8 & 38,1 & 13 & 61,9 & \\
\hline $\begin{array}{l}\text { ldade } \\
\text { Até } 45 \text { anos }\end{array}$ & & & & & 0,476 \\
\hline $\begin{array}{l}\text { Ate } 45 \text { anos } \\
46 \text { a } 59 \text { anos }\end{array}$ & 1 & 16,7 & 5 & 83,3 & \\
\hline 60 anos ou + & $\begin{array}{l}8 \\
1\end{array}$ & $\begin{array}{l}44,4 \\
20,0\end{array}$ & $\begin{array}{l}10 \\
4\end{array}$ & $\begin{array}{l}55,6 \\
80,0\end{array}$ & \\
\hline Escolaridade & & & & & 0,012 \\
\hline $1-4$ & 6 & 85,7 & 1 & 14,3 & \\
\hline $5-8$ & 1 & 14,3 & 6 & 85,7 & \\
\hline $9-11$ & 2 & 22,2 & 7 & 77,8 & \\
\hline 12 ou + & 1 & 16,7 & 5 & 83,3 & \\
\hline
\end{tabular}

Tal observação pode demonstrar que o baixo nivel de compreensão da população de menor escolaridade é devido a utilização de expressões pouco usuais, reforçado pela alta porcentagem de dúvidas.

A dúvida de maior freqüência relatada pelos entrevistados foi sobre o significado do termo "gordura saturada" (Quadro 8).

Quadro 8. Distribuição das dúvidas apresentadas quanto à orientação 5. São Paulo, 2004

\begin{tabular}{ll}
\hline Dúvida & Frequéncia \\
\hline O que é gordura saturada e/ou colesterol? & 8 \\
Como medir a quantidade de colesterol? & 2 \\
\hline Total & 10 \\
\hline
\end{tabular}


Com o objetivo de melhorar a orientação $41,1 \%$ dos entrevistado fariam algum tipo de mudança (Tabela 27), e a sugestão relatada por todos eles foi "Explicar o que é colesterol e gordura saturada".

Tabela 27: Distribuição da amostra quanto à substituição de palavra na Orientação 5. São Paulo, 2004

\begin{tabular}{lll}
\hline Alguma palavra deve ser trocada? & Frequeencia & Porcentagem \\
\hline Sim & 12 & 41,4 \\
Não & 17 & 58,6 \\
\hline Total & 29 & 100,0 \\
\hline
\end{tabular}

Tal como observado na orientação 2 , em que a amostra sugeriu trocar conceitos científicos e/ou pouco usuais, nesta orientação também observou-se a necessidade de substituição por termos coloquiais, a fim de que toda a população compreenda a orientação, sendo este dado mais significativo para indivíduos do sexo feminino se comparado aos do sexo masculino, $p=0,093$ (Tabela 28). 
Tabela 28: Distribuição da amostra quanto à substituição de palavra na orientação 5 , segundo sexo, idade e escolaridade dos entrevistados. São Paulo, 2004.

\begin{tabular}{|c|c|c|c|c|c|}
\hline \multirow[t]{2}{*}{ Características } & \multicolumn{2}{|l|}{ Sim } & \multicolumn{2}{|c|}{ Não } & \multirow[t]{2}{*}{$P$} \\
\hline & & $\%$ & $\mathbf{N}$ & $\%$ & \\
\hline Sexo & & & & & 0,093 \\
\hline Masculino & 1 & 12,5 & 7 & 87,5 & \\
\hline $\begin{array}{l}\text { Feminino } \\
\text { Idade }\end{array}$ & 11 & 52,4 & 10 & 47,6 & 0,206 \\
\hline Até 45 anos & 1 & 16,7 & 5 & 83,3 & \\
\hline 46 a 59 anos & 10 & 55,6 & 8 & 44,4 & \\
\hline $\begin{array}{l}60 \text { anos ou }+ \\
\text { Escolaridade }\end{array}$ & 1 & 20,0 & 4 & 80,0 & 0.439 \\
\hline $1-4$ & 4 & 57,1 & 3 & 42,9 & \\
\hline $5-8$ & 1 & 14,3 & 6 & 85,7 & \\
\hline $9-11$ & 4 & 44,4 & 5 & 55,6 & \\
\hline 12 ou + & 3 & 50,0 & 3 & 50,0 & \\
\hline
\end{tabular}

Parece que as mulheres se mostraram mais solicitas à sugestões do que os homens, além de demonstraram mais preocupação na compreensão da orientação.

Quanto à concordância com a orientação, $96,6 \%$ concordaram totalmente com a orientação, enquanto $3,4 \%$ concordaram parcialmente com a orientação (Tabela 29), independente do sexo, idade e escolaridade dos entrevistados (Anexo V).

Tabela 29: Distribuição da amostra quanto à concordância com a Orientação 5. São Paulo, 2004

\begin{tabular}{lll}
\hline Concordáncia com a orientação & Freqüencia & Porcentagem \\
\hline Concorda totalmente com essa orientaçáo & 28 & 96,6 \\
Concorda parcialmente com essa orientaçăo & 1 & 3,4 \\
\hline Total & 29 & 100,0 \\
\hline
\end{tabular}


Quando questionados quanto à importância da orientação, todos os individuos disseram ser muito importante a orientação para o controle do colesterol e gordura no sangue.

Ao analisar a periodicidade dos entrevistados em seguirem a orientação, verificou-se que a porcentagem dos que "sempre e/ou freqüentemente seguem" foi de $75,8 \%$ em relação aos $24,1 \%$ que "nunca e/ou quase nunca a seguem" (Tabela 30).

Tabela 30: Distribuição da amostra quanto ao cumprimento da Orientação 5. São Paulo, 2004.

\begin{tabular}{lll}
\hline Segue a orientaçăo? & Frequência & Porcentagem \\
\hline Sempre segue essa orientaçăo & 17 & 58,6 \\
Freqüentemente segue & 5 & 17,2 \\
Quase nunca segue & 6 & 20,7 \\
Nunca segue & 1 & 3,4 \\
\hline Total & 29 & 100,0 \\
\hline
\end{tabular}

A escolaridade influenciou significativamente nas respostas dos entrevistados, sendo que os indivíduos de menor escolaridade dizem cumprir mais a orientação em relação àqueles de maior escolaridade, $p=0,010$, (Tabela $31, p$ : nivel descritivo do teste de associação de Fisher). 
Tabela 31: Distribuição da amostra quanto ao cumprimento da orientação 5, segundo sexo, idade e escolaridade dos entrevistados. São Paulo, 2004.

\begin{tabular}{|c|c|c|c|c|c|c|c|c|c|}
\hline \multirow[t]{2}{*}{ Características } & \multicolumn{2}{|c|}{$\begin{array}{l}\text { Sempre } \\
\text { segue }\end{array}$} & \multicolumn{2}{|c|}{$\begin{array}{l}\text { Frequen- } \\
\text { temente }\end{array}$} & \multicolumn{2}{|c|}{$\begin{array}{l}\text { Quase } \\
\text { nunca }\end{array}$} & \multicolumn{2}{|c|}{ Nunca } & \multirow[t]{2}{*}{$\mathbf{p}$} \\
\hline & $\boldsymbol{N}$ & $\%$ & $N$ & $\%$ & $\boldsymbol{N}$ & $\%$ & $\mathbf{N}$ & $\%$ & \\
\hline Masculino & 4 & 50,0 & 1 & 12,5 & 2 & 25,0 & 1 & 12,5 & 0,499 \\
\hline $\begin{array}{l}\text { Feminino } \\
\text { Idade }\end{array}$ & 13 & 61,9 & 4 & 19,0 & 4 & 19,0 & 0 & 0,0 & \\
\hline Até 45 anos & 3 & 50,0 & 2 & 33,3 & 1 & 16,7 & 0 & 0,0 & 0,910 \\
\hline 46 a 59 anos & 10 & 55,6 & 3 & 16,7 & 4 & 22,2 & 1 & 5,6 & \\
\hline $\begin{array}{l}60 \text { anos ou }+ \\
\text { Escolaridade }\end{array}$ & 4 & 80,0 & 0 & 0,0 & 1 & 20,0 & 0 & 0,0 & \\
\hline $1-4$ & 6 & 85,7 & 0 & 0,0 & 0 & 0,0 & 1 & 14,3 & 0,010 \\
\hline $5-8$ & 5 & 71,4 & 0 & 0,0 & 2 & 28,6 & 0 & 0,0 & \\
\hline $9-11$ & 2 & 22,2 & 5 & 55,6 & 2 & 22,2 & 0 & 0,0 & \\
\hline 12 ou + & 4 & 66,7 & 0 & 0,0 & 2 & 33,3 & 0 & 0,0 & \\
\hline
\end{tabular}

Como a orientação apresentou alta porcentagem de dúvidas e esta também foi mais significativa para os entrevistados com menor grau de escolaridade, o cumprimento da orientação apresentou resultados antagônicos, mostrando que individuos com menor grau de escolaridade cumprem mais a orientação. Este fato pode ser explicado pelo constrangimento dos indivíduos que mesmo após o esclarecimento, não entenderam realmente a orientação e, a fim de evitar maiores explicações, disseram cumprir a orientação. 


\subsubsection{Orientação 6: Fracionar a dieta, fazendo três refeições e dois lanches}

entre elas, escolhendo alimentos saudáveis.

Na população avaliada foi constatado que $65,5 \%$ não demonstraram dúvida a respeito desta orientaçăo (Tabela 32 ).

Tabela 32: Distribuição da amostra quanto à dúvida na Orientação 6. São Paulo, 2004

\begin{tabular}{lll}
\hline Dúvida sobre a orientaçåo & Frequéncia & Porcentagem \\
\hline Sim & 10 & 34,5 \\
Não & 19 & 65,5 \\
\hline Total & 29 & 100,0 \\
\hline
\end{tabular}

Os $34,5 \%$ dos individuos que tiveram dúvidas relataram não saber o significado da palavra "fracionar".

Este dado foi mais significativo para os individuos com até 4 anos de estudo comparado com aqueles com 12 ou mais anos de estudo, $p=0,020$, (Tabela 33, $p$ : nivel descritivo do teste de associação de Fisher). 
Tabela 33: Distribuição da amostra quanto à dúvida sobre a orientação 6, segundo sexo, idade e escolaridade dos entrevistados. São Paulo, 2004

\begin{tabular}{|c|c|c|c|c|c|}
\hline \multirow[t]{2}{*}{ Características } & \multicolumn{2}{|c|}{ Sim } & \multicolumn{2}{|c|}{ Não } & \multirow[t]{2}{*}{$\boldsymbol{P}$} \\
\hline & $\mathbf{N}$ & $\%$ & $\mathbf{N}$ & $\%$ & \\
\hline Sexo & & & & & 0,675 \\
\hline Masculino & 2 & 25,0 & 6 & 75,0 & \\
\hline Feminino & 8 & 38,1 & 13 & 61,9 & \\
\hline Idade & & & & & 0,476 \\
\hline Até 45 anos & 1 & 16,7 & 5 & 83,3 & \\
\hline 46 a 59 anos & 8 & 44,4 & 10 & 55,6 & \\
\hline 60 anos ou + & 1 & 20,0 & 4 & 80,0 & \\
\hline Escolaridade & & & & & 0,020 \\
\hline $1-4$ & 5 & 71,4 & 2 & 28,6 & \\
\hline $5-8$ & 0 & 0,0 & 7 & 100,0 & \\
\hline $9-11$ & 4 & 44,4 & 5 & 55,6 & \\
\hline 12 ou + & 1 & 16,7 & 5 & 83,3 & \\
\hline
\end{tabular}

p: nivel descritivo

Assim como observado na orientação 5 , a utilização de termos pouco usuais como "fracionar", pode causar mais dúvidas na população de menor grau de escolaridade e portanto dificultar sua compreensão.

Em relação à substituição de palavras na orientação, $51,7 \%$ dos indivíduos disseram que alguma palavra deveria ser trocada (Tabela 34) e a maioria deles sugeriu que o termo fracionar fosse trocado por dividir (Quadro 9), fato que poderia esclarecer à parte dos indivíduos que relataram dúvidas na compreensão da orientação, independente das três variáveis estudadas (Anexo V). 
Tabela 34: Distribuição da amostra quanto à substituição de palavra na Orientação 6. São Paulo, 2004

\begin{tabular}{lll}
\hline Alguma palavra deve ser trocada? & Freqúência & Porcentagem \\
\hline Sim & 15 & 51,7 \\
Não & 14 & 48,3 \\
\hline Total & 29 & 100,0 \\
\hline
\end{tabular}

Quadro 9. Distribuição de sugestōes quanto à troca de palavras da orientação 6. São Paulo, 2004.

\begin{tabular}{ll}
\hline Sugestões & Frequência \\
\hline Substituir fracionar por dividir & 8 \\
Acrescentaria "dois lanches de frutas" & 4 \\
Mudaria para comer mais vezes e menos alimentos & 2 \\
Acrescentaria "comer nas horas certas" & 1 \\
\hline Total & 15 \\
\hline
\end{tabular}

Quanto à concordância com a orientação, $79,5 \%$ dos individuos concordaram totalmente com a orientação (Tabela 35).

Tabela 35: Distribuiçāo da amostra quanto à concordância com a Orientação 6. São Paulo, 2004.

\begin{tabular}{lll}
\hline Concordåncia com a orientação & Frequéncia & Porcentagem \\
\hline Concorda totalmente com essa orientaçăo & 23 & 79,3 \\
Concorda parcialmente com essa orientaçâo & 5 & 17,2 \\
Discorda dessa orientaçåo & 1 & 3,4 \\
\hline Total & 29 & 100,0 \\
\hline
\end{tabular}


Este dado foi mais significativo para os indivíduos do sexo feminino em relação aos indivíduos do sexo masculino, $p=0,089$, bem como para indivíduos com idade até 45 anos em relação àqueles com mais de 60 anos de idade, $p=0,095$ (Tabela 36, p: nível descritivo do teste de associação de Fisher).

Tabela 36: Distribuição da amostra quanto à concordância com a orientação 6, segundo sexo, idade e escolaridade dos entrevistados. São Paulo, 2004.

\begin{tabular}{|c|c|c|c|c|c|c|c|}
\hline \multirow[t]{2}{*}{ Características } & \multicolumn{2}{|c|}{$\begin{array}{l}\text { Concorda } \\
\text { totalmente }\end{array}$} & \multicolumn{2}{|c|}{$\begin{array}{l}\text { Concorda } \\
\text { parcialmente }\end{array}$} & \multicolumn{2}{|c|}{ Discorda } & \multirow[t]{2}{*}{$\boldsymbol{P}$} \\
\hline & $\boldsymbol{N}$ & $\%$ & $\mathbf{N}$ & $\%$ & $\boldsymbol{N}$ & $\%$ & \\
\hline Sexo & & & & & & & 0,089 \\
\hline Masculino & 7 & 87,5 & 0 & 0,0 & 1 & 12,5 & \\
\hline $\begin{array}{l}\text { Feminino } \\
\text { Idade }\end{array}$ & 16 & 76,2 & 5 & 23,8 & 0 & 0,0 & 0,095 \\
\hline Até 45 anos & 6 & 100,0 & 0 & 0,0 & 0 & 0,0 & \\
\hline 46 a 59 anos & 13 & 72,2 & 5 & 27,8 & 0 & 0,0 & \\
\hline $\begin{array}{l}60 \text { anos ou }+ \\
\text { Escolaridade }\end{array}$ & 4 & 80,0 & 0 & 0,0 & 1 & 20,0 & 0,535 \\
\hline $1-4$ & 6 & 85,7 & 1 & 14,3 & 0 & 0,0 & \\
\hline $5-8$ & 6 & 85,7 & 0 & 0,0 & 1 & 14,3 & \\
\hline $9-11$ & 6 & 66,7 & 3 & 33,3 & 0 & 0,0 & \\
\hline 12 ou + & 5 & 83,3 & 1 & 16,7 & 0 & 0,0 & \\
\hline
\end{tabular}

Tal relação pode refletir uma maior preocupação das mulheres, que muitas vezes são as responsáveis pela formação dos hábitos alimentares da familia, em concordar com a orientação, além de se preocuparem mais com a saúde de seus familiares e possuirem maior acesso a informaçōes quanto ao controle de colesterol e gordura no sangue.

Como o conceito de comer mais vezes durante o dia e em menor quantidade é ainda "recente", pessoas com mais idade ainda têm o hábito de fazer 
apenas três refeiçōes, e portanto não concordarem com a orientaçăo como os individuos de menor faixa etária.

Quanto ao grau de importância da orientaçăo, $79,3 \%$ dos individuos disseram ser muito importante (Tabela 37).

Tabela 37: Distribuiçăo da amostra quanto à importância da Orientação 6. São Paulo, 2004.

\begin{tabular}{lll}
\hline Importância da orientaçăo & Frequéncia & Porcentagem \\
\hline Muito importante & 26 & 89,7 \\
Um pouco importante & 1 & 3,4 \\
Năo é importante & 2 & 6,9 \\
\hline Iotal & 29 & 100,0 \\
\hline
\end{tabular}

Este dado fol mais significativo para os indivíduos do sexo feminino em relaçăo ao masculino, $p=0,017$ (Tabela 38 , $p$ : nível descritivo do teste de associação de Fisher). 
Tabela 38: Distribuição da amostra quanto à importância da orientação 6, segundo sexo, idade e escolaridade dos entrevistados. São Paulo, 2004.

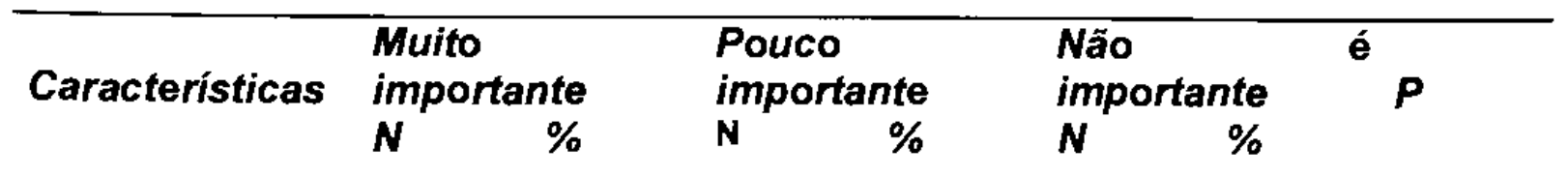

Sexo

\begin{tabular}{|c|c|c|c|c|c|c|c|}
\hline Masculino & 5 & 62,5 & 1 & 12,5 & 2 & 25,0 & 0,017 \\
\hline $\begin{array}{l}\text { Feminino } \\
\text { Idade }\end{array}$ & 21 & 100,0 & 0 & 0,0 & 0 & 0,0 & \\
\hline Até 45 anos & 6 & 100,0 & 0 & 0,0 & 0 & 0,0 & 0,120 \\
\hline 46 a 59 anos & 17 & 94,4 & 0 & 0,0 & 1 & 5,6 & \\
\hline $\begin{array}{l}60 \text { anos ou }+ \\
\text { Escolaridade }\end{array}$ & 3 & 60,0 & 1 & 20,0 & 1 & 20,0 & \\
\hline $1-4$ & 6 & 85,7 & 0 & 0,0 & 1 & 14,3 & 0,472 \\
\hline $5-8$ & 5 & 71,4 & 1 & 14,3 & 1 & 14,3 & \\
\hline $9-11$ & 9 & 100,0 & 0 & 0,0 & 0 & 0,0 & \\
\hline $12 \mathrm{ou}+$ & 6 & 100,0 & 0 & 0,0 & 0 & 0,0 & \\
\hline
\end{tabular}

p: nível descritivo

Como comentado anteriormente, essa relação pode ser explicada pela maior preocupação das mulheres em relação aos hábitos alimentares da familia, além de possuírem maior curiosidade e interesse em informações relativas a saúde podendo refletir a importância da orientação para o controle do colesterol e gordura no sangue. 
Sobre o cumprimento da orientaçāo pelos entrevistados, $34,5 \%$ dos entrevistados disseram "sempre" seguirem a orientaçăo (Tabela 39).

Observou-se uma alta porcentagem de năo cumprimento da orientaçâo; muitos dos entrevistados relataram "falta de tempo" e "falta de condições financeiras" para seguir a orientação.

Tabela 39: Distribuição dos individuos quanto ao cumprimento da Orientação 6. São Paulo, 2004.

\begin{tabular}{lll}
\hline Seque a orientacäo? & Freqüencia & Porcentagem \\
\hline Sempre segue essa orientação & 10 & 34,5 \\
Freqüentemente segue & 8 & 20,7 \\
Quase nunca segue & 9 & 31,0 \\
Nunca segue & 4 & 13,0 \\
\hline Total & 29 & 100,0 \\
\hline
\end{tabular}

Este dado foi mais significativo para os individuos com menor grau de instruçăo em relaçäo àqueles com mais tempo de estudo, $p=0,048$ (Tabela 40, $p$ : nivel descritivo do teste de associaçăo de Fisher). 
Tabela 40: Distribuição da amostra quanto ao cumprimento da orientação 6, segundo sexo, idade e escolaridade dos entrevistados. São Paulo, 2004.

\begin{tabular}{|c|c|c|c|c|c|c|c|c|c|}
\hline \multirow[t]{2}{*}{ Características } & \multicolumn{2}{|c|}{$\begin{array}{l}\text { Sempre } \\
\text { segue }\end{array}$} & \multicolumn{2}{|c|}{$\begin{array}{l}\text { Frequen- } \\
\text { temente }\end{array}$} & \multicolumn{2}{|c|}{$\begin{array}{l}\text { Quase } \\
\text { nunca }\end{array}$} & \multicolumn{2}{|c|}{ Nunca } & \multirow{2}{*}{$\mathbf{p}$} \\
\hline & $\mathbf{N}$ & $\%$ & $\boldsymbol{N}$ & $\%$ & $\boldsymbol{N}$ & $\%$ & $\boldsymbol{N}$ & $\%$ & \\
\hline Masculino & 3 & 37,5 & 1 & 12,5 & 4 & 50,0 & 0 & 0,0 & 0,491 \\
\hline $\begin{array}{l}\text { Feminino } \\
\text { Idade }\end{array}$ & 7 & 33,3 & 5 & 23,8 & 5 & 23,8 & 4 & 19,0 & \\
\hline Até 45 anos & 2 & 33,3 & 3 & 50,0 & 0 & 0,0 & 1 & 16,7 & 0,295 \\
\hline 46 a 59 anos & 6 & 33,3 & 3 & 16,7 & 6 & 33,3 & 3 & 16,7 & \\
\hline $\begin{array}{l}60 \text { anos ou }+ \\
\text { Escolaridade }\end{array}$ & 2 & 40,0 & 0 & 0,0 & 3 & 60,0 & 0 & 0,0 & \\
\hline $1-4$ & 5 & 71,4 & 0 & 0,0 & 1 & 14,3 & 1 & 14,3 & 0,048 \\
\hline $5-8$ & 1 & 14,3 & 1 & 14,3 & 5 & 71,4 & 0 & 0,0 & \\
\hline $9-11$ & 1 & 11,1 & 3 & 33,3 & 3 & 33,3 & 2 & 22,2 & \\
\hline 12 ou + & 3 & 50,0 & 2 & 33,3 & 0 & 0,0 & 1 & 16,7 & \\
\hline
\end{tabular}

Essa relaçăo observada entre indivíduos de menor escolaridade que disseram " sempre seguir" a orientação, pode ser explicada pelos mesmos motivos relatados na orientação 5 , onde o constrangimento da nāo compreensão da orientação pode ter influenciado na resposta quanto ao seu cumprimento. 


\subsubsection{Orientação 7: Evitar o consumo de frituras.}

Os resultados relativos à orientação 7 mostraram que $96,4 \%$ dos indivíduos não tiveram dúvidas a respeito da orientação alimentar (Tabela 41), independente das variáveis estudadas (Anexo V).

A única dúvida relatada ("Não pode nem de vez em quando?") não dizia respeito ao entendimento da orientação, mas sim sobre a possibilidade de cumprimento eventual da orientação, revelando a facilidade de sua compreensão.

Tabela 41: Distribuição da amostra quanto à dúvida na Orientação 7. São Paulo, 2004.

\begin{tabular}{lll}
\hline Dúvida sobre a orientaçăo & Freqúência & Porcentagem \\
\hline Sim & 1 & 3,6 \\
Nåo & 27 & 96,4 \\
\hline Total & 28 & 100,0 \\
\hline
\end{tabular}

Quando questionados sobre a substituição de palavras na orientação, 92,6\% dos indivíduos relataram que năo havia necessidade de troca (Tabela 42).

Tabela 42: Distribuição da amostra quanto à substituição de palavra na Orientação 7.

\begin{tabular}{lll}
\hline Alguma palavra deve ser trocada? & Freqüência & Porcentagem \\
\hline Sim & 2 & 7,4 \\
Năo & 25 & 92,6 \\
\hline Total & 27 & 100,0 \\
\hline
\end{tabular}


Este dado foi mais significativo para os indivíduos do sexo masculino em relação aos do sexo feminino, $p=0,060$ (Tabela 43, $p$ : nivel descritivo do teste de associação de Fisher).

Tabela 43: Distribuição da amostra quanto à substituição de palavras na orientação 7, segundo, sexo, idade e escolaridade dos entrevistados. São Paulo, 2004.

\begin{tabular}{|c|c|c|c|c|c|}
\hline \multirow[t]{2}{*}{ Características } & \multicolumn{2}{|c|}{ Sim } & \multicolumn{2}{|c|}{ Não } & \multirow[t]{2}{*}{$\boldsymbol{P}$} \\
\hline & $\mathbf{N}$ & $\%$ & $\mathbf{N}$ & $\%$ & \\
\hline Sexo & & & & & 0,060 \\
\hline Masculino & 2 & 28,6 & 5 & 71,4 & \\
\hline $\begin{array}{l}\text { Feminino } \\
\text { Idade }\end{array}$ & 0 & 0,0 & 20 & 100,0 & 0.569 \\
\hline Até 45 anos & 1 & 20,0 & 4 & 80,0 & \\
\hline 46 a 59 anos & 1 & 5,6 & 17 & 94,4 & \\
\hline 60 anos ou + & 0 & 0,0 & 4 & 100,0 & 0,090 \\
\hline $1-4$ & 1 & 14,3 & 6 & 85,7 & 0,000 \\
\hline $5-8$ & 0 & 0,0 & 6 & 100,0 & \\
\hline $9-11$ & 1 & 11,1 & 8 & 88,9 & \\
\hline 12 ou + & 0 & 0,0 & 5 & 100,0 & \\
\hline
\end{tabular}

A relação apresentada entre o sexo e a sugestão de troca de palavras pode ser explicada pelo fato de que as mulheres são geralmente as responsáveis pela elaboração das refeições e o termo "fritura" é muito usual e comum na culinária brasileira, enquanto os homens podem necessitar explicaçōes diretas ("Evitar coxinha, lingüiça, etc.") para melhor compreensão da orientação. 
Quanto à aceitação da orientação, todos os indivíduos concordaram totalmente com a orientação, assim como com a importância da orientação para o controle de colesterol e gordura no sangue.

Tais observaçбés demonstram que a população associa o termo "fritura" ao colesterol e, portanto, revela que esta orientação é a mais compreensivel e aceita pela amostra estudada.

Apesar de a população aceitar e entender a orientação, um número significativo dos entrevistados $(44,4 \%)$ disse não seguir sempre a orientação (Tabela 44), independente das variáveis estudadas (Anexo V).

Tabela 44: Distribuição dos indivíduos quanto ao cumprimento da Orientação 7. São Paulo, 2004.

\begin{tabular}{lll}
\hline Segue a orientação? & Frequaencia & Porcentagem \\
\hline Sempre segue essa orientaçåa & 15 & 55,6 \\
Freqüentemente segue & 5 & 18,5 \\
Quase nunca segue & 5 & 18,5 \\
Nunca segue & 2 & 7,4 \\
\hline Total & 27 & 100,0 \\
\hline
\end{tabular}

Os indivíduos que disseram não seguirem sempre a orientação revelaram que não as seguem devido a hábitos alimentares ("É dificil não comer coisas fritas", "batata frita é tão gostosa"). 
5.2.8 Orientação 8: Consumir produtos de origem animal moderadamente.

Considerando a dúvida a respeito desta orientação, $79,3 \%$ dos entrevistados não tiveram dúvidas (Tabela 45), independente das variáveis estudadas (Anexo V). As dúvidas mais freqüentes foram a respeito dos termos "produto" e "moderadamente" (Quadro 10), observando-se, mais uma vez, a necessidade de trocar termos pouco usuais por palavras do dia-a-dia da população.

Tabela 45: Distribuição da amostra quanto à dúvida na Orientação 8. São Paulo, 2004.

\begin{tabular}{lll}
\hline Dúvida sobre a orientaçă & Frequéncia & Porcentagem \\
\hline Sim & 6 & 20,7 \\
Nåo & 23 & 79,3 \\
\hline Total & 29 & 100,0 \\
\hline
\end{tabular}

Quadro 10. Distribuiçăo das dúvidas apresentadas quanto à orientação 8. São Paulo, 2004.

\begin{tabular}{ll}
\hline Dúvida & Fregúencia \\
\hline O que é produto? & 2 \\
O que é moderadamente? & 3 \\
Produto é a gordura da carne vermelha? & 1 \\
\hline Total & 6 \\
\hline
\end{tabular}

Em relaçăo à substituiçăo de palavras na orientaçāo, $25 \%$ dos individuos disseram que a orientação deveria ser substituída por "Coma menos carne vermelha", independente das variáveis estudadas (Anexo V). 
Podemos notar que a populaçăo associa produtos de origem animal somente às carnes, năo mencionando ovos, leite, manteiga, queijo, creme de leite, embutidos (presunto, salsicha) e outros normalmente consumidos.

Quanto à concordância com a orientação, $78,6 \%$ dos indivíduos concordaram totalmente com a orientaçăo e $21,4 \%$ concordaram parcialmente (Tabela 46).

Tabela 46: Distribuição da amostra quanto à concordância com a Orientação 8. São Paulo, 2004.

\begin{tabular}{lll}
\hline Concordância com a orientação & Frequéncia & Porcentagem \\
\hline Concorda totalmente com essa orientaçăo & 22 & 78,6 \\
Concorda parcialmerite com essa orientaçăo & 6 & 21,4 \\
\hline Total & 28 & 100,0 \\
\hline
\end{tabular}


Houve associaçăo entre a idade do entrevistado e a concordância da onentação, indivíduos com $p=0,073$ (Tabela 47, $p$ : nível descritivo do teste de associaçăo de Fisher).

Tabela 47: Distribuição da amostra quanto à concordância com a orientação 8 , segundo sexo, idade escolaridade dos entrevistados. São Paulo, 2004.

\begin{tabular}{|c|c|c|c|c|c|c|c|}
\hline \multirow[t]{2}{*}{ Características } & \multicolumn{2}{|c|}{$\begin{array}{l}\text { Concorda } \\
\text { totalmente }\end{array}$} & \multicolumn{2}{|c|}{$\begin{array}{l}\text { Concorda } \\
\text { parcialmente }\end{array}$} & \multicolumn{2}{|c|}{ Discorda } & \multirow[t]{2}{*}{$\boldsymbol{P}$} \\
\hline & $\boldsymbol{N}$ & $\%$ & N & $\%$ & $\boldsymbol{N}$ & $\%$ & \\
\hline Sexo & & & & & & & 0,999 \\
\hline Masculino & 6 & 85,7 & 1 & 14,3 & 0 & 0,0 & \\
\hline Feminino & 16 & 76,2 & 5 & 23,8 & 0 & 0,0 & $0 \cap 73$ \\
\hline Até 45 anos & 3 & 50,0 & 3 & 50,0 & 0 & 0,0 & \\
\hline 46 a 59 anos & 16 & 88,9 & 2 & 11,1 & 0 & 0,0 & \\
\hline 60 anos ou + & 3 & 75,0 & 1 & 25,0 & 0 & 0,0 & \\
\hline Escolaridade & & & & & & & 0,408 \\
\hline $1-4$ & 7 & 100,0 & 0 & 0,0 & 0 & 0,0 & \\
\hline $5-8$ & 4 & 66,7 & 2 & 33,3 & 0 & 0,0 & \\
\hline $9-11$ & 6 & 66,7 & 3 & 33,3 & 0 & 0,0 & \\
\hline 12 ou + & 5 & 83,3 & 1 & 16,7 & 0 & 0,0 & \\
\hline
\end{tabular}

p: nivel descritivo

Assim como observado na orientaçăo 3, os indivíduos de mais idade, talvez por terem mais chance de apresentarem problemas de saúde e possivelmente já recebido algum tipo de orientação a respeito da relação entre o consumo de carne e o aumento de colesterol e gordura no sangue, concordem mais com a orientaçåo do que individuos de menor faixa etária. 
Quando questionados quanto à importância da orientação, $78,6 \%$ dos indivíduos disseram ser muito importante, $17,9 \%$ dos indivíduos disseram ser pouco importante e $3,6 \%$ dos individuos não acharam a orientação importante (Tabela 48), independente das variáveis estudadas (Anexo V).

Tabela 48: Distribuição dos indivíduos quanto à importância da Orientaçăo 8. Săo Paulo, 2004.

\begin{tabular}{lll}
\hline Importáncia da orientaçăo & Frequéncia & Porcentagem \\
\hline Muito importante & 22 & 78,6 \\
Um pouco importante & 5 & 17,9 \\
Năo é importante & 1 & 3,6 \\
\hline Total & 28 & 100,0 \\
\hline
\end{tabular}

Sobre o cumprimento da orientaçăo pelos entrevistados $57,1 \%$ dos individuos relataram sempre seguirem a orientação, 21,4\% disseram freqüentemente seguir a orientação, $17,9 \%$ disseram quase nunca seguir esta orientação e 3,6\% disseram nunca seguir (Tabela 49).

Tabela 49: Distribuição da amostra quanto ao cumprimento da Orientação 8. São Paulo, 2004.

\begin{tabular}{lll}
\hline Seque a orientaçăo? & Freqúéncia & Porcentagem \\
\hline Sempre segue essa orientaçåo & 16 & 57,1 \\
Freqüentemente segue & 6 & 21,4 \\
Quase nunca segue & 5 & 17,9 \\
Nunca segue & 1 & 3,6 \\
\hline Total & 28 & 100,0 \\
\hline
\end{tabular}

Os indivíduos que disseram năo seguir sempre a orientação revelaram que nåo as seguem devido a hábitos alimentares ("não consigo viver sem churrasco", "a gente tem que comer came"). 
Este dado foi mais significativo para individuos com menor grau de escolaridade em relaçăo aos que tinham maior tempo de estudo, $p=0,086$ (Tabela 50, p: nível descritivo do teste de associaçăo de Fisher).

Tabela 50: Distribuição da amostra quanto ao cumprimento da orientação B, segundo sexo, idade e escolaridade dos entrevistados. São Paulo, 2004.

\begin{tabular}{|c|c|c|c|c|c|c|c|c|c|}
\hline \multirow[t]{2}{*}{ Caracteristicas } & \multicolumn{2}{|c|}{$\begin{array}{l}\text { Sempre } \\
\text { segue }\end{array}$} & \multicolumn{2}{|c|}{$\begin{array}{l}\text { Frequen- } \\
\text { temente }\end{array}$} & \multicolumn{2}{|c|}{$\begin{array}{l}\text { Quase } \\
\text { nunca }\end{array}$} & \multicolumn{2}{|c|}{ Nunca } & \multirow[t]{2}{*}{$\mathbf{p}$} \\
\hline & $N$ & $\%$ & $N$ & $\%$ & $\boldsymbol{N}$ & $\%$ & $\boldsymbol{N}$ & $\%$ & \\
\hline Masculino & 4 & 57,1 & 1 & 14,3 & 2 & 28,6 & 0 & 0,0 & 0,770 \\
\hline $\begin{array}{l}\text { Feminino } \\
\text { ldade }\end{array}$ & 12 & 57,1 & 5 & 23,8 & 3 & 14,3 & 1 & 4,8 & \\
\hline Até 45 anos & 2 & 33,3 & 3 & 50,0 & 1 & 16,7 & 0 & 0,0 & 0,495 \\
\hline 46 a 59 anos & 11 & 61,1 & 2 & 11,1 & 4 & 22,2 & 1 & 5,6 & \\
\hline $\begin{array}{l}60 \text { anos ou }+ \\
\text { Escolaridade }\end{array}$ & 3 & 75,0 & 1 & 25,0 & 0 & 0,0 & 0 & 0,0 & \\
\hline $1-4$ & 7 & 100,0 & 0 & 0,0 & 0 & 0,0 & 0 & 0,0 & 0,086 \\
\hline $5-8$ & 2 & 33,3 & 2 & 33,3 & 1 & 16,7 & 1 & 16,7 & \\
\hline$g-11$ & 5 & 55,6 & 3 & 33,3 & 1 & 11,1 & 0 & 0,0 & \\
\hline 12 ou + & 2 & 33,3 & 1 & 16,7 & 3 & 50.0 & 0 & 0,0 & \\
\hline
\end{tabular}

Como comentado em outras orientaçōes, o constrangimento pela năo compreensäo da pode ter refletido na resposta em relaçäo ao cumprimento da orientação, já que esta apresentou dúvidas quanto ao seu entendimento. 


\subsubsection{Orientação 9: Preferir carnes magras e retirar gorduras visíveis.}

A Tabela 51 mostra que $93,1 \%$ dos entrevistados não tiveram dúvidas sobre a forma de como a orientação 9 foi redigida, independente das três variáveis estudadas (Anexo V). As dúvidas relatadas pelos indivíduos foram "Visível é a gordura das beiradas?" e "Figado é came magra?".

\section{Tabela 51: Distribuição da amostra quanto à dúvida na Orientação 9.} São Paulo, 2004.

\begin{tabular}{lll}
\hline Dúvida sobre a orientaçåo & Frequência & Porcentagem \\
\hline Sim & 2 & 6,9 \\
Nåo & 27 & 93,1 \\
\hline Total & 29 & 100,0 \\
\hline
\end{tabular}

Em relação à substituiçăo de palavras na orientaçăo, apenas $6,9 \%$ dos individuos disseram que alguma palavra deveria ser trocada a fim de facilitar o entendimento da orientaçăo (Tabela 52), independente das variáveis estudadas (Anexo V).

A sugestão foi incluir a palavra "sempre" na orientação, com o intuito de ressaltar a importância da mensagem para o controle de colesterol e gordura no sangue.

Tabela 52: Distribuição da amostra quanto à substituiçăo de palavra na Orientação 9. Săo Paulo, 2004.

\begin{tabular}{lll}
\hline Alguma palavra deve ser trocada? & Frequencia & Porcentagem \\
\hline Sim & 2 & 6,9 \\
Năo & 27 & 93,1 \\
\hline Total & 29 & 100,0 \\
\hline
\end{tabular}


Quanto à concordância com a orientaçâo, $93,1 \%$ dos individuos concordaram totalmente (Tabela 53).

Tabela 53: Distribuiçăo da amostra quanto à concordância com a Orientaçăo 9. São Paulo, 2004.

\begin{tabular}{lll}
\hline Concordáncia com a orientaçăo & Frequéncia & Porcentagem \\
\hline Concorda totalmente com essa orientação & 27 & 93,1 \\
Concorda parcialmente com essa orientaçáo & 2 & 6,9 \\
\hline Total & 29 & 100,0 \\
\hline
\end{tabular}

Este dado foi mais significativo para indivíduos do sexo masculino em relação aos do sexo feminino, $p=0,069$ (Tabela 54, $p$ : nível descritivo do teste de associaçăo de Fisher).

Tabela 54: Distribuição da amostra quanto à concordância com a orientaçăo 9, segundo sexo, idade e escolaridade dos entrevistados. Säo Paulo, 2004.

\begin{tabular}{|c|c|c|c|c|c|c|c|}
\hline \multirow[t]{2}{*}{ Caracteristicas } & \multicolumn{2}{|c|}{$\begin{array}{l}\text { Concorda } \\
\text { totalmente }\end{array}$} & \multicolumn{2}{|c|}{$\begin{array}{l}\text { Conconda } \\
\text { parcialmente }\end{array}$} & \multicolumn{2}{|c|}{ Disconda } & \multirow[t]{2}{*}{$\boldsymbol{P}$} \\
\hline & $\boldsymbol{N}$ & $\%$ & $\mathbf{N}$ & $\%$ & $N$ & $\%$ & \\
\hline Sexo & & & & & & & 0,068 \\
\hline Masculino & 6 & 75,0 & 2 & 25,0 & 0 & 0,0 & \\
\hline $\begin{array}{l}\text { Feminino } \\
\text { Idade }\end{array}$ & 21 & 100,0 & 0 & 0,0 & 0 & 0,0 & 0,144 \\
\hline Até 45 anos & 5 & 83,3 & 1 & 16,7 & 0 & 0,0 & \\
\hline 46 a 59 anos & 18 & 100,0 & 0 & 0,0 & 0 & 0,0 & \\
\hline $\begin{array}{l}60 \text { anos ou + } \\
\text { Escolaridade }\end{array}$ & 4 & 80,0 & 1 & 20,0 & 0 & 0,0 & 0,999 \\
\hline $1-4$ & 7 & 100,0 & 0 & 0,0 & 0 & 0,0 & \\
\hline $5-8$ & 6 & 85,7 & 1 & 14,3 & 0 & 0,0 & \\
\hline $9-11$ & B & $88_{1} 9$ & 1 & 11,1 & 0 & 0,0 & \\
\hline 12 ou + & 6 & 100,0 & 0 & 0,0 & 0 & 0,0 & \\
\hline
\end{tabular}

p: nível descritivo 
Pelos mesinos motivos relatados anteriormente em que as mulheres têm mais acesso a informação sobre a importância da alimentaçãa na saúde da farnilia, além de serem as responsáveis pela elaboraçāo das refeiçōes, estes fatores podern ter contribuído para a melhor compreensão e a concordância com a arientaçãa,

Quando questionados quanto à importância da orientação, $96,6 \%$ dos individuos disseram ser muito impartante e apenas $3,4 \%$ acharam a orientaçăo pouco importante (Tabela 55), independente das variáveis estudadas (Anexo V).

Tabela 55: Distribuição da amostra quanto à importáncia da Orientação 9. Sẵo Paulo, 2004.

\begin{tabular}{lll}
\hline Importáncia da or̉enlaçâo & Frequéncia & Porcentagem \\
\hline Muíto importante & 28 & 96,6 \\
Náo é importante & 1 & 3,4 \\
\hline Total & 29 & 100,0 \\
\hline
\end{tabular}


Sobre o cumprimento da orientaçăo pelos entrevistados, $69 \%$ dos individuos relataram sempre seguir a orientaçăo, $20,7 \%$ disserarn freqüentemente seguir a orientaçăo e $10,3 \%$ relataram nunca ou quase nunca seguir a orientação (Tabela 56), independente das variáveis estudadas (Anexo V). Aqueles que disseram năo seguir sempre a orientação revelaram que nāo as seguem devido a hábitos alimentares ("came sem gordura fica sem gosto").

Tabela 56: Distribuição dos individuos quanto ao cumprimento da Orientação 9. Săo Paulo, 2004.

\begin{tabular}{lll}
\hline Segue a orientaçåo? & Freqüéncia & Porcentagem \\
\hline Sempre segue essa orientaçắ & 20 & 69,0 \\
Freqüentemente segue & 6 & 20,7 \\
Quase nunca segue & 2 & 6,9 \\
Nunca seque & 1 & 3,4 \\
\hline Total & 29 & 100,0 \\
\hline
\end{tabular}




\subsubsection{Orientaçâo 10: Consumir açúcar e doces com moderação.}

Sobre a existência de dúvidas em relaçăo a esta orientaçăo, todos os individuos disseram não apresentarem dúvidas.

Em relação à substituição de palavras na orientaçăo, $96,6 \%$ dos individuos relataram que näo havia necessidade de troca (Tabela 57), independente das variáveis estudadas (Anexo $\mathrm{V}$ ).

Tabela 57: Distribuição da amostra quanto à substituição de palavra na Orientação 10. Săo Paulo, 2004.

\begin{tabular}{lll}
\hline Alguma palavra deve ser trocada? & Freqüencia & Porcentagem \\
\hline Sim & 1 & 3,4 \\
Nấo & $2 \theta$ & 96,6 \\
\hline Total & 29 & 100,0 \\
\hline
\end{tabular}

A sugestăo foi substituir a orientação por " ${ }^{n}$ Consumir pouco açúcar doces". Observando-se que, da mesma maneira que ocorreu em relação às orientações 2 (basear a alimentaçăo no consumo de alimentos derivados de grăos e raizes, hortaliças e frutas), 3 (evitar a obesidade, mantendo o peso desejável), 5 (selecionar uma dieta com baixa quantidade de gordura, colesterol e gordura saturada), 6 (fracionar a dieta, fazendo três refeiçöes e dois lanches entre elas, escolhendo alimentos saudáveis) e 8 (consumir produtos de origem animal moderadamente), os individuos sugeriram a troca de vocábulos cultos por termos 
mais coloquiais e fáceis de serem compreendidos - fator que pode também aumentar a credibilidade, a importância e o cumprimento da orientação.

Quanto à concordância com a orientação, nenhum entrevistado discordou da orientação, sendo que a grande maioria deles $(93,1 \%)$ concordou totalmente (Tabela 58), independente das variáveis estudadas (Anexo V).

\begin{tabular}{|c|c|c|}
\hline Concordância com a orientação & Frequência & Porcentagem \\
\hline $\begin{array}{l}\text { Concorda totalmente com essa orientação } \\
\text { Concorda parcialmente com essa orientacáo }\end{array}$ & 27 & $\begin{array}{l}93,1 \\
6.9\end{array}$ \\
\hline Total & 29 & 100,0 \\
\hline
\end{tabular}

Quando questionados quanto à importância da orientação, $89,7 \%$ dos individuos disseram ser muito importante, $6,9 \%$ disseram ser um pouco importante e apenas $3,4 \%$ acharam que a orientação não é importante (Tabela 59), independente das variáveis estudadas (Anexo V).

Tais dados demonstraram que a orientação apresentou visivel credibilidade, apesar de o mesmo não ter ocorrido em relação à sua importância. Esta questão pode ser explicada pelo fato de que as pessoas associam o consumo de açúcar ao diabetes e não ao controle de colesterol. 
Tabela 59: Distribuição da amostra quanto à importância da Orientação 10. São Paulo, 2004.

\begin{tabular}{lll}
\hline Importância da orientaçăo & Freqüência & Porcentagem \\
\hline Muito importante & 26 & 89,7 \\
Um pouco importante & 2 & 6,9 \\
Năo é importante & 1 & 3,4 \\
\hline Total & 29 & 100,0 \\
\hline
\end{tabular}

Sobre o cumprimento da orientação pelos entrevistados, $65,5 \%$ dos indivíduos relataram sempre seguir a orientação, $13,8 \%$ disseram freqüentemente seguir a orientação e $20,7 \%$ disseram nunca ou quase nunca seguir essa orientação (Tabela 60), independente das variáveis estudadas (Anexo V).

Assim como observado em grande parte das orientações, a maioria da população estudada achou importante, acreditou e concordou com as mensagens propostas, embora o mesmo não tenha ocorrido quando questionada sobre 0 cumprimento da orientação, o que revelou que nem sempre o que é compreendido e aceito é seguido, talvez em razāo de hábitos alimentares incorretos ("adoro doces", "abuso de chocolate").

Tabela 60: Distribuição da amostra quanto ao cumprimento da Orientação 10. São Paulo, 2004.

\begin{tabular}{lll}
\hline Segue a orientação? & Frequência & Porcentagem \\
\hline Sempre segue essa orientaçăo & 19 & 65,5 \\
Freqüentemente segue & 4 & 13,8 \\
Quase nunca segue & 4 & 13,8 \\
Nunca segue & 2 & 6,9 \\
\hline Total & 29 & 100,0 \\
\hline
\end{tabular}




\subsubsection{Orientação 11: Reduzir o consumo de sal}

Sobre a existência de dúvidas em relação a esta orientação, $6,9 \%$ dos individuos relataram apresentar dúvidas (Tabela 61), independente das variáveis estudadas (Anexo V).

Porém, tal como ocorrido na orientação 3 (Evitar o consumo de frituras), as dúvidas não eram sobre a sua compreensão, e sim sobre a quantidade e/ou periodicidade da orientação (Quadro 11).

Tabela 61: Distribuição da amostra quanto à dúvida na Orientação 11. São Paulo, 2004.

\begin{tabular}{lll}
\hline Dúvida sobre a orientação & Frequéncia & Porcentagem \\
\hline Sim & 2 & 6,9 \\
Não & 27 & 93,1 \\
\hline Total & 29 & 100,0 \\
\hline
\end{tabular}

Quadro 11. Distribuição das dúvidas apresentadas quanto à orientação 11. São Paulo, 2004.

\begin{tabular}{ll}
\hline Dúvida & Freqüe̊ncia \\
\hline É só uma pitadinha? & 1 \\
Qual a quantidade ideal? & 1 \\
\hline Total & 2 \\
\hline
\end{tabular}


Em relação à substituição de palavras na orientação, $10,7 \%$ dos individuos disseram que alguma palavra deveria ser trocada (Tabela 62).

A sugestão relatada foi substituir o reduzir por diminuir.

Tabela 62: Distribuição da amostra quanto à substituição de palavra na Orientação 11. São Paulo, 2004.

\begin{tabular}{lll}
\hline Alguma palavra deve ser trocada? & Freqüência & Porcentagem \\
\hline Sim & 3 & 10,7 \\
Nāo & 25 & 89,3 \\
\hline Total & 28 & 100,0 \\
\hline
\end{tabular}

Este dado foi mais significativo para individuos com escolaridade entre 9 a 11 anos de estudo $p=0,093$, (Tabela 63, $p$ : nível descritivo do teste de associação de Fisher).

Tabela 63: Distribuição da amostra quanto à substituição de palavras na orientação 11, segundo, sexo, escolaridade e idade dos entrevistados. São Paulo, 2004.

\begin{tabular}{llllll}
\hline Caracteristicas & Sim & \multicolumn{3}{c}{ Não } & $P$ \\
\cline { 2 - 5 } & $\mathbf{N}$ & $\%$ & $\mathbf{N}$ & $\%$ & \\
\hline Sexo & 0 & 0,0 & 8 & 100,0 & \\
$\begin{array}{l}\text { Masculino } \\
\text { Feminino }\end{array}$ & 3 & 15,0 & 17 & 85,0 & \\
Idade & & & & & 0,754 \\
Até 45 anos & 0 & 0,0 & 6 & 100,0 & \\
46 a 59 anos & 3 & 17,6 & 14 & 82,4 & \\
60 anos ou + & 0 & 0,0 & 5 & 100,0 & \\
Escolaridade & & & & & 0,093 \\
$1-4$ & 0 & 0,0 & 7 & 100,0 & \\
$5-8$ & 0 & 0,0 & 7 & 100,0 & \\
$9-11$ & 3 & 33,3 & 6 & 66,7 & \\
12 ou + & 0 & 0,0 & 5 & 100,0 & \\
\hline
\end{tabular}

p: nivel descritivo 
A associação observada entre o tempo de estudo e a sugestăo de troca de palavras pode ser explicada pela nivel cultural da população. Esses indivíduos cursaram o ensino médio e a apesar de compreenderam a orientação, sugeriram a utilização de palavras mais "comuns" do vocabulário.

Quanto à concordância, $93,1 \%$ dos individuos concordaram totalmente e 6,9\% parcialmente (Tabela 64), independente das variáveis estudadas (Anexo V).

Tabela 64: Distribuição da amostra quanto à concordância com a Orientação 11. São Paulo, 2004.

\begin{tabular}{lll}
\hline Concordância com a orientaçăo & Freqúéncia & Porcentagem \\
\hline Concorda totalmente com essa orientaçăo & 27 & 93,1 \\
Concorda parcialmente com essa orientaçăo & 2 & 6,9 \\
\hline Total & 29 & 100,0 \\
\hline
\end{tabular}

Quando questionados quanto à importância da orientação, apenas $6,9 \%$ dos entrevistados acharam a orientação pouco importante (Tabela 65), independente das variáveis estudadas (Anexo $V$ ).

Tabela 65: Distribuição da amostra quanto à importância da Orientação 11. São Paulo, 2004.

\begin{tabular}{lll}
\hline Importancia da orientação & Frequéncia & Porcentagem \\
\hline Muito importante & 27 & 93,1 \\
Um pouco importante & 2 & 6,9 \\
\hline Total & 29 & 100,0 \\
\hline
\end{tabular}


Sobre o cumprimento da orientação pelos entrevistados, $82,8 \%$ dos individuos relataram sempre ou freqüentemente seguir a orientação e 6,9\% disseram quase nunca seguir esta orientação (Tabela 66), independente das variáveis estudadas (Anexo V)

O alto percentual de cumprimento observado foi relatado pelos entrevistados devido à presença de hipertensão do mesmo ou de algum familiar, fator comum em pessoas com a média de idade dos entrevistados.

Tabela 66: Distribuição dos indivíduos quanto ao cumprimento da Orientação 11. São Paulo, 2004.

\begin{tabular}{lll}
\hline Segue a orientação? & Freqüència & Porcentagem \\
\hline Sempre segue essa orientação & 23 & 79,3 \\
Frequentemente segue & 4 & 13,8 \\
Quase nunca segue & 2 & 6,9 \\
\hline Total & 29 & 100,0 \\
\hline
\end{tabular}


5.2.12 Orientação 12: Limitar o consumo de álcool, se ingerir, faça-o com moderação.

Sobre a existência de dủvidas em relaçăo a esta orientação, $10,7 \%$ dos individuos relataram apresentar dúvidas (Tabela 67), independente das variáveis estudadas (Anexo V).

A dúvida relatada pelos indivíduos foi em relaçăo à quantidade a ser ingerida ("quanto posso tomar?") e năo ao entendimento da orientaçăo, fato comentado em outros casos citados.

Tabela 67: Distribuiçăo da amostra quanto à dúvida na Orientação 12. São Paulo, 2004.

\begin{tabular}{lll}
\hline Dúvida sobre a orientaçäo & Frequéncia & Porcentagem \\
\hline Simn & 3 & 10,7 \\
Năo & 25 & 89,3 \\
\hline Total & 28 & 100,0 \\
\hline
\end{tabular}

Quando questionados sobre a substituiçáo de palavras na orientaçăo, $20,7 \%$ dos individuos disseram que alguma palavra deveria ser trocada (Tabela 68), independente das variáveis estudadas (Anexo V). A maioria das sugestōes relatou o fato da intolerância à bebida alcoólica, expressada por termos como "parar de beber" e "nunca beber" (Quadro 12). 
Tabela 68: Distribuiçấo da amostra quanto à substituição de palavra na Orientação 12. São Paulo, 2004.

\begin{tabular}{lll}
\hline Alguma palavra deve ser trocada? & Frequéncia & Porcentagem \\
\hline Sim & 8 & 20,7 \\
Nơo & 23 & 79,3 \\
\hline Total & 29 & 100,0 \\
\hline
\end{tabular}

Quadro 12. Dístribuiçäo das sugestöes quanto à troca de palavras da orientação 12. São Paulo, 2004.

\begin{tabular}{ll}
\hline Dúvida & Freguencia \\
\hline Trocaria limitar por deixar, parar, nunca beber & 4 \\
Trocaria com moderaça por pouco ou menos & 2 \\
\hline Total & 6 \\
\hline
\end{tabular}

Quanto à concordância com a orientaçăo, todos as individuos concordaram totalmente com a orientaçäo.

Quando questionados quanto à importância da orientaçăo, $82,8 \%$ individuos disseram ser muito importante e $17,2 \%$ acharam a orientaçăo pouco importante (Tabela 69)

Tabela 69: Distribuiçăo da amostra quanto à importância da Orientação 12. São Paulo, 2004.

\begin{tabular}{lll}
\hline Importáncia da orientação & Frequéncia & Porcentagem \\
\hline Muito importante & 24 & 82,8 \\
Un pouco importante & 5 & 17,2 \\
\hline Total & 29 & 100,0 \\
\hline
\end{tabular}


Estes dados foram mais significativos para individuos com menor escolaridade, $p=0,025$ (Tabela 70, $p$ : nivel descritivo do teste de associaçåo de Fisher).

Tabela 70: Distribuiçăo da amostra quanto à importância da orientação 12, segundo sexo, idade e escolaridade dos entrevistados. São Paulo, 2004.

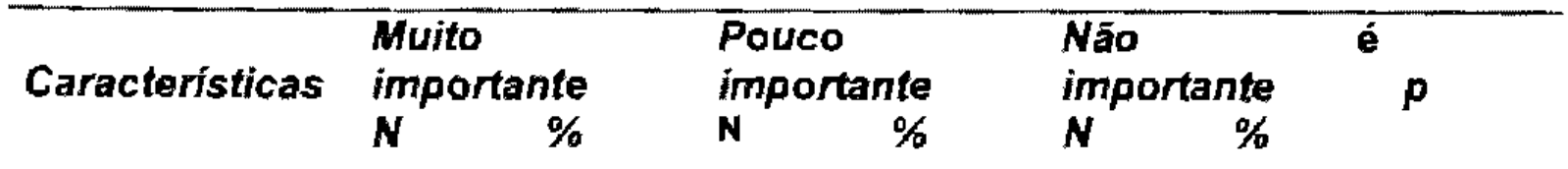

Sexo

Masculino

$7 \quad 87,5$

Feminino

17

$81,0 \quad 4$

12,5

0,0

0,999

Idade

Até 45 anos

46 a 59 anos 15

60 anos ou +5

$66,7 \quad 2$

$83,3 \quad 3$

$100,0 \quad 0$

19,0

0,0

Escolaridade

$1-4$

$5-8$

$100,0 \quad 0$

$71,4 \quad 2$

$100,0 \quad 0$

$33,3 \quad 0$

0,0

0,511

$16,7 \quad 0 \quad 0,0$

$\begin{array}{lll}0,0 & 0 & 0,0\end{array}$

$9-11$

$50,0 \quad 3$

0,0

$0 \quad 0,0$

0,025

12 ou +

9

p: nivel descritivo

3

$3 \quad 50,0$

$0,0 \quad 0 \quad 0,0$

$50,0 \quad 0 \quad 0,0$

A relaçăo observada entre a importância e a escolaridade do entrevistado onde aqueles com maior tempo de escolaridade acreditam que a orientaçăo é pouco importante quanto aqueles com menor tempo de escolaridade pode ser explicado pela associação entre a orientaçăo e o controle do colesterol e gordura no sangue. Os individuos de menor escolaridade podem nāo ter relacionado o consumo de bebida alcóblica ao controle de dislipidemias mas sim ao alcoolismo, e por isso a importância da orientaçăo. Já os indivíduos com mais tempo de estudo, podem ter achado que essa relação năo era importante. 
Sobre o cumprimento da orientação pelos entrevistados, $96,6 \%$ dos individuos relataram sempre seguir a orientação, enquanto $3,4 \%$ disseram quase nunca seguir esta orientação (Tabela 71), independente das variáveis estudadas (Anexo V).

Tabela 71: Distribuição da amostra quanto ao cumprimento da Orienta ção 12. São Paulo, 2004.

\begin{tabular}{lll}
\hline Segue a orientagáa? & Freqüéncia & Porcentagem \\
\hline Sempre segue essa arientaçåo & 28 & 96,6 \\
Quase nunca segue & 1 & 3,4 \\
\hline Total & 29 & 100,0 \\
\hline
\end{tabular}




\subsubsection{Orientaçäo 13: Não esquecer de consumir água, pois é essencial à}

saúde.

Sobre a existência de dúvidas em relação a esta orientaçăo, 6,9\% dos individuos relataram apresentar dúvidas sobre a orientação e 93,1\% disseram não apresentar dúvidas (Tabela 72), independente das variáveis estudadas (Anexo V). As dúvidas relatadas foram "Qual a quantidade de água ídeal a ser consumida?"e "Suco também conta?".

Tabela 72: Distribuição da amostra quanto à dủvida na Orientação 13. São Paulo, 2004.

\begin{tabular}{lll}
\hline Dúvida sobre a orientaçăo & Freqüencia & Porcentagem \\
\hline Sim & 2 & 6,9 \\
Năo & 27 & 93,1 \\
\hline Total & 29 & 100,0 \\
\hline
\end{tabular}

Em relaçăo à substituição de palavras na orientação, apenas $3,4 \%$ dos indivíduos disseram que alguma palavra deveria ser trocada (Tabela 73), independente das variáveis estudadas (Anexo V).

Tabela 73: Distribuição da amostra quanto a substituição de palavra na Orientação 13, Săo Paulo, 2004.

\begin{tabular}{lll}
\hline Alguma palavra deve ser trocada? & Freqüencie & Porcentagem \\
\hline Sim & 1 & 3,4 \\
Năo & 28 & 96,8 \\
\hline Tolal & 29 & 100,0 \\
\hline
\end{tabular}

Quanto à concordância, todos os individuos concordaram totalmente com a onientaçăo. Quando questionados quanto à importância, todos os indivíduos disseram ser muito importante a orientaçăo. 
Sobre o cumprimento da orientação pelos entrevistados, $72,4 \%$ dos indivíduos relataram sempre seguir a orientação, $13,8 \%$ disseram freqüentemente seguir a orientação e $13,8 \%$ disseram quase nunca seguir (Tabela 74), independente das variáveis estudadas (Anexo V).

Tabela 74: Distribuição da amostra quanto ao cumprimento da Orientação 13. São Paulo, 2004.

\begin{tabular}{lll}
\hline Segue a orientaçăo? & Freqüência & Porcentagem \\
\hline Sempre segue essa orientaçåo & 21 & 72,4 \\
Frequientemente segue & 4 & 13,8 \\
Quase nunca segue & 4 & 13,8 \\
\hline Total & 29 & 100,0 \\
\hline
\end{tabular}

Os individuos que disseram não seguir sempre a orientação revelaram que não as seguem devido à falta de hábito de beber água, embora tenham reconhecido sua importância. 
$\mathrm{Na}$ análise conjunta dos resultados de todas as orientações, observou-se que a maioria das treze normas alimentares propostas teve um percentual satisfatório em relação às dúvidas quanto à orientação, pois aproximadamente $90 \%$ dos entrevistados, relataram não ter qualquer dificuldade no entendimento.

No entanto, algumas normas precisam ser reescritas visando melhorar seu entendimento, pois apresentaram um percentual significativo de dúvidas pelos entrevistados. Essas normas foram: as orientações "2 - Basear a alimentação no consumo de alimentos derivados de grãos e raízes, frutas e hortaliças" $(27,6 \%)$, "5 - Selecionar uma dieta com baixa quantidade de gordura, colesterol e gordura saturada" $(34,5 \%)$, "6 - Fracionar a dieta, fazendo três refeições e dois lanches entre elas" $(34,5 \%)$ e " 8 - Consumir produtos de origem animal moderadamente" $(20,7 \%)$.

Assim, quando esclarecidas as dúvidas quanto à compreensão das orientações, uma porcentagem dos entrevistados sugeriu algum tipo de alteração na forma e/ou estrutura da mensagem; $27,2 \%$ dos entrevistados sugeriram mudanças na orientação $2 ; 41 \%$ sugeriram alguma alteração na orientação 5 ; $51,7 \%$ alterariam a orientação 6 ; e $25 \%$ mudariam a orientação 8 . Apesar da orientaçăo "12 - Limitar o consumo de álcool e se ingerir, faça-o com moderação" não apresentar um alto percentual de dúvidas, cerca de $20 \%$ dos entrevistados fariam algum tipo de alteração na mensagem. 
Avaliando as informações fornecidas para todas as orientações, verificou-se que a amostra estudada concordou na essência da mensagem entre 80 e 90\%.

Da mesma forma, a avaliação da importância das mensagens propostas pelas treze orientações como "muito importante" foi entre 80 e $100 \%$, reforçando a credibilidade das orientações.

Com referência à população que relatou "sempre ou freqüentemente seguir as orientações" está em torno de 73 e $96 \%$, com exceção da orientação "4 Praticar atividades físicas regularmente e com orientação" (49\%) e da orientação "6- Fracionar a dieta, fazendo três refeições e dois lanches entre elas, escolhendo alimentos saudáveis" (51\%), que possivelmente têm a interferência de hábitos alimentares e/ou estilo de vida.

$\mathrm{Na}$ literatura são escassos os estudos que avaliaram a compreensão da população em relação às mensagens para uma alimentação saudável. Destaca-se entre eles o de OLIVEIRA e col. (2002) realizada pelo Instituto Danone.

Neste estudo, os autores elaboraram Normas e Guias para a População Brasileira, como instrumento de promoção de Nutrição/Saúde, e constituem um recurso para a população a adotar hábitos alimentares saudáveis. Para verificar a compreensăo das nove normas elaboradas resultantes de um prévio estudo qualitativo, foi desenvolvido um questionário composto de perguntas abertas e fechadas, as quais serviram de base para o presente estudo. A amostra foi 
composta de 720 mães entre 20 e 60 anos idade pertencentes às classes sociais A, B, C e D de cinco cidades brasileiras (Manaus, Belo Horizonte, Goiânia, Natal e Florianópolis). Cada uma das nove normas foram analisadas para cada uma das seis perguntas fechadas do questionário de acordo com as seis varáveis: classe social da familia, idade dos filhos da entrevistada, grau de escolaridade da entrevistada, relação da entrevistada com o chefe da casa, idade da entrevistada, e a cidade onde a entrevistada residia.

Foi realizado o teste de Qui-quadrado de Pearson a fim de verificar a associaçăo entre as variáveis e a resposta das perguntas fechadas. $E$ as perguntas abertas foram avaliadas pela distribuição de freqüência.

As Normas avaliadas foram:

- Faça, pelo menos, as três básicas cada dia e coma alimentos variados;

- Beba leite todos os dias;

- Tome água várias vezes ao dia;

- Coma verduras, legumes e frutas todos os dias;

- Coma menos açúcar e sal;

- Coma alimentos essenciais como arroz e feijão;

- Inclua pequena quantidade de carne vermelha ou branca em uma das refeições;

- Use óleo em pequenas quantidades e diminua o consumo de gordura;

- Inclua pães, macarrão, batata, milho e farinha na sua alimentação. 
Os resultados mostraram-se semelhantes aos do presente estudo, onde a compreensão das mensagens foi em torno de $90 \%$, um percentual das entrevistadas faria algum tipo de modificação na forma ou estrutura da mensagem a fim de facilitar sua compreensão, por exemplo: trocar a palavra incluir por comer, fazer três refeições diárias por fazer as três refeições básicas. Nota-se principalmente a troca de termos menos usuais por palavra do dia a dia da população.

Quanto à concordância, cumprimento da orientação e importância, algumas mensagens esbarraram em preconceitos e hábitos, assim como observado no presente estudo.

ARCHER e col. (2003), em seu estudo de coorte examinaram a associação entre as mudanças na dieta e o grau de instrução de homens e mulheres negras e brancas. Foram aplicados dois questionários com 700 itens: um no momento inicial e outro sete anos depois e concluíram que as maiores mudanças na dieta ocorreram em indivíduos com mais de 12 anos de estudo, principalmente na diminuição da ingestão de gordura saturada e colesterol. Portanto, as campanhas nacionais de saúde pública terão maior impacto entre aqueles com maior grau de instrução. 
Para que se faça uma análise mais completa dos resultados obtidos nesse estudo é necessário a realização de mais pesquisas nessa área a fim de avaliar a compreensão da população em relação às mensagens para uma alimentação saudável. 


\section{CONCLUSÃO}

A partir dos resultados obtidos no presente estudo, pôde-se perceber que a maioria das mensagens contidas nos "Passos para uma Alimentação Saudável do Guia Alimentar para Controle de Colesterol e Gordura no Sangue" é de fácil compreensão, sendo consideradas importantes para sua finalidade, e apresentaram grande credibilidade na população estudada, mesmo para individuos com menor escolaridade. Apesar disso, considera-se necessária a modificação da linguagem de alguns termos contidos nas orientações do Guia, já que a utilização de conceitos científicos e/ou termos pouco usuais dificultou a compreensão das mensagens, não cumprindo seu propósito.

Sugere-se que sejam considerados:

Orientação 2 - substituição da terminologia "grãos e raizes" por exemplos usuais como arroz, feijäo, batata, mandioca, cenoura, lentilha, etc.;

$>$ Orientação 4 - complementação da frase: "praticar atividade física regularmente e com orientação...", com o termo "profissional", aludindo a médicos e/ou educadores físicos; 
Orientação 5 - explicação detalhada e coloquial das palavras "colesterol" e "gordura saturada";

Orientação 6 - troca do verbo "fracionar" por "dividir";

Orientação 8 - substituição da palavra "moderadamente" por "menos"; "produto de origem animal" por "ovos e derivados de carne e leite";

Orientação 10 - troca da expressão "com moderação" por "pouco";

Orientação 11 - substituição de "reduzir" por "diminuir";

Orientação 12 - troca de "com moderação" por "pouco"; 


\section{REFERÊNCIAS BIBLIOGRÁFICAS}

Segundo as normas propostas pelo Comitê Internacional de Revistas Biomédicas, conhecido como Grupo de Vancouver, seguem as referências do material consultado nesse trabalho:

Abreu ES. Elaboração e avaliação da eficácia do sistema de pontos de um instrumento de orientação alimentar como ferramenta para intervenções dietéticas em indivíduos hiperlipidêmicos. São Paulo; 2003 [Tese de Doutorado - Faculdade de Saúde Pública das USP].

Agresti A. Categorical data analysis. $2^{\text {nd }}$ edition. New York: Wiley Interscience; 2002.

American Health Association, 2000 [on line]. Disponivel em URL < available from www.americanheartassociation.com.> [2 agosto 2003].

Anderson KM, Castelli WP, Levy D. Cholesterol and mortality 30 year follow up from Framinghan Study. JAMA 1987; 257: 2176-2180.

Araújo EAC. Diferenciais dos fatores de risco cardiovascular nas populações migrantes e não migrantes de Minas Gerais. São Paulo; 2002. [Tese de doutorado - Faculdade de Saúde Pública].

Araújo LMB. Dislipidemias e obesidade. In: Martinez, TLR. Condutas Clínicas nas Dislipidemias. Belo Horizonte: Ed. Saúde; 1997.p.261-7 
Archer SL, Hilner JE, Dyer AR, Greenlund KJ, Colangelo LA, Kiefe Cl, Liu K, Coronary Artery Risk Development in Young Adults (CARDIA). Association of education with dietary intake among young adults in the bi-ethnic Coronary Artery Risk Development in Young Adults (CARDIA) cohort. Public Health Nutr 2003; 6 (7):689-95.

Batista MCR \& Franceschini SCC. Impacto da atenção nutricional na redução dos niveis de colesterol sérico de pacientes atendidos em serviços públicos de saúde. Arq Bras Cardiol 2003; 80 (2): 162-6.

Barna M \& Biró G. Atherosclerosis: dietary considerations. World Review Nutrition Dietetic 1989; 59: 126-155.

Bowman SA, Lino M, Gerrior AS, Basiotis PP. The healthy eating index: 199496, USDA, Center for Nutrition Policy and Promotion, CNPP-5.

Castelli WP. Epidemiology of coronary heart disease: The Framingham study. Am J Med 1984;27:4-12.

Cervato AM, Mazzilli RN, Martins IS, Marucci MF. Dieta habitual a fatores de risco para doenças cardiovasculares. Rev. Saúde Pública 1997; 31 (3): 227-35. 
Connor SL, Gustafson JR, Artaud- Wild SM, Favell DP, Classick-Kohn CJ, Hatcher LF, Connor WE. The Cholesterol/saturated-fat index: an indication of hipercolesterolemic and atherogenic potential of food. Lancet 1986; (May): 122932.

Connor SL, Gustafson JR, Artaud- Wild SM, Classick- Kohn CJ, Connor WE. The cholesterol-satured fat index of coronary prevention: Background, use, and a comprehensive table of food. J Am Diet Assoc 1989; 89:807-816.

Conselho Nacional de saúde. Regulamentação de pesquisas envolvendo seres humanos. Resolução n 196/96. Brasília (DF); 1996

Davi G, Guagnano MT, Ciabattoni G, Basili S, Falco A, Marinopiccoli M, Nutini M, Sensi S, Patrono C. Platelet Activation in Obese Women. JAMA 2002; 288 (16): 2008- 2014.

Esposito K, Pontillo A, Di Palo C, Giugliano G, Masella M, Marfella R, Giugliano D. Effect of weight loss and lifestyle changes on vascular inflammatory markers in obese women: a randomized trial. JAMA 2003; 289 (14):1799-804.

Fisberg RM, Stella RH, Morimoto JM, Paquali LS, Phillipi ST, Latorre MRDO. Perfil Lipídico de Estudantes de Nutrição e sua Associação com Fatores de Risco para Doenças Cardiovasculares. Arq Bras Cardiol 2001; 72 (2): 137-42 
Fornés NS, Martins IS, Hernan M, Velásquez- Meléndez, Ascherio A. Freqüência de consumo alimentar e niveis séricos de lipoproteinas na população de Cotia, SP, Brazil. Rev Saúde Pública 2000; 34(4): 380-7

Gordon T. The diet- heart idea: outline of a history. Am J Epidemiol 1988; 127:220-225.

Hu FB \& Willet WC. Optimal diets for prevention of coronay diseases. JAMA 2002; 288(20): 2569- 2578.

Junior JBS, Gomes FBC, Cezário AC, Moura L. Doenças e Agravos não Transmissíveis. In: Rouquayrol MZ, Filho NA. Epidemiologia e Saúde. MEDSI; 2003. p.289-312.

Keys A. Coronary heart disease in seven countries. Circulation 1970; 41 (suppl 1): $162: 183$

Keys A. Seven Countries: A Multivariate analysis of death and coronary heart disease. Cambrige, Mass: Harvard University Press, 1980.

Kato H, Tillotson J, Nichaman MZ, Rhoads GG, Hamilton HB. Epidemiologics studies of coronary heart diseaseand stroke in japanese men living in Jpan, Hawaii an California. Am J Epidemiolo 1973; 97 (6): 372-385 
Lajolo FM, coordenador, Menezes EW, Penteado MVC, Filisetti TMCC, Marquez UML. Tabela Brasileira de composição de alimentos. [on line]. Disponível em http://www.usp.br/fff/tabela [2002 jun 20].

Laurenti R, Buchalla CM. Os mitos a respeito das doenças cardiovasculares. Arq Bras Cardiol 2001; 76(2):99-104.

Lima JC. As dislipidemias e suas avaliações laboratoriais. Rev Bras Hipertens 1999;6 (2): 133-137.

Lotufo PA. Mortalidade por doenças do coração no Brasil. Comparação com outros paises. Arq Bras Cardiol 1998; 70 (5):321-325.

Lotufo PA, Lolio CA. Tendências de evolução da mortalidade por doenças cardiovasculares: o caso do estado de São Paulo. In: Monteiro CA. Velhos e Novos Males da Saúde no Brasil - A evolução do País e suas Doenças. São Paulo: HUCITEC NUPENS/USP; 1995. p.279-287.

Marggets BM, Nelson M. Design concepts in nutricional epidemiology . Oxford: Oxford University Press; 1991. 
Martinez TLR, Santos RD, Armaganijan D, Torres KP, Lourtes-Vale A, Magalhães ME, Lima JC. et al. Campanha nacional de alerta sobre o colesterol elevado. Determinação de nivel de colesterol de 81.262 brasileiros. Arq Bras Cardiol 2003; 80 (6): $631-4$.

Martins IS, Gomes AD, Pasini U. Níveis Lipidêmicos e alguns fatores de risco de doenças cardiovasculares em população no município de São Paulo, SP (Brasil). Rev Saúde Pública 1989; 23 (1):23-38

Matsudo V, Matsudo S, Andrade D, Araujo T, Andrade E, Oliveira LC, Braggion G. Nivel de atividade física da população do estado de São Paulo: análise de acordo com o gênero, idade, nível sócio-econômico, distribuição geográfica e de conhecimento. Rev. Bras. Ciên. Mov 2002; 10 (4):41-50.

McCance RA, Winddonson EM. The composition of foods. $5^{\text {th }}$ ed. Porthland: Book News, 1991.

McCullough ML, Feskanich D, Stampfer MJ, Rosner BA, Hu FB, Hunter DJ, Variyam JN, Colditz GA, Willet WC. Adherence to the Dietary guidelines for Americans and risk of major chronic disease in women. Am J Clin Nutr 2000; 72 : $1214-1222$. 
Ministério da Saúde. Secretaria Nacional de Ações Básicas de Saúde. Divisão Nacional de Epidemiologia. Doenças cardiovasculares no Brasil - Sistema Único de Saúde - suS. Brasília: Centro de Documentação do Ministério da Saúde, 1993.

Ministério da Saúde. Estatísticas de Mortalidade. [on line] Disponivel em URL $<$ www.saude.gov.br $>$ [20 fevereiro 2003].

Mitchell DT, Korslund MK, Brewer BK, Novanscone MA. Developmente and validation of the Cholesterol-Saturated Fat Index (CSI) Scorecard: a dietary selfmonitoring tool. J Am Diet Assoc 1996; 96 (2) 132-6.

Molina V, Pena M. Guias de Alimentacion en América latina. In: Anais do I Workshop do Instituto Danone. Alimentação equilibrada para a população brasileira. Florianópolis/SC 1998. p.31-45.

Monteiro CA, Mondini L. Mudanças na composição e adequação nutricional da dieta alimentar nas áreas metropolitanas do Brasil (1966-1988). Rev Saúde Pública 1994; 28 (6):433-39.

Nacif MAL. Guia Alimentar para controle de colesterol e gordura no sangue Concordância do sistema de pontos. São Paulo; 2003 [Dissertação de Mestrado - FCF/FEA/FSP da USP - Programa de Pós Graduação Interunidades em Nutrição Humana e Aplicada - PRONUT] 
[NECP] National Choleterol Education Program. Detection, evaluation, and treatment of high blood cholesterol in adults (adult treatment panel II). Circulation 1994; 89(3):1330-445.

[NECP] National Choleterol Education Program. Executive summary of the third report of the National Cholesterol Education Program (NCEP) expert panel on detection, avaluation, and treatment of high blood cholesterol in adults (Adult treatment panel III). JAMA 2001; 285(19):2486-97

Oliveira JED, Moreira EAM, Portella O, Berezovsky MW. Normas e guias alimentares para a população brasileira - Delineamentos metodológicos e critérios técnicos. Instituto Danone, São Paulo, 2002.

Panagiotakos DB, Pitsavos C, Chrysohoou C, Skoumas J, Stefanadis C. Status and management of blood lipids in Greek adults and their relation to sociodemographic, lifestyle and dietary factors: the ATTICA Study. Blood lipids distribution in Greece. Atherosclerosis 2004;173(2):353-61.

Pena M e Monina V. Guías Alimentarias y promoción de la salud en América Latina. Organización Panamericana de La Salud - Instituto de Nutricion de Centroamérica y Panamá (INCAP), 1998.

Pennington JAT. Use the Core Foods Model to Estimate Mineral Intakes - Part 1. Selection of U. S. Core Foods. J Food Comp Anal 2001;14: 295-300. 
Philippi ST, Laterzza AR, Cruz ATR, Ribeiro LC. Pirâmide alimentar: Guia para escolha de alimentos. Rev Nutr PUCCAMP 1999; 1(12): 65-80.

Santos JE. Terapêutica das hiperpidemias: como e por quê? Rev Bras Hipertens 1999;6 (2): 158-162.

Seishima M. Guideline for hyperlipidemia. Rinsho Byor 2003; 51(6):576-80.

Sociedade Brasileira de Cardiologia. $2^{\circ}$ Consenso Brasileiro sobre Dislipidemia Avaliação - Deteccão - Tratamento. Arq Bras Cardiol 1996; 67:101-29.

Sociedade Brasileira de Cardiologia. III Diretrizes Brasileiras de Dislipidemias e Prevenção da Aterosclerose do Departamento de Aterosclerose da Sociedade Brasileira de Cardiologia. Arq Bras Cardiol 2001;77 (suplemento III): 1-48.

Sociedade Brasileira de Cardiologia. Diretrizes para Cardiologistas sobre Excesso de Peso e Doença Cardiovascular dos Departamentos de Aterosclerose, Cardiologia Clínica e FUNCOR da Sociedade Brasileira de Cardiologia. Arq. Bras. Cardiol. 2002; 78 (Suplemento I): 3-14.

Stamler J. Is relationship between serum cholesterol and risk of premature death from coronary heart disease contínuos and graded? Finding in 356,222 primary screenees of the Multiples Risk Factor Trial (MRFIT). JAMA 1986; 256:2823. 
Torres EAFS. Teor de lipídeos em alimentos e sua importância na nutrição.

São Paulo; 2000 [Tese de Livre Docência - Faculdade de Saúde Pública da USP].

Universidade de São Paulo. Faculdade de Saúde Pública. Departamento de Nutrição. Guia Alimentar para Controle de Colesterol e Gordura no Sangue Ajude seu coração a viver Mais e Melhor. São Paulo, 2002.

Villar BS. Desenvolvimento e validação de um questionário semi-quantitativo de freqüência alimentar para adolescentes. São Paulo; 2001 [Tese de Doutorado - Faculdade de Saúde Pública das USP].

Welsh S, Davis C, Shaw A. A brief history of food guides in the United States. Nutrition Today, 1992;6 (27) 6-11.

[WHO] World Heath Organization. Obesity - preventing a managing the global epidemic. Report. Geneva; 1998 (Report of a WHO Consultation on Obesity).

World Heath Organization. Diet Nutrition and the prevention of chronic disease. Report. Geneva; 2002.

Willett WC. Eat, drink and be healthy. The Harvard Medical School Guide to Healthy Eating. New York; 2001. 
Willet WC. Nutritional Epidemiology. $2^{\text {nd }}$ ed. New York: Oxford University Press; 1998.

Woo J. Relationships among diet, physical activity and other lifestyle factors and debilitating diseases in the elderly. Eur J Clin Nutr; 2000; 54 (Suppl 3):143-7.

Zilversmit DB. Cholesterol index in foods. J Am Diet Assoc 1979; 74:562-65. 
ANEXO I

Sistema de Pontos para Controle de Colesterol e Gordura no Sangue

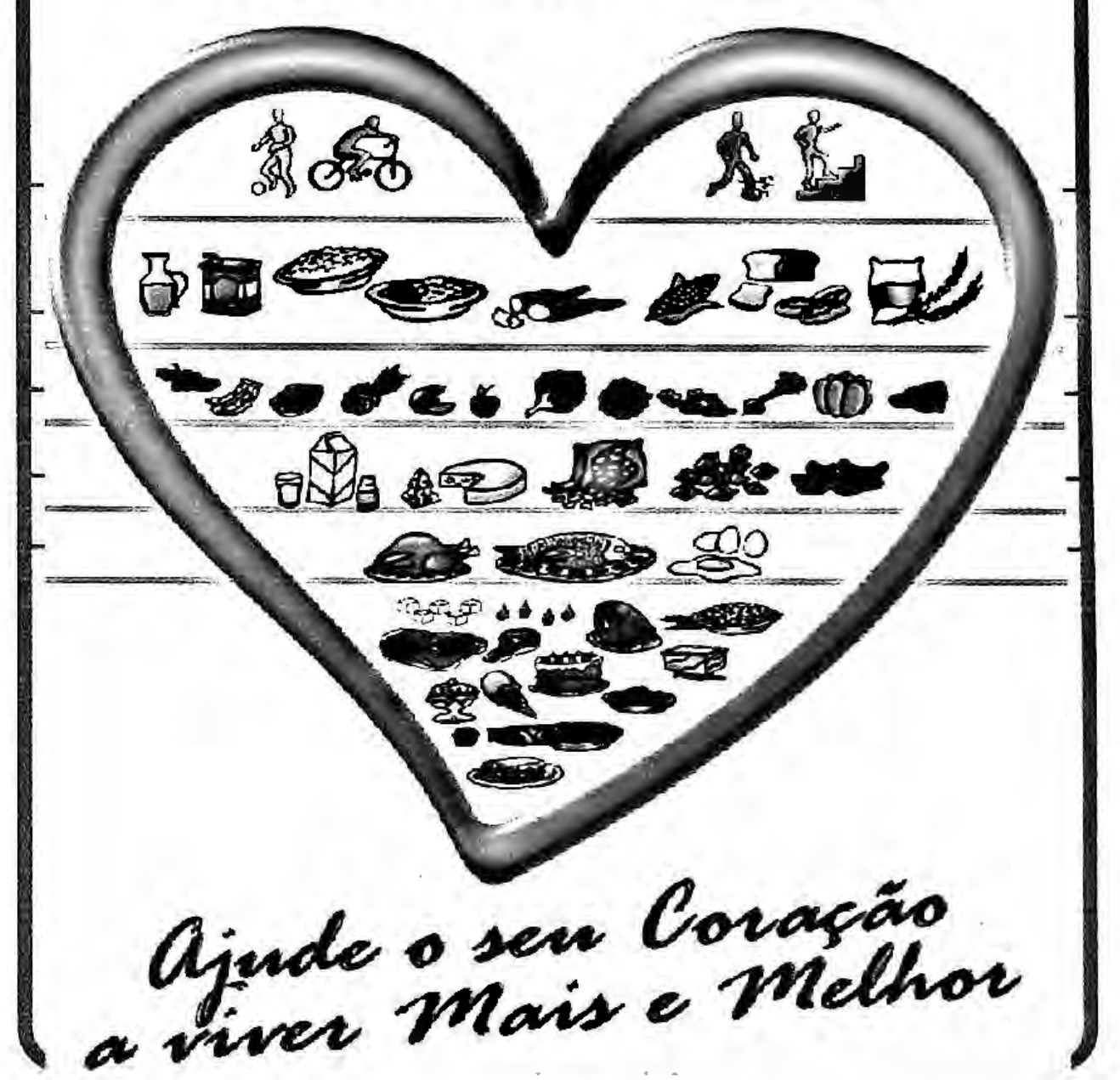




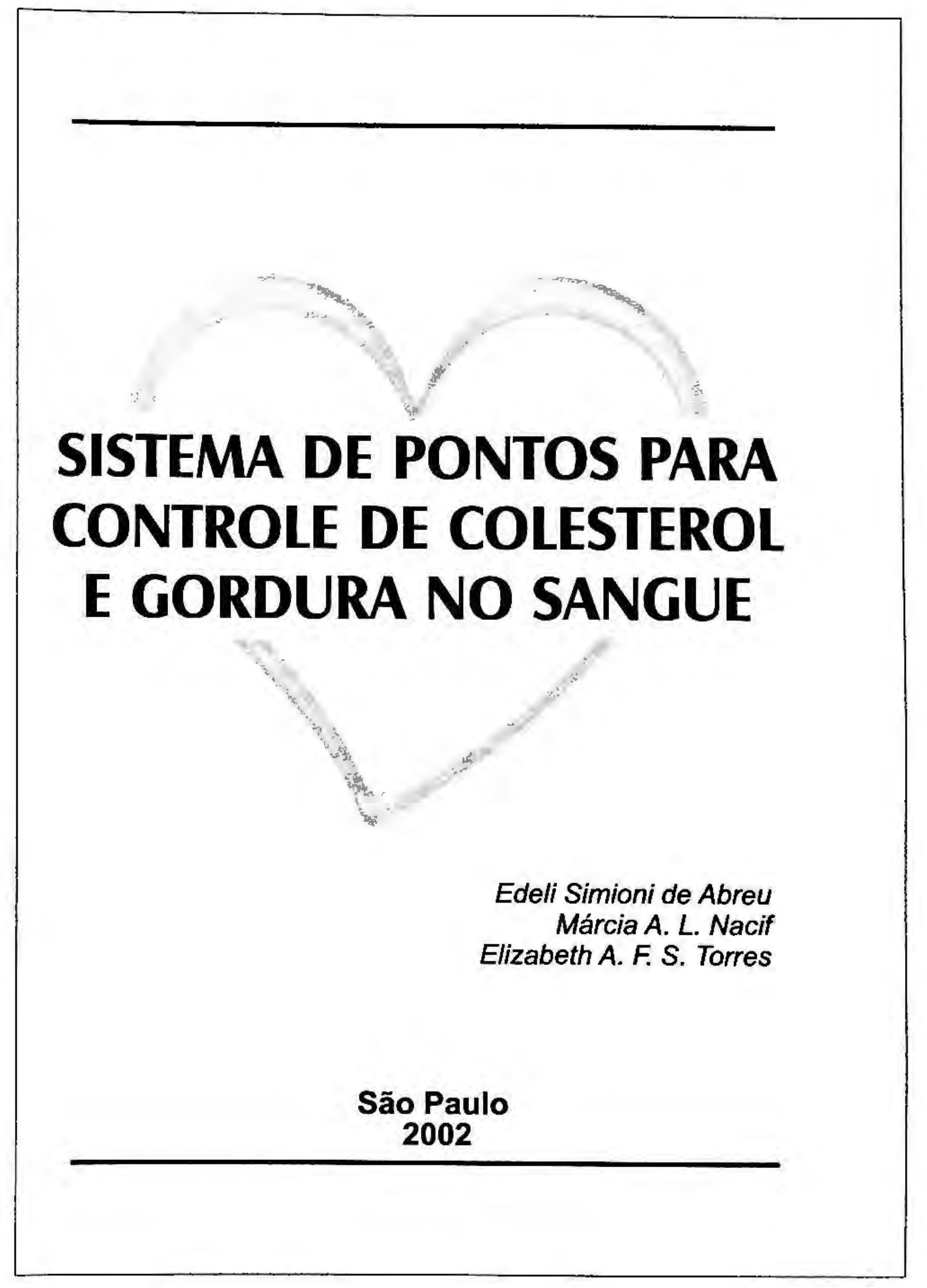




\section{Apresentação}

A alimentação saudável tem papel fundamental na prevenção de doenças e na redução e manutenção dos níveis de colesterol no sangue. Sabe-se que uma dieta com elevados índices de colesterol e gordura saturada agrava esses riscos. Assim, fica fácil deduzir que o consumo de alimentos com reduzido teor de gordura saturada e pobres em colesterol é importante na redução dos niveis de colesterol sangüíneos.

O que fica difícil medir é o potencial de aumentar o colesterol que cada alimento possui. Para facilitar esse entendimento foi desenvolvido um índice de colesterol/gordura saturada - ICS, que pode ser utilizado para comparar diferentes alimentos e preparações, por meio de pontuaçōes.

Controlar o peso é outro fator que diminui os riscos para o aumento de colesterol $e$, conseqüentemente, previne o aparecimento de doenças do coração, diabetes, hipertensão arterial, entre outras. Porém, isso não é tarefa fácil, mas com um pouco de boa vontade, é possível atingir o objetivo, sem fazer grandes sacrifícios. O que é necessánio é aprender a escolher os alimentos certos.

Para começar, devemos banir a idéia de "fazer regime", que está associada a fazer sacrificio durante um tempo e depois abandonar, voltando, muitas vezes, à estaca zero. O correto é adotar um plano dietético, ou seja, uma forma de se alimentar hoje, nos próximos dias e sempre.

Para auxiliar na promoçäo de um melhor estado nutricional e no estabelecimento de hábitos alimentares adequados, foi desenvolvido o presente Sistema de Pontos, de fácil compreensão e manejo, que pode ser calculado pelo próprio indivíduo que aprenderá a elaborar sua dieta através de pontuações de ICS, além de uma representação gráfica da alimentação saudável. 


\section{Representação Gráfica da Alimentação Saudável}

Uma ferramenta para controle e prevenção de colesterol elevado e gordura no sangue.

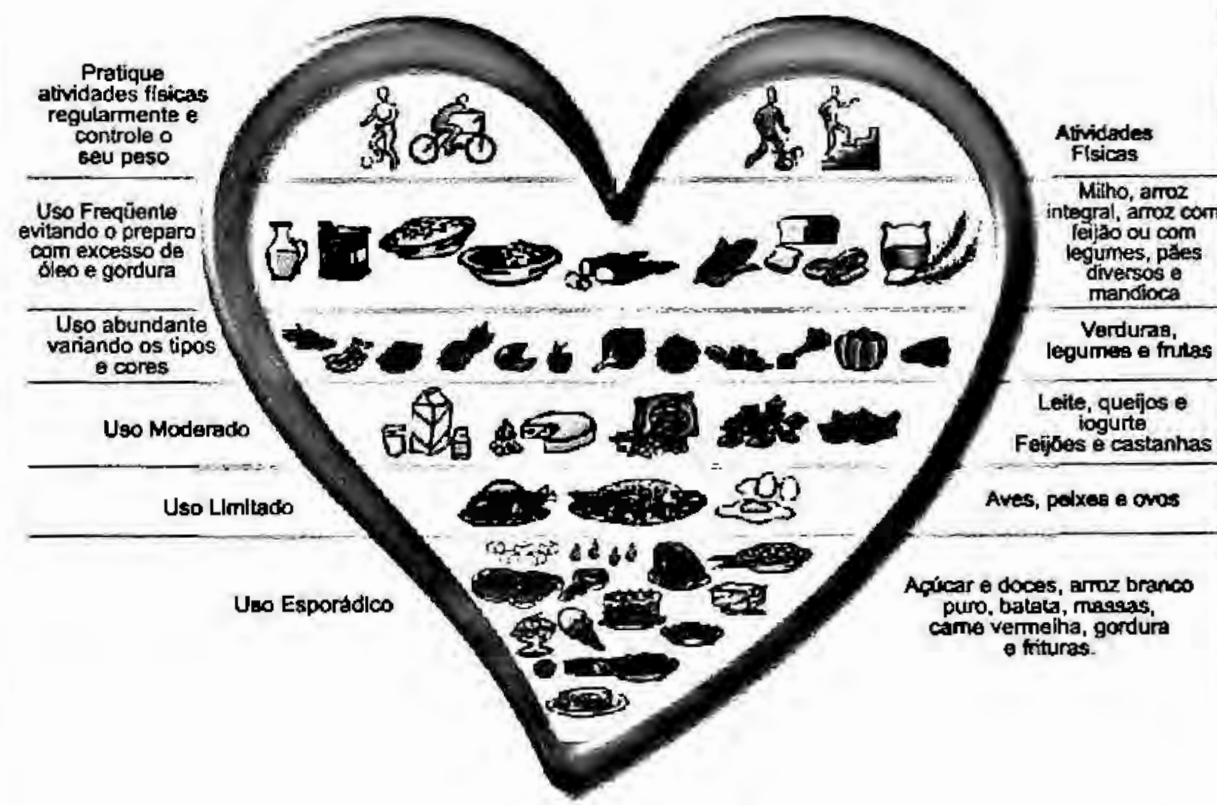

ESCOLHA UMA ALIMENTAÇÃO SAUDÁVEL 


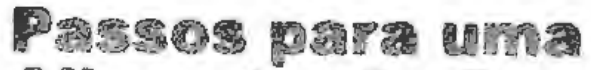

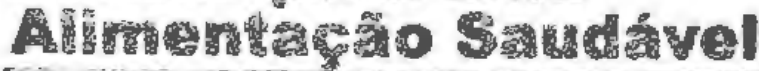

\section{1 - CONSUMIR UMA ALIMENTAÇAO VARIADA \\ 2 - BASEAR A ALIMENTACAO NO CONSUMO DE ALIMENTOS DERIVADOS DE GRAOS E RAIZES, LEGUMES, VERDURAS E FRUTAS}

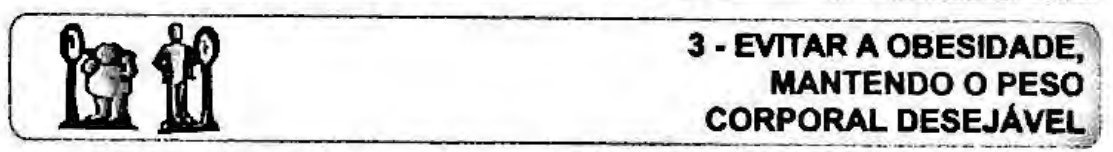

\section{4 - PRATICAR ATIMIDADES FISICAS}

REGULARMENTE E COM ORIENTAÇAO
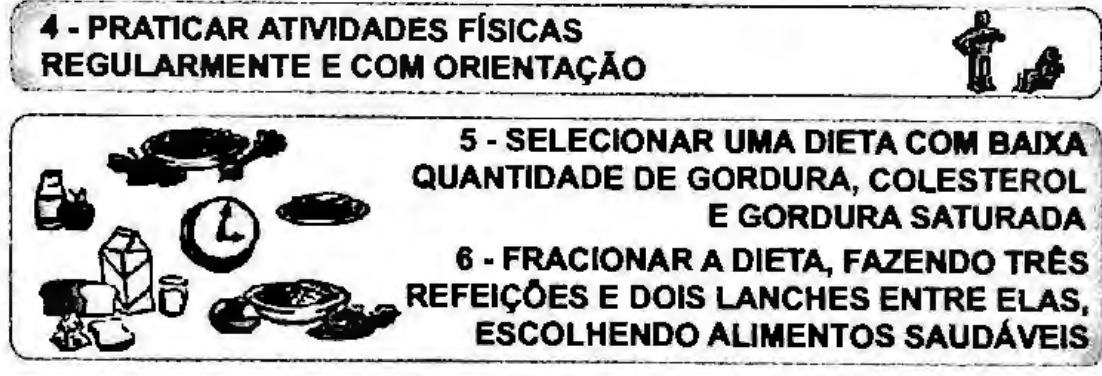

7 - EVITAR O CONSUMO DE FRITURAS

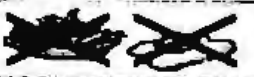

000

8 - CONSUMIR PRODUTOS DE ORIGEM ANIMAL MODERADAMENTE

9 - PREFERIR AS CARNES MAGRAS E RETIRAR GORDURAS VISIVEIS

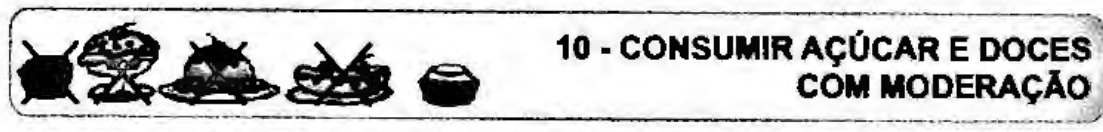

11 - REDUZIR O CONSUMO DE SAL 12 - LIMITAR O CONSUMO DE ALCOOL,
SE INGERIR, FAÇA-O COM MODERAÇAO

13 - NAO ESQUECER DE CONSUMIR AGUA, POIS É ESSENCIAL A SAÚDE

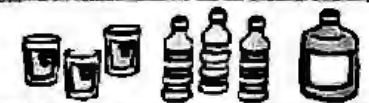




\section{ANEXO II \\ TERMO DE CONSENTIMENTO}
(Obrigatório para Pesquisa Científica em Seres Humanos - Resolução n. ${ }^{\circ} 196$ 10/10/1996 CSN)

\section{Pesquisa: AVALIAÇÃO DAS NORMAS DE UM SISTEMA DE PONTOS PARA CONTROLE DE COLESTEROL E GORDURA NO SANGUE}

Objetivo: Avaliar a compreensão da populaçăo em relaçăo aos passos para uma alimentação saudável propostas pelo sistema de pontos para o controle de colesterol e gordura no sangue, considerando a clareza do conteúdo e a forma que foram expressos.

A pesquisa a ser desenvolvida será realizada pelo Departamento de Nutriçăo da Faculdade de Saúde Püblica - de autoria e responsabilidade da nutricionista Priscilla Primi Hardt CRN3-6587, sob a orientação da Prof'. Assoc. Elizabeth AFS Torres.

Fui esclarecido sobre os procedimentos a serem realizados, e me submeterei á pesquisa respondendo às perguntas que compõe o estudo. Estou ciente que esta pesquisa é importante para o desenvolvimento de um instrumento para orientação de alimentação adequadas à prevenção e controle do colesterol e gordura no sangue.

Fui esclarecido pela pesquisadora que:

$\checkmark$ todas as dúvidas acerca da pesquisa serão respondidas, a participaçăo é voluntária e a desistência não acarretará algum tipo de prejuizo;

$\checkmark$ A pesquisadora se compromete a não identificar o indivlduo e a manter o caráter confidencial das informaçóes relacionadas a sua privacidade.

Declaro que, após ter sido convenientemente esclarecido pela pesquisadora, eu consinto em participar desta pesquisa.

Såo Paulo, de de 200

assinatura da pesquisadora

assinatura do participante

Maiores informaçס̄es: Priscilla Primi Hardt e Profe. Elizabeth AFS Torres - Departamento de Nutriçăo da Faculdade de Saúde Pública da Universidade de Såo Paulo, Av. Dr. Arnaldo, 715 ou pelos telefones: (11) 3066.7701 , (11) 3066.3637 


\section{ANEXO III}

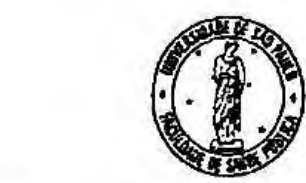

Universidade de São Paulo

Faculdade de Saúde Püblica

COMITEDEE ETTCA-COEP

Av. Dr. Amaldo, 715 - CEP 01246-904 - Săo Paulo - Brasil

Telefones: (55-11) 3066- 7779 - fone/fax (55-11) 3064 -7314 - e-mail: mderacas@usp.br

\section{Of.COEP/191/03}

14 de novembro de 2003

Pelo presente, informo que o Comitê de Ética em Pesquisa da Faculdade de Saúde Pública da Universidade de Såo Paulo-COEP, analisou e aprovou "ad referendum", em 13.11.2003, de acordo com os requisitos da Resoluçåo CNS/196/96, o Protocolo de Pesquisa n." 1048, intitulado: "VALDAÇĀO DAS NORMAS DE UM SISTEMA DE PONTOS PARA CONTROLE DE COLESTEROL. E GORDURA NO SANGUE", apresentado pela pesquisadora Priscila Primi Hardt.

Atenciosamente,

$$
\begin{aligned}
& \text { Paulo Antonio de Crvalho Fortes } \\
& \text { Professor orsociado }
\end{aligned}
$$

Coordenador do Comitê de Ética em Pełquisa da FSP-COEP 


\section{ANEXO IV}

\section{QUESTIONÁRIO PARA ESTUDO VALIDAÇÃO DAS NORMASI GUIAS}

ALIMENTARES PROPOSTOS NOS PASSOS PARA UMA ALIMENTAÇÃO

SAUDÁVEL

\begin{tabular}{|c|c|}
\hline Questionário n.: & \\
\hline Nome: & \\
\hline Endereço: & \\
\hline Bairro: & \\
\hline Cidade: & Tel.: \\
\hline Entrevistador: & Data: I I \\
\hline Sexo: & \\
\hline Idade do Entrevistado: & \\
\hline $\begin{array}{l}\text { Escolaridade: } \\
-1-4()\end{array}$ & \\
\hline - $5-8()$ & \\
\hline - $9-11()$ & \\
\hline - 12 ou $+\operatorname{anos}()$ & \\
\hline
\end{tabular}

Bom dia/ Boa Tarde!. Eu sou da Universidade de São Paulo e nós estamos fazendo uma pesquisa aqui no Incor e gostaria de fazer algumas perguntas.

A. $O$ (A) senhor(a) concorda em colaborara conosco nesta pesquisa?

() $\mathrm{Sim} \Rightarrow$ CONTINUE

( ) Não $\Rightarrow$ AGRADEÇA E ENCERRE

B. Até qual série o(a) senhor(a) estudou ?

Não estudou ( )

$1-4$
$5-8$
$9-11$
12 ou + anos ()

Se a entrevista se enquadrou em um dos grupos pesquisados $\Rightarrow$ CONTINUE Se não, agradeça e encerre.

C. Qual sua idade? Anos 
Introduçăo: A pesquisa que estamos realizando é para conhecermos a opiniåo das pessoas sobre algumas orientações sobre alimentação saudável para controle de colesterol e gordura no sangue. Não existem respostas certas ou erradas, é a sua opiniăo que queremos conhecer.

\section{ORIENTACĀO 1: CONSUMIR UMA ALIMENTACĀO VARIADA}

1. Nesse cartão, o (a) senhor(a) pode ter uma orientação para uma alimentação saudável para controle de colesterol e gordura no sangue. Eu gostaria de saber se o (a) Sr. (a) tem alguma dúvida quanto ao que diz essa orientaçăo.

$\begin{array}{lll}\text { SIM } & (1) & \Rightarrow \text { CONTINUE } \\ \text { NAOO } & (j & \Rightarrow \text { PERGUNTA 2 }\end{array}$

1A. Qual a dúvida que a $\mathrm{Sr}(\mathrm{a})$ tem com relação a esta orientação? (REGISTRAR EXATAMENTE O QUE FOI DITO PELA ENTREVISTADA E NÄO DAR QUALQUER TIPO DE EXPLICAÇĀO)

2. Se o(a) Sr. (a) fosse contar a orientação contida nesse cartão à um(a) amigo(a) seu(a), que não conhecesse essa orientaçāo, como o $\mathrm{Sr}$.(a) contaria? O que mais diria?

3. Existe alguma palavra ou termo nesta orientação que o(a) $\mathrm{Sr}$.(a) acha que deveria ser trocada, para que as pessoas entendam melhor o que diz essa orientaçāo?

$\begin{array}{ll}\operatorname{SIM} & (\text { ) }\end{array} \quad$ ( ) Qual?

4. Pensando agora no quanto o(a) Sr.(a) está de acordo com o que diz essa orientação (APRESENTAR ORIENTAÇĀO), o(a) Sr.(a) diria que

- Concorda totalmente com essa orientação ( ) - Ir para pergunta 5

- Concorda parcialmente com essa orientação, ou ( ) - CONTINUE

- Discorda dessa orientação ( ) - CONTINUE

Porque?

5. Pensando na alimentação das pessoas que têm colesterol ou gordura no sangue, o(a) Sr.(a) diria que esta orientação (APRESENTAR ORIENTAÇĀO)

- E muito importante, ( ) - Ir para P.7

- É só um pouco importante ou ( ) - CONTINUE

- Não é importante ( ) - CONTINUE

6A. Por que o(a) Sr.(a) acha que essa orientaçăo ? (RESPOSTA DADA NA P.5)

6. Pensando agora na sua alimentação, o(a) Sr. (a) diria que (APRESENTAR ORIENTAÇÃO)

- Sempre segue essa orientaçăo, ( ) - IR PARA P.8

- Freqüentemente segue o que diz essa orientação ( ) - CONTINUE

- Quase nunca segue essa orientação, ou ( ) - CONTINUE

- Nunca segue o que diz essa orientaçao ( ) - CONTINUE

7.A Por que? (RESPOSTA DADA NA P.6) 
7. Que sugestão o(a) Sr.(a) daria para melhorar esta orientação? Tanto em relação ao que a orientação diz, como em relação a maneira como foi escrita

\section{ORIENTAČ̃̃O 2: BASEAR A ALIMENTACĀO NO CONSUMO DE DERIVADOS DE GRÃOS E RAIZZES, LEGUMES, VERDURAS E FRUTAS}

8. Nesse cartăo, o (a) senhor(a) pode ter uma orientação para uma alimentação saudável para controle de colesterol e gordura no sangue. Eu gostaria de saber se o (a) Sr. (a) tem alguma dúvida quanto ao que diz essa orientaçảo.
SIM
( )
$\Rightarrow$ CONTINUE
NÃO
$\Rightarrow$ PERGUNTA 9

9. Qual a dúvida que a $\operatorname{Sr}(a)$ tem com relação a esta orientação? (REGISTRAR EXATAMENTE O QUE FOI DITO PELA ENTREVISTADA E NÄO DAR QUALQUER TIPO DE EXPLICAÇĀO)

10. Se o(a) Sr.(a) fosse contar a orientação contida nesse cartão à um(a) amigo(a) seu(a), que não conhecesse essa orientação, como o Sr.(a) contaria? O que mais diria?

11. Existe alguma palavra ou termo nesta orientação que o(a) $\mathrm{Sr}$.(a) acha que deveria ser trocada, para que as pessoas entendam melhor o que diz essa orientação?

$\begin{array}{ll}\mathrm{SIM} & (\text { ) }\end{array} \quad \Rightarrow$ Qual ?

12. Pensando agora no quanto o(a) Sr.(a) está de acordo com o que diz essa orientaçäo (APRESENTAR ORIENTAÇĀO), o(a) Sr.(a) diria que

- Concorda totalmente com essa orientação ( ) - Ir para pergunta 13

- Concorda parcialmente com essa orientaçäo, ou ( ) - CONTINUE

- Discorda dessa orientação ( ) - CONTINUE

Porque?

13. Pensando na alimentação das pessoas que têm colesterol ou gordura no sangue, o(a) $\mathrm{Sr}$.(a) diria que esta orientação (APRESENTAR ORIENTAÇÃO)

- E muito importante, ( ) - Ir para P.14

- É só um pouco importante ou ( ) - CONTINUE

- Não é importante ( ) - CONTINUE

Por que?

14. Pensando agora na sua alimentação, o(a) Sr.(a) diria que (APRESENTAR ORIENTAÇÃO)

- Sempre segue essa orieritação, ( ) - IR PARA P.15

- Freqüeritemente segue o que diz essa orientação ( ) - CONTINUE

- Quase nunca segue essa orientação, ou ( ) - CONTINUE

- Nunca segue o que diz essa orientação ( ) - CONTINUE

Por que?

Que sugestäo o(a) Sr.(a) daria para melhorar esta orientação? Tanto em relação ao que a orientação diz, como em relação a maneira como foi escrita 


\section{ORIENTACĀO 3: EVITAR A OBESIDADE, MANTENDO O PESO CORPÓRAL DESEJÁVEL}

Nesse cartão, o (a) senhor(a) pode ter uma orientação para controle de colesterol e gordura no sangue. Eu gostaria de saber se o (a) Sr. (a) tem alguma dúvida quanto ao que diz essa orientação.
SIM
NĀO
$\Rightarrow$ CONTINUE
( ) $\quad \Rightarrow$ PERGUNTA 15

15. Qual a dúvida que a $\mathrm{Sr}(\mathrm{a})$ tem com relação a esta orientação? (REGISTRAR EXATAMENTE O QUE FOI DITO PELA ENTREVISTADA E NĀO DAR QUALQUER TIPO DE EXPLICAÇĀO)

16. Se o(a) Sr.(a) fosse contar a orientação contida nesse cartão à um(a) amigo(a) seu(a), que não conhecesse essa orientaçăo, como o Sr.(a) contaria? O que mais diria?

17. Existe alguma palavra ou termo nesta orientaçåa que o(a) $\mathrm{Sr}$.(a) acha que deveria ser trocada, para que as pessoas entendam melhor o que diz essa orientaçāo?
$\operatorname{SiM}$
NÃO
( ) $\quad \Rightarrow$ Qual?
( )

18. Pensando agora no quanto o(a) Sr.(a) está de acordo com o que diz essa orientaçăo (APRESENTAR ORIENTAÇĀO), o(a) Sr.(a) diria que

- Concorda totalmente com essa orientaçåo ( ) - Ir para pergunta 5

- Concorda parcialmente com essa orientação, ou ( ) - CONTINUE

- Discorda dessa orientaçăo ( ) - CONTINUE

Porque?

19. Pensando na alimentação das pessoas que têm colesterol ou gordura no sangue, o(a) Sr.(a) diria que esta orientação (APRESENTAR ORIENTAÇĀO)

- É muito importante, ( ) - Ir para P.20

- É só um pouco importante ou ( ) - CONTINUE

- Nāo é importante ( ) - CONTINUE

Por que?

20. Pensando agora na sua saúde, o(a) Sr.(a) diria que (APRESENTAR ORIENTAÇĀO)

- Sempre segue essa orientaçăo, ( ) - IR PARA P.21

- Freqüentemente segue o que diz essa orientação ( ) - CONTINUE

- Quase nunca segue essa orientação, ou ( ) - CONTINUE

- Nunca segue o que diz essa orientaçäo ( ) - CONTINUE

Por que?

Que sugestão o(a) Sr.(a) daria para melhorar esta orientaçăo? Tanto em relação ao que a orientaçāo diz, como em relação a maneira como foi escrita 


\section{ORIENTACÃO 4: PRATICAR ATIVIDADE FISICA REGULARMENTE E COM ORIENTACÃO}

21. Nesse cartăo, o (a) senhor(a) pode ter uma orientação para controle de colesterol e gordura no sangue. Eu gostaria de saber se o (a) Sr. (a) tem alguma dúvida quanto ao que diz essa orientação.

$\begin{array}{lll}\text { SIM } & (\text { ) } & \Rightarrow \text { CONTINUE } \\ \text { NÄO } & \text { ( ) } & \Rightarrow \text { PERGUNTA 22 }\end{array}$

22. Qual a dúvida que a $\operatorname{Sr}(a)$ tem com relação a esta orientaçäo? (REGISTRAR EXATAMENTE O QUE FOI DITO PELA ENTREVISTADA E NÄO DAR QUALQUER TIPO DE EXPLICAÇĀO)

23. Se o(a) Sr.(a) fosse contar a orientação contida nesse cartão à um(a) amigo(a) seu(a), que não conhecesse essa orientação, como o Sr.(a) contaria? O que mais diria?

24. Existe alguma palavra ou termo nesta orientaçāo que o(a) $\mathrm{Sr}$.(a) acha que deveria ser trocada, para que as pessoas entendam melhor o que diz essa orientação?
SIM
NAO
( ) $\quad \Rightarrow$ Qual ?
( )

25. Pensando agora no quanto o(a) Sr.(a) está de acordo com o que diz essa orientaçăo (APRESENTAR ORIENTAÇĀO), o(a) Sr.(a) diria que

- Concorda totalmente com essa orientaçăo ( ) - Ir para pergunta 26

- Concorda parcialmente com essa orientação, ou ( ) - CONTINUE

- Discorda dessa orientaçăo ( ) - CONTINUE

Porque?

26. Pensando na alimentação das pessoas que têm colesterol ou gordura no sangue, o(a) Sr.(a) diria que esta orientação (APRESENTAR ORIENTAÇĀO)

- E muito importante, ( ) - Ir para P.27

- E só um pouco importante ou ( ) - CONTINUE

- Não è importante ( ) - CONTINUE

Por que?

27. Pensando agora na sua saúde, o(a) Sr.(a) diria que (APRESENTAR ORIENTAÇÃO)

- Sempre segue essa orientaçāo, ( ) - IR PARA P.28

- Freqüentemente segue o que diz essa orientaçäo ( ) - CONTINUE

- Quase nunca segue essa orientação, ou ( ) - CONTINUE

- Nunca segue o que diz essa orientação ( ) - CONTINUE

Por que?

28. Que sugestão o(a) Sr.(a) daria para melhorar esta orientação? Tanto em relação ao que a orientação diz, como em relaçăo a maneira como foi escrita 


\section{ORIENTACÃO 5: SELECIONAR UMA DIETA COM BAIXA QUANTIDADE DE GORDURA, COLESTEROL E \\ GORDURA SATURADA}

29. Nesse cartão, o (a) senhor(a) pode ter uma orientaçăo para uma alimentação saudável para controle de colesterol e gordura no sangue. Eu gostaria de saber se o (a) $\mathrm{Sr}$. (a) tem alguma dúvida quanto ao que diz essa orientaçāo.
SIM
NÃO
( ) $\Rightarrow$ CONTINUE
( ) $\quad \Rightarrow$ PERGUNTA 30

30. Qual a dúvida que a $\operatorname{Sr}(a)$ tem com relação a esta orientaçăo? (REGISTRAR EXATAMENTE O QUE FOI DITO PELA ENTREVISTADA E NÄO DAR QUALQUER TIPO DE EXPLICAÇĀO)

31. Se o(a) Sr.(a) fosse contar a orientação contida nesse cartão à um(a) amigo(a) seu(a), que não conhecesse essa orientação, como o Sr.(a) contaria? O que mais diria?

32. Existe alguma palavra ou termo nesta orientação que o(a) $\mathrm{Sr}$.(a) acha que deveria ser trocada, para que as pessoas entendam melhor o que diz essa orientaçāo?

$\begin{array}{ll}\mathrm{SIM} & \text { ( ) }\end{array} \quad \Rightarrow$ Qual ?

33. Pensando agora no quanto o(a) Sr.(a) está de acordo com o que diz essa orientação (APRESENTAR ORIENTAÇĂO), o(a) Sr.(a) diria que

- Concorda totalmente com essa orientação ( ) - Ir para pergunta 34

- Concorda parcialmente com essa orientação, ou ( ) - CONTINUE

- Discorda dessa orientação ( ) - CONTINUE

Porque?

34. Pensando na alimentação das pessoas que têm colesterol ou gordura no sangue, o(a) Sr.(a) diria que esta orientaçăo (APRESENTAR ORIENTAÇAO)

- E muito importante, ( ) - Ir para P.35

- É só um pouco importante ou ( ) - CONTINUE

- Näo é importante ( ) - CONTINUE

Por que?

35. Pensando agora na sua alimentação, o(a) Sr.(a) diria que (APRESENTAR ORIENTAÇAO)

- Sempre segue essa orientação, ( ) - IR PARA P.36

- Freqüentemente segue o que diz essa orientaçăo ( ) - CONTINUE

- Quase nunca segue essa orientação, ou ( ) - CONTINUE

- Nunca segue o que diz essa orientação ( ) - CONTINUE

Por que?

36. Que sugestão o(a) Sr.(a) daria para melhorar esta orientação? Tanto em relação ao que a orientação diz, como em relaçäo a maneira como foi escrita 


\section{ORIENTACÃO 6: FRACIONAR A DIETA, FAZENDO TRÊS REFEICÕ̃ES E DOIS LANCHES ENTRE ELAS,} ESCOLHENDO ALIMENTOS SAUDÁVEIS

37. Nesse cartão, o (a) senhor(a) pode ter uma orientaçăo para uma alimentaçăo saudável para controle de colesterol e gordura no sangue. Eu gostaria de saber se o (a) Sr. (a) tem alguma dúvida quanto ao que diz essa orientação.
SIM
( )
$\Rightarrow$ CONTINUE
NĀO
$\Rightarrow$ PERGUNTA 38

38. Qual a dúvida que a $\mathrm{Sr}(\mathrm{a})$ tem com relaçăo a esta orientação? (REGISTRAR FOI DITO PELA ENTREVISTADA E NÄO DAR QUALQUER TIPO DE EXPLICAÇẢO)

39. Se o(a) Sr.(a) fosse contar a orientaçảo contida nesse cartão à um(a) amigo(a) seu(a), que nåo conhecesse essa orientaçāo, como o $\mathrm{Sr}$.(a) contaria? O que mais diria?

40. Existe alguma palavra ou termo nesta orientação que o(a) $\mathrm{Sr}$.(a) acha que deveria ser trocada, para que as pessoas entendam melhor o que diz essa orientação?
SIM
NĀO
( )
$\Rightarrow$ Qual ?

41. Pensando agora no quanto o(a) Sr.(a) está de acordo com o que diz essa orientaçăo (APRESENTAR ORIENTAČÃO), o(a) Sr.(a) diria que

- Concorda totalmente com essa orientaçăo ( ) - Ir para pergunta 42

- Concorda parcialmente com essa orientação, ou ( ) - CONTINUE

- Discorda dessa orientaçäo ( ) - CONTINUE

Porque?

42. Pensando na alimentação das pessoas que têm colesterol ou gordura no sangue, o(a) Sr.(a) diria que esta orientação (APRESENTAR ORIENTAÇĀO)

- É muito importante, ( ) - Ir para P.43

- É só um pouco importante ou ( ) - CONTINUE

- Nāo é importante ( ) - CONTINUE

Por que?

43. Pensando agora na sua alimentação, o(a) Sr.(a) diria que (APRESENTAR ORIENTAÇÃO)

- Sempre segue essa orientaçāo, ( ) - IR PARA P.44

- Freqüentemente segue o que diz essa orientação ( ) - CONTINUE

- Quase nunca segue essa orientaçảo, ou ( ) - CONTINUE

- Nunca segue o que diz essa orientaçăo ( ) - CONTINUE

Por que?

44. Que sugestão o(a) Sr.(a) daria para melhorar esta orientação? Tanto em relaçăo ao que a orientaçăo diz, como em relação a maneira como foi escrita 


\section{ORIENTACAAO 7: EVITAR O CONSUMO DE FRITURAS}

45. Nesse cartão, o (a) senhor(a) pode ter uma orientação para uma alimentaçāo saudável para controle de colesterol e gordura no sangue. Eu gostaria de saber se o (a) Sr. (a) tem alguma dúvida quanto ao que diz essa orientaçăo.
SIM
( ) $\quad \Rightarrow$ CONTINUE
NÃO
$\Rightarrow$ PERGUNTA 46

46. Qual a dúvida que a $\operatorname{Sr}($ a) tem com relação a esta orientação? (REGISTRAR EXATAMENTE O QUE FOI DITO PELA ENTREVISTADA E NĀO DAR QUALQUER TIPO DE EXPLICAÇĀO)

47. Se o(a) Sr.(a) fosse contar a orientação contida nesse cartão à um(a) amigo(a) seu(a), que não conhecesse essa orientação, como o $\mathrm{Sr}$.(a) contaria? O que mais diria?

48. Existe alguma palavra ou termo nesta orientação que o(a) Sr.(a) acha que deveria ser trocada, para que as pessoas entendam melhor o que diz essa orientaçāo?
SIM
NĀO
()
$\Rightarrow$ Qual ?
( )

49. Pensando agora no quanto o(a) Sr.(a) está de acordo com o que diz essa orientação (APRESENTAR ORIENTAÇÄO), o(a) Sr.(a) diria que

- Concorda totalmente com essa orientação ( ) - Ir para pergunta 50

- Concorda parcialmente com essa orientação, ou ( ) - CONTINUE

- Discorda dessa orientação ( ) - CONTINUE

Porque?

50. Pensando na alimentação das pessoas que têm colesterol ou gordura no sangue, o(a) $\mathrm{Sr}$.(a) diria que esta orientaçāo (APRESENTAR ORIENTAÇÃO)

- É muito importante, ( ) - Ir para P.51

- É só um pouco importante ou ( ) - CONTINUE

- Não è importante ( ) - CONTINUE

Por que?

51. Pensando agora na sua alimentação, o(a) Sr.(a) diria que (APRESENTAR ORIENTAÇÃO)

- Sempre segue essa orientação, ( ) - IR PARA P.52

- Freqüentemente segue o que diz essa orientação ( ) - CONTINUE

- Quase nunca segue essa orientação, ou ( ) - CONTINUE

- Nunca segue o que diz essa orientação ( ) - CONTINUE

Por que?

52. Que sugestão o(a) Sr.(a) daria para melhorar esta orientaçảo? Tanto em relação ao que a orientação diz, como em relaçảo a maneira como foi escrita 


\section{ORIENTACÃO 8: CONSUMIR PRODUTOS DE ORIGEM ANIMAL MODERADAMENTE}

53. Nesse cartão, o (a) senhor(a) pode ter uma orientação para uma alimentação saudável para controle de colesterol e gordura no sangue. Eu gostaria de saber se o (a) $\mathrm{Sr}$. (a) tem alguma dúvida quanto ao que diz essa orientação.

$\begin{array}{lll}\text { SIM } & (\text { ) } & \Rightarrow \text { CONTINUE } \\ \text { NAOO } & (\text { ) } & \Rightarrow \text { PERGUNTA } 54\end{array}$

54. Qual a dúvida que a Sr(a) tem com relaçāo a esta orientaçăo? (REGISTRAR EXATAMENTE O QUE FOI DITO PELA ENTREVISTADA E NẢO DAR QUALQUER TIPO DE EXPLICAÇÄO)

55. Se o(a) Sr.(a) fosse contar a orientação contida nesse cartão à um(a) amigo(a) seu(a), que não conhecesse essa orientação, como o Sr.(a) contaria? O que mais diria?

56. Existe alguma palavra ou termo nesta orientaçăo que o(a) $\mathrm{Sr}$.(a) acha que deveria ser trocada, para que as pessoas entendam melhor o que diz essa orientação?

$\mathrm{SIM}_{\mathrm{NAOO}} \quad$ ( ) $\quad \Rightarrow$ Qual ?

57. Pensando agora no quanto o(a) $\mathrm{Sr}$.(a) está de acordo com o que diz essa orientação (APRESENTAR ORIENTAÇĀAO), o(a) Sr.(a) diria que

- Concorda totalmente com essa orientação ( ) - ir para pergunta 58

- Concorda parcialmente com essa orientação, ou ( ) - CONTINUE

- Discorda dessa orientação ( ) - CONTINUE

Porque?

58. Pensando na alimentaçăo das pessoas que têm colesterol ou gordura no sangue, o(a) Sr.(a) diria que esta orientação (APRESENTAR ORIENTAÇĀO)

- E muito importante, ( ) - Ir para P.59

- É só um pouco importante ou ( ) - CONTINUE

- Não é importante ( ) - CONTINUE

Por que?

59. Pensando agora na sua alimentação, o(a) Sr.(a) diria que (APRESENTAR ORIENTAÇAO)

- Sempre segue essa orientaçăo, ( ) - IR PARA P.60

- Freqüentemente segue o que diz essa orientação ( ) - CONTINUE

- Quase nunca segue essa orientação, ou ( ) - CONTINUE

- Nunca segue o que diz essa orientação ( ) - CONTINUE

Por que?

60. Que sugestão o(a) Sr.(a) daria para melhorar esta orientação? Tanto em relação ao que a orientação diz, como em relação a maneira como foi escrita 


\section{ORIENTACĀO 9: PREFERIR CARNES MAGRAS E RETIRAR GORDURAS VISIVEIS}

61. Nesse cartão, o (a) senhor(a) pode ter uma orientaçăo para uma alimentaçăo saudável para controle de colesterol e gordura no sangue. Eu gostaria de saber se o (a) $\mathrm{Sr}$. (a) tem alguma dúvida quanto ao que diz essa orientação.
SIM
$\mathrm{NẢO}$
( )
$\Rightarrow$ CONTINUE
( ) $\quad \Rightarrow$ PERGUNTA 62

62. Qual a dúvida que a $\mathrm{Sr}(\mathrm{a})$ tem com relação a esta orientaçăo? (REGISTRAR FOI DITO PELA ENTREVISTADA E NAO DAR QUALQUER TIPO DE EXPLICAÇĀO)

63. Se o(a) Sr.(a) fosse contar a orientação contida nesse cartão à um(a) amigo(a) seu(a), que não conhecesse essa orientaçăo, como o Sr.(a) contaria? O que mais diria?

64. Existe alguma palavra ou termo nesta orientaçăo que o(a) $\mathrm{Sr}$.(a) acha que deveria ser trocada, para que as pessoas entendam melhor o que diz essa orientação?
SIM
NÄO
( ) $\quad \Rightarrow$ Qual ?
( )

65. Pensando agora no quanto o(a) Sr.(a) está de acordo com o que diz essa orientaçāo (APRESENTAR ORIENTAÇÃO), o(a) Sr.(a) diria que

- Concorda totalmente com essa orientaçăo ( ) - Ir para pergunta 66

- Concorda parcialmente com essa orientação, ou ( ) - CONTINUE

- Discorda dessa orientação ( ) - CONTINUE

Porque?

66. Pensando na alimentação das pessoas que têm colesterol ou gordura no sangue, o(a) Sr.(a) diria que esta orientação (APRESENTAR ORIENTAÇÃO)

- É muito importante. ( ) - Ir para P.67

- É só um pouco importante ou ( ) - CONTINUE

- Não é importante ( ) - CONTINUE

Por que?

67. Pensando agora na sua alimentaçăo, o(a) Sr.(a) diria que (APRESENTAR ORIENTAÇÃO)

- Sempre segue essa orientação, ( ) - IR PARA P.68

- Freqüentemente segue o que diz essa orientação ( ) - CONTINUE

- Quase nunca segue essa orientaçăo, ou ( ) - CONTINUE

- Nunca segue o que diz essa orientação ( ) - CONTINUE

Por que?

68. Que sugestăo o(a) Sr.(a) daria para melhorar esta orientação? Tanto em relação ao que a orientaçăo diz, como em relação a maneira como foi escrita 


\section{ORIENTACĀO 10: CONSUMIR ACÚCAR E DOCES COM MODERACÃO}

69. Nesse cartăo, o (a) senhor(a) pode ter uma orientação para uma alimentação saudável para controle de colesterol e gordura no sangue. Eu gostaria de saber se o (a) $\mathrm{Sr}$. (a) tem alguma dúvida quanto ao que diz essa orientação.
SIM
( )
$\Rightarrow$ CONTINUE
NAOO
$\Rightarrow$ PERGUNTA 70

70. Qual a dúvida que a Sr(a) tem com relação a esta orientaçäo? (REGISTRAR EXATAMENTE O QUE FOI DITO PELA ENTREVISTADA E NẢO DAR QUALQUER TIPO DE EXPLICAÇĀO)

71. Se o(a) Sr.(a) fosse contar a orientação contida nesse cartão à um(a) amigo(a) seu(a), que não conhecesse essa orientaçāo, como o Sr.(a) contaria? O que mais diria?

72. Existe alguma palavra ou termo nesta orientação que o(a) $\mathrm{Sr}$.(a) acha que deveria ser trocada, para que as pessoas entendam melhor o que diz essa orientaçāo?
SIM
NAOO
( ) $\quad \Rightarrow$ Qual ?
( )

73. Pensando agora no quanto o(a) Sr.(a) está de acordo com o que diz essa orientação (APRESENTAR ORIENTAÇĀO), o(a) Sr.(a) diria que

- Concorda totalmente com essa orientaçäo ( ) - Ir para pergunta 74

- Concorda parcialmente com essa orientaçăo, ou ( ) - CONTINUE

- Discorda dessa orientação ( ) - CONTINUE

Porque?

74. Pensando na alimentação das pessoas que têm colesterol ou gordura no sangue, o(a) Sr.(a) diria que esta orientação (APRESENTAR ORIENTAÇAO)

- E muito importante, ( ) - Ir para P.75

- É só um pouco importante ou ( ) - CONTINUE

- Năo é importante ( ) - CONTINUE

Por que?

75. Pensando agora na sua alimentaçăo, o(a) Sr.(a) diria que (APRESENTAR ORIENTAÇĀO)

- Sempre segue essa orientação, ( ) - IR PARA P.76

- Freqüentemente segue o que diz essa orientação ( ) - CONTINUE

- Quase nunca segue essa orieritação, ou ( ) - CONTINUE

- Nunca segue o que diz essa orientaçăo ( ) - CONTINUE

Por que?

76. Que sugest5o o(a) Sr.(a) daria para melhorar esta orientaçăo? Tanto em relaçăo ao que a orientaçāo diz, como em relação a maneira como foi escrita 


\section{ORIENTACÄO 11: REDUZIR O CONSUMO DE SAL}

77. Nesse cartão, $O$ (a) senhor(a) pode ter uma orientaçăo para uma alimentaçăo saudável para controle de colesterol e gordura no sangue. Eu gostaria de saber se o (a) Sr. (a) tem alguma dúvida quanto ao que diz essa orientação.

$\begin{array}{lll}\text { SIM } & (\text { ) } & \Rightarrow \text { CONTINUE } \\ \text { NAO } & () & \Rightarrow \text { PERGUNTA 78 }\end{array}$

78. Qual a dúvida que a Sr(a) tem com relaçăo a esta orientação? (REGISTRAR EXATAMENTE O QUE FOI DITO PELA ENTREVISTADA E NA̧O DAR QUALQUER TIPO DE EXPLICAÇĀO)

79. Se o(a) Sr.(a) fosse contar a orientação contida nesse cartão à um(a) amigo(a) seu(a), que não conhecesse essa orientaçāo, como o Sr.(a) contaria? O que mais diria?

80. Existe alguma palavra ou termo nesta orientação que o(a) $\mathrm{Sr}$.(a) acha que deveria ser trocada, para que as pessoas entendam melhor 0 que diz essa orientaçăo?

$\begin{array}{ll}\mathrm{SIM} & \quad(\text { ) }\end{array}$

81. Pensando agora no quanto o(a) Sr.(a) está de acordo com o que diz essa orientação (APRESENTAR ORIENTAÇÄO), o(a) Sr.(a) diria que

- Concorda totalmente com essa orientação ( ) - Ir para pergunta 82

- Concorda parcialmente com essa orientaçăo, ou ( ) - CONTINUE

- Discorda dessa orientação ( ) - CONTINUE

Porque?

82. Pensando na alimentação das pessoas que têm colesterol ou gordura no sangue, o(a) $\mathrm{Sr}$.(a) diria que esta orientação (APRESENTAR ORIENTAÇAO)

- É muito importante, ( ) - Ir para P.83

- É só um pouco importante ou ( ) - CONTINUE

- Năo é importante ( ) - CONTINUE

Por que?

83. Pensando agora na sua alimentação, o(a) $\mathrm{Sr}$.(a) dina que (APRESENTAR ORIENTAÇAO)

- Sempre segue essa orientação, ( ) - IR PARA P.84

- Freqüentemente segue o que diz essa orientaçäo ( ) - CONTINUE

- Quase nunca segue essa orientação, ou ( ) - CONTINUE

- Nunca segue o que diz essa orientação ( ) - CONTINUE

Por que?

84. Que sugestāo o(a) Sr.(a) daria para melhorar esta orientaçăo? Tanto em relaçăo ao que a orientaçăo diz, como em relação a maneira como foi escrita 


\section{ORIENTACAO 12: LIMITAR O CONSUMO DE ÁLCCOL, SE INGERIR, FACA-O COM MODERACÃO}

85. Nesse cartāo, o (a) senhor(a) pode ter uma orientação para uma alimentação saudável para controle de colesterol e gordura no sangue. Eu gostaria de saber se o (a) $\mathrm{Sr}$. (a) tem alguma dúvida quanto ao que diz essa orientaçāo.
SIM
NAO
( )
$\Rightarrow$ CONTINUE
( )
$\Rightarrow$ PERGUNTA 86

86. Qual a dúvida que a $\mathrm{Sr}(\mathrm{a})$ tem com relaçăo a esta orientaçăo? (REGISTRAR EXATAMENTE O QUE FOI DITO PELA ENTREVISTADA E NAO DAR QUALQUER TIPO DE EXPLICAÇĀO)

87. Se o(a) Sr.(a) fosse contar a orientação contida nesse cartão à um(a) amigo(a) seu(a), que não conhecesse essa orientaçäo, como o Sr.(a) contaria? O que mais diria?

88. Existe alguma palavra ou termo nesta orientaçăo que o(a) Sr.(a) acha que deveria ser trocada, para que as pessoas entendam melhor o que diz essa orientaçāo?
SIM
()
$\Rightarrow$ Qual ?
NẢO
()

89. Pensando agora no quanto o(a) Sr.(a) está de acordo com o que diz essa orientaçăo (APRESENTAR ORIENTAÇÃO), o(a) Sr.(a) diria que

- Concorda totalmente com essa orientaçăo ( ) - Ir para pergunta 90

- Concorda parcialmente com essa orientaçăo, ou ( ) - CONTINUE

- Discorda dessa orientaçāo ( ) - CONTINUE

Porque?

90. Pensando na alimentaçāo das pessoas que têm colesterol ou gordura no sangue, o(a) Sr.(a) diria que esta orientaçāo (APRESENTAR ORIENTAÇÃO)

- É muito importante, ( ) - Ir para P.91

- É só um pouco importante ou ( ) - CONTINUE

- Não é importante ( ) - CONTINUE

Por que ?

91. Pensando agora na sua alimentaçāo, o(a) Sr.(a) diria que (APRESENTAR ORIENTAÇĀO)

- Sempre segue essa orientação, ( ) - IR PARA P.92

- Freqüentemente segue o que diz essa orientaçäo ( ) - CONTINUE

- Quase nunca segue essa orientação, ou ( ) - CONTINUE

- Nunca segue o que diz essa orientação ( ) - CONTINUE

Por que?

92. Que sugestão o(a) Sr.(a) daria para melhorar esta orientaçăo? Tanto em relação ao que a orientaçāo diz, como em relação a maneira como foi escrita 


\section{ORIENTACAO 13: NÃO ESQUECER DE CONSUMIR ÁGUA, POIS É ESSENCIAL PARA A SAÚDE}

93. Nesse cartảo, o (a) senhor(a) pode ter uma orientação para uma alimentaçăo saudável para controle de colesterol e gordura no sangue. Eu gostaria de saber se o (a) $\mathrm{Sr}$. (a) tem alguma dúvida quanto ao que diz essa orientação.
SIM
NAO
()
$\Rightarrow$ CONTINUE
() $\Rightarrow$ PERGUNTA 94

94. Qual a dúvida que a $\operatorname{Sr}(a)$ tem com relação a esta orientaçăo? (REGISTRAR FOI DITO PELA ENTREVISTADA E NẢO DAR QUALQUER TIPO DE EXPLICAÇĀO)

95. Se o(a) Sr.(a) fosse contar a orientação contida nesse cartão à um(a) amigo(a) seu(a), que não conhecesse essa orientação, como o Sr.(a) contaria? O que mais diria?

96. Existe alguma palavra ou termo nesta orientação que o(a) $\mathrm{Sr}$.(a) acha que deveria ser trocada, para que as pessoas entendam meihor o que diz essa orientaçăo?
SIM
NÃO
( ) $\quad \Rightarrow$ Qual ?
( )

97. Pensando agora no quanto o(a) Sr.(a) está de acordo com o que diz essa orientaçäo (APRESENTAR ORIENTAÇĀO), o(a) Sr.(a) diria que

- Concorda totalmente com essa orientação ( ) - Ir para pergunta 98

- Concorda parcialmente com essa orientação, ou ( ) - CONTINUE

- Discorda dessa orientaçăo ( ) - CONTINUE

Porque?

98. Pensando na alimentação das pessoas que têm colesterol ou gordura no sangue, o(a) Sr.(a) diria que esta orientação (APRESENTAR ORIENTAÇÃO)

- E muito importante, ( ) - Ir para P.99

- É só um pouco importante ou ( ) - CONTINUE

- Não é importante ( ) - CONTINUE

Por que?

99. Pensando agora na sua alimentação, o(a) Sr.(a) diria que (APRESENTAR ORIENTAÇAO)

- Sempre segue essa orientação, ( ) - IR PARA P.100

- Freqüentemente segue o que diz essa orientação ( ) - CONTINUE

- Quase nunca segue essa orientação, ou ( ) - CONTINUE

- Nunca segue o que diz essa orientação ( ) - CONTINUE

Por que?

100.Que sugestão o(a) Sr.(a) daria para melhorar esta orientação? Tanto em relação ao que a orientaçăo diz, como em relaçăo a maneira como foi escrita 


\section{ANEXO V}

Tabela 1: Resultados do estudo de associação entre sexo e as respostas observadas.

\begin{tabular}{|c|c|c|c|c|c|}
\hline & & $\begin{array}{c}\text { Nivel } \\
\text { descritivo }\end{array}$ & & & $\begin{array}{c}\text { Nivel } \\
\text { descritivo }\end{array}$ \\
\hline Orientaçảo 1 & $\begin{array}{l}\text { Dúvida } \\
\text { Substituir } \\
\text { palavra } \\
\text { Concordância } \\
\text { Importância } \\
\text { Cumprimento }\end{array}$ & $\begin{array}{l}0,999 \\
0,999 \\
0,999 \\
0,999 \\
0,186 \\
\end{array}$ & Orientação 8 & $\begin{array}{l}\text { Dúvida } \\
\text { Substituir } \\
\text { palavra } \\
\text { Concordância } \\
\text { Importancia } \\
\text { Cumprimento }\end{array}$ & $\begin{array}{l}0,647 \\
0,639 \\
0,999 \\
0,999 \\
0,770 \\
\end{array}$ \\
\hline Orientação 2 & $\begin{array}{l}\text { Dúvida } \\
\text { Substituir } \\
\text { palavra } \\
\text { Concordância } \\
\text { Importância } \\
\text { Cumprimento }\end{array}$ & $\begin{array}{l}0,999 \\
0,999 \\
0,284 \\
0,545 \\
0,999 \\
\end{array}$ & Orientação 9 & $\begin{array}{l}\text { Dúvida } \\
\text { Substituir } \\
\text { palavra } \\
\text { Concordância } \\
\text { Importåncia } \\
\text { Cumprimento } \\
\end{array}$ & $\begin{array}{l}0,999 \\
0,483 \\
0,069 \\
0,276 \\
0,543 \\
\end{array}$ \\
\hline Orientação 3 & $\begin{array}{l}\text { Dúvida } \\
\text { Substituir } \\
\text { palavra } \\
\text { Concordanncia } \\
\text { Importåncia } \\
\text { Cumprimento }\end{array}$ & $\begin{array}{l}0,999 \\
0,999 \\
0,999 \\
0,267 \\
0,567 \\
\end{array}$ & Orientação 10 & $\begin{array}{l}\text { Dúvida } \\
\text { Substituir } \\
\text { palavra } \\
\text { Concordância } \\
\text { Importância } \\
\text { Cumprimento }\end{array}$ & $\begin{array}{c}- \\
0,999 \\
0,483 \\
0,330 \\
0,895 \\
\end{array}$ \\
\hline Orientação 4 & $\begin{array}{l}\text { Dúvida } \\
\text { Substituir } \\
\text { palavra } \\
\text { Concordância } \\
\text { Importancia } \\
\text { Cumprimento }\end{array}$ & $\begin{array}{l}0,999 \\
0,999 \\
0,999 \\
0,999 \\
0,212 \\
\end{array}$ & Orientação 11 & $\begin{array}{l}\text { Dúvida } \\
\text { Substituir } \\
\text { palavra } \\
\text { Concordância } \\
\text { Importância } \\
\text { Cumprimento }\end{array}$ & $\begin{array}{l}0,483 \\
0,536 \\
0,999 \\
0,999 \\
0,583 \\
\end{array}$ \\
\hline Orientação 5 & $\begin{array}{l}\text { Dúvida } \\
\text { Substituir } \\
\text { palavra } \\
\text { Concordância } \\
\text { Importância } \\
\text { Cumprimento } \\
\end{array}$ & $\begin{array}{c}0,675 \\
0,093 \\
0,999 \\
- \\
0,499 \\
\end{array}$ & Orientaçăo 12 & $\begin{array}{l}\text { Dúvida } \\
\text { Substituir } \\
\text { palavra } \\
\text { Concordanncia } \\
\text { Importancia } \\
\text { Cumprimento } \\
\end{array}$ & $\begin{array}{c}0,999 \\
0,647 \\
- \\
0,999 \\
0,999 \\
\end{array}$ \\
\hline Orientação 6 & $\begin{array}{l}\text { Dúvida } \\
\text { Substituir } \\
\text { palavra } \\
\text { Concordanncia } \\
\text { Importåncia } \\
\text { Cumprimento } \\
\end{array}$ & $\begin{array}{l}0,675 \\
0,427 \\
0,089 \\
0,017 \\
0,491 \\
\end{array}$ & Orientaçăo 13 & $\begin{array}{l}\text { Dúvida } \\
\text { Substituir } \\
\text { palavra } \\
\text { Concordancia } \\
\text { Importância } \\
\text { Cumprimento } \\
\end{array}$ & $\begin{array}{c}0,483 \\
0,999 \\
- \\
- \\
0,572 \\
\end{array}$ \\
\hline Orientação 7 & $\begin{array}{l}\text { Dúvida } \\
\text { Substituir } \\
\text { palavra } \\
\text { Concordância } \\
\text { Importância } \\
\text { Cumprimento } \\
\end{array}$ & $\begin{array}{c}0,999 \\
0,060 \\
- \\
- \\
0,683\end{array}$ & & & \\
\hline
\end{tabular}


Tabela 2: Resultados do estudo de associação entre escolaridade e as respostas observadas.

\begin{tabular}{|c|c|c|c|c|c|}
\hline & & $\begin{array}{c}\text { Nivel } \\
\text { descritivo }\end{array}$ & & & $\begin{array}{c}\text { Nivel } \\
\text { descritivo }\end{array}$ \\
\hline Orientação 1 & $\begin{array}{l}\text { Dúvida } \\
\text { Substituir } \\
\text { palavra } \\
\text { Concordância } \\
\text { Importáncia } \\
\text { Cumprimento } \\
\end{array}$ & $\begin{array}{l}0,572 \\
0,886 \\
0,785 \\
0,700 \\
0,163 \\
\end{array}$ & Orientação 8 & $\begin{array}{l}\text { Dúvida } \\
\text { Substituir } \\
\text { palavra } \\
\text { Concordåncia } \\
\text { Importância } \\
\text { Cumprimento } \\
\end{array}$ & $\begin{array}{l}0,595 \\
0,785 \\
0,408 \\
0,924 \\
0,086 \\
\end{array}$ \\
\hline Orientação 2 & $\begin{array}{l}\text { Dúvida } \\
\text { Substituir } \\
\text { palavra } \\
\text { Concordância } \\
\text { Importảncia } \\
\text { Cumprimento } \\
\end{array}$ & $\begin{array}{l}0,186 \\
0,753 \\
0,886 \\
0,594 \\
0,568 \\
\end{array}$ & Orientação 9 & $\begin{array}{l}\text { Dúvida } \\
\text { Substituir } \\
\text { palavra } \\
\text { Concordância } \\
\text { Importância } \\
\text { Cumprimento }\end{array}$ & $\begin{array}{l}0,999 \\
0,146 \\
0,999 \\
0,691 \\
0,456 \\
\end{array}$ \\
\hline Orientação 3 & $\begin{array}{l}\text { Dúvida } \\
\text { Substituir } \\
\text { palavra } \\
\text { Concordáncia } \\
\text { Importância } \\
\text { Cumprimento } \\
\end{array}$ & $\begin{array}{l}0,700 \\
0,593 \\
0,999 \\
0,999 \\
0,101 \\
\end{array}$ & Orientação 10 & $\begin{array}{l}\text { Dúvida } \\
\text { Substituir } \\
\text { palavra } \\
\text { Concordáncia } \\
\text { Importância } \\
\text { Cumprimento } \\
\end{array}$ & $\begin{array}{c}- \\
0,999 \\
0,999 \\
0,749 \\
0,856 \\
\end{array}$ \\
\hline Orientaçăo 4 & $\begin{array}{l}\text { Dúvida } \\
\text { Substituir } \\
\text { palavra } \\
\text { Concordáncia } \\
\text { Importância } \\
\text { Cumprimento } \\
\end{array}$ & $\begin{array}{l}0,151 \\
0,206 \\
0,236 \\
0,999 \\
0,597 \\
\end{array}$ & Orientação 11 & $\begin{array}{l}\text { Dúvida } \\
\text { Substituir } \\
\text { palavra } \\
\text { Concordåncia } \\
\text { Importância } \\
\text { Cumprimento }\end{array}$ & $\begin{array}{l}0,450 \\
0,093 \\
0,239 \\
0,692 \\
0,402 \\
\end{array}$ \\
\hline Orientação 5 & $\begin{array}{l}\text { Dúvida } \\
\text { Substituir } \\
\text { palavra } \\
\text { Concordância } \\
\text { Importáncia } \\
\text { Cumprimento } \\
\end{array}$ & $\begin{array}{c}0,012 \\
0,439 \\
0,999 \\
- \\
0,010 \\
\end{array}$ & Orientaçâo 12 & $\begin{array}{l}\text { Dúvida } \\
\text { Substituir } \\
\text { palavra } \\
\text { Concordância } \\
\text { Importância } \\
\text { Cumprimento } \\
\end{array}$ & $\begin{array}{c}0,999 \\
0,435 \\
- \\
0,025 \\
0,209 \\
\end{array}$ \\
\hline Orientação 6 & $\begin{array}{l}\text { Dúvida } \\
\text { Substituir } \\
\text { palavra } \\
\text { Concordancia } \\
\text { Importáncia } \\
\text { Cumprimento }\end{array}$ & $\begin{array}{l}0,020 \\
0,454 \\
0,535 \\
0,472 \\
0,048 \\
\end{array}$ & Orientação 13 & $\begin{array}{l}\text { Dúvida } \\
\text { Substituir } \\
\text { palavra } \\
\text { Concordância } \\
\text { Importância } \\
\text { Cumprimento }\end{array}$ & $\begin{array}{c}0,999 \\
0,209 \\
- \\
- \\
0,731 \\
\end{array}$ \\
\hline Orientação 7 & $\begin{array}{l}\text { Dúvida } \\
\text { Substituir } \\
\text { palavra } \\
\text { Concordância } \\
\text { Importância } \\
\text { Cumprimento }\end{array}$ & $\begin{array}{c}0,679 \\
0,999 \\
- \\
- \\
0,288 \\
\end{array}$ & & & \\
\hline
\end{tabular}


Tabela 3: Resultados do estudo de associação entre a Idade do respondedor $e$ as respostas observadas.

\begin{tabular}{|c|c|c|c|c|c|}
\hline & & $\begin{array}{c}\text { Nivel } \\
\text { descritivo }\end{array}$ & & & $\begin{array}{c}\text { Nivel } \\
\text { descritivo }\end{array}$ \\
\hline Orientação 1 & $\begin{array}{l}\text { Dúvida } \\
\text { Substituir } \\
\text { palavra } \\
\text { Concordância } \\
\text { Importância } \\
\text { Cumprimento } \\
\end{array}$ & $\begin{array}{l}0,655 \\
0,999 \\
0,396 \\
0,999 \\
0,117 \\
\end{array}$ & Orientaçăo 8 & $\begin{array}{l}\text { Dúvida } \\
\text { Substituir } \\
\text { palavra } \\
\text { Concordância } \\
\text { Importância } \\
\text { Cumprimento } \\
\end{array}$ & $\begin{array}{l}0,999 \\
0,567 \\
0,073 \\
0,213 \\
0,495 \\
\end{array}$ \\
\hline Orientação 2 & $\begin{array}{l}\text { Dúvida } \\
\text { Substituir } \\
\text { palavra } \\
\text { Concordância } \\
\text { Importância } \\
\text { Cumprimento }\end{array}$ & $\begin{array}{l}0,614 \\
0,110 \\
0,443 \\
0,741 \\
0,465 \\
\end{array}$ & Orientaçăo 9 & $\begin{array}{l}\text { Dúvida } \\
\text { Substituir } \\
\text { palavra } \\
\text { Concordancia } \\
\text { Importância } \\
\text { Cumprimento } \\
\end{array}$ & $\begin{array}{l}0,629 \\
0,999 \\
0,144 \\
0,999 \\
0,893 \\
\end{array}$ \\
\hline Orientação 3 & $\begin{array}{l}\text { Dúvida } \\
\text { Substituir } \\
\text { palavra } \\
\text { Concordância } \\
\text { Importância } \\
\text { Cumprimento } \\
\end{array}$ & $\begin{array}{l}0,999 \\
0,752 \\
0,013 \\
0,999 \\
0,725 \\
\end{array}$ & Orientaçăo 10 & $\begin{array}{l}\text { Dúvida } \\
\text { Substituir } \\
\text { palavra } \\
\text { Concordância } \\
\text { Importância } \\
\text { Cumprimento } \\
\end{array}$ & $\begin{array}{c}- \\
0,999 \\
0,378 \\
0,389 \\
0,383 \\
\end{array}$ \\
\hline Orientação 4 & $\begin{array}{l}\text { Dúvida } \\
\text { Substituir } \\
\text { palavra } \\
\text { Concordância } \\
\text { Importância } \\
\text { Cumprimento } \\
\end{array}$ & $\begin{array}{l}0,655 \\
0,999 \\
0,999 \\
0,655 \\
0,336 \\
\end{array}$ & Orientaçăo 11 & $\begin{array}{l}\text { Dúvida } \\
\text { Substituir } \\
\text { palavra } \\
\text { Concordância } \\
\text { Importância } \\
\text { Cumprimento } \\
\end{array}$ & $\begin{array}{l}0,999 \\
0,754 \\
0,999 \\
0,999 \\
0,791 \\
\end{array}$ \\
\hline Orientação 5 & $\begin{array}{l}\text { Dúvida } \\
\text { Substituir } \\
\text { palavra } \\
\text { Concordância } \\
\text { Importância } \\
\text { Cumprimento } \\
\end{array}$ & $\begin{array}{c}0,476 \\
0,206 \\
0,999 \\
- \\
0,910 \\
\end{array}$ & Orientação 12 & $\begin{array}{l}\text { Dúvida } \\
\text { Substituir } \\
\text { palavra } \\
\text { Concordancia } \\
\text { Importância } \\
\text { Cumprimento } \\
\end{array}$ & $\begin{array}{c}0,754 \\
0,372 \\
- \\
0,511 \\
0,999 \\
\end{array}$ \\
\hline Orientaçăo 6 & $\begin{array}{l}\text { Dúvida } \\
\text { Substituir } \\
\text { palavra } \\
\text { Concordancia } \\
\text { Importância } \\
\text { Cumprimento } \\
\end{array}$ & $\begin{array}{l}0,476 \\
0,876 \\
0,095 \\
0,120 \\
0,295 \\
\end{array}$ & Orientaçăo 13 & $\begin{array}{l}\text { Dúvida } \\
\text { Substituir } \\
\text { palavra } \\
\text { Concordancia } \\
\text { Importância } \\
\text { Cumprimento } \\
\end{array}$ & $\begin{array}{c}0,378 \\
0,999 \\
- \\
- \\
0,999\end{array}$ \\
\hline Orientação 7 & $\begin{array}{l}\text { Dúvida } \\
\text { Substituir } \\
\text { palavra } \\
\text { Concordância } \\
\text { Importância } \\
\text { Cumprimento } \\
\end{array}$ & $\begin{array}{c}0,999 \\
0,569 \\
- \\
- \\
0,913\end{array}$ & & & \\
\hline
\end{tabular}

